\title{
Toxicidade pulmonar da radioterapia conformacional torácica em mulheres com câncer de mama. Repercussões funcionais, tomográficas, sistêmicas e seus reflexos na qualidade de vida.
}




\section{ADRIANA ASSIS MIRANDA CHAVES}

\section{Versão Corrigida}

A versão original encontra-se disponível no Departamento de Clínica Médica da FMRPUSP

Toxicidade pulmonar da radioterapia conformacional torácica em mulheres com câncer de mama. Repercussões funcionais, tomográficas, sistêmicas e seus reflexos na qualidade de vida.

Tese que será apresentada à Faculdade de Medicina de Ribeirão Preto da Universidade de São Paulo para obtenção de titulo de Doutor em Ciências Médicas.

Área de Concentração: Clínica Médica.

Orientador: Professor Doutor João Terra Filho

Ribeirão Preto

2013 
Autorizo a reprodução e divulgação total ou parcial deste trabalho, por qualquer meio convencional ou eletrônico, para fins de estudo e pesquisa, desde que citada a fonte.

FICHA CATALOGRÁFICA

Miranda-Chaves, Adriana Assis

Toxicidade pulmonar da radioterapia conformacional torácica em mulheres com câncer de mama. Repercussões funcionais, tomográficas, sistêmicas e seus reflexos na qualidade de vida. Ribeirão Preto, 2013.

183p.: il.; $30 \mathrm{~cm}$

Tese de Doutorado, apresentada à Faculdade de Medicina de Ribeirão Preto/USP. Área de Concentração: Clínica Médica.

Orientador: Professor Doutor João Terra Filho

1 Radioterapia torácica. 2 Tomografia. 3 Qualidade de vida. 4 IL-1ß. 5 IL-6. 6 TNF- $\alpha .7$ Função Pulmonar. 


\section{FOLHA DE APROVAÇÃO}

Adriana Assis Miranda Chaves

Toxicidade pulmonar da radioterapia conformacional torácica em mulheres com câncer de mama. Repercussões funcionais, tomográficas, sistêmicas e seus reflexos na qualidade de vida.

Tese apresentada à Faculdade de Medicina de Ribeirão Preto da Universidade de São Paulo para obtenção de título de Doutora em Ciências Médicas.

Área de Concentração: Clínica Médica.

Aprovado em:

\section{Banca Examinadora}

Prof. Dr. João Terra Filho.

Instituição: USP

Assinatura:

Prof. Dr. Harley Francisco de Oliveira

Instituição: USP

Assinatura:

Prof. Dr. Helio Humberto Angotti Carrara

Instituição: USP

Assinatura:

Prof. Dr. José Roberto de Brito Jardim

Instituição: Unifesp

Assinatura:

Prof. Dr. Manuel Lopes dos Santos

Instituição: Uninove

Assinatura: 


\section{Dedicatória}

A Deus por ser tão bom comigo. Deu-me uma família muito abençoada e que amo muito, um marido melhor do que pedi a ELE e pelo privilégio de ter feito um doutorado na USP, um das melhores universidades do país.

Aos meus amados pais, José Sebastião Miranda e Terezinha Assis Miranda, que sempre foram exemplos de fé em Deus, caráter, bondade, honestidade, carinho para comigo e meu irmão. Pai, obrigada por ser e sempre ter sido essa pessoa abençoada em nossas vidas. Mãe, obrigada por ser e sempre ter sido a minha melhor amiga.

Ao meu irmão, Alberto Alexandre Assis Miranda, que sempre foi e continua sendo brilhante, tanto que aos 27 anos já tinha feito mestrado e doutorado UNICAMP. Sempre o admirei muito e tentei seguir seus passos, apesar dele ser o irmão mais novo. Beto, obrigada por ser e sempre ter sido o meu melhor amigo.

Ao meu amado marido, Fábio Chaves, pelo amor, carinho, compreensão e, principalmente, por ser uma pessoa maravilhosa, esforçada, inteligente, carinhosa, e bondosa. Eu agradeço à Deus todos os dias por ter me dado você como meu companheiro. 


\section{Agradecimentos}

A Deus por ter possibilitado a imensa honra de fazer doutorado na USP, uma das melhores universidades do país.

Ao Prof. Dr. João Terra Filho, exemplo de profissional e sabedoria, por ter me dado a honra de ser sua orientada, por todo o tempo dispendido comigo não só nas orientações do doutorado, que ocorreram até nos finais de semana, mas por todos os conselhos, que me ajudaram a realizar o meu sonho/objetivo de vida profissional: ser professora universitária.

Às voluntárias que participaram do meu protocolo de pesquisa, mesmo estando enfrentando uma das mais temidas doenças, e que ainda tiveram a disponibilidade de colaborar.

Às voluntárias do Centro de Saúde Escola que ofereceram-se para doar sangue para minha pesquisa ao ficarem sabendo das dificuldades que encontrava para conseguir mulheres saudáveis e dispostas a colaborar na população atendida no CSE. Um agradecimento muito especial à enfermeira Maria Cristina Jordão Ferrari, principal colaboradora neste processo.

A toda equipe do Ambulatório de Radioterapia do HCRP pela viabilização desta pesquisa. De um modo especial ao Prof. Dr. Harley Francisco de Oliveira, à médica Viviane Bighetti, à técnica de enfermagem Irene Batista, às oficiais administrativas Ninervina Maria dos Reis Fontana, Beatriz Chiapini Fernandes Braga, Elaine Aparecida Querino e Vera Lucia Valadares por todo o empenho em ajudar no recrutamento das pacientes. 
A toda equipe do Ambulatório de Imaginologia do HCRP, de um modo especial ao Prof. Dr. Jorge Elias Junior e ao Prof. Dr. Marcel Koenigkam Santos por ter possibilitado e realizada as tomografias computadorizadas de alta resolução.

A toda equipe do Ambulatório de Mastologia do HCRP pela indispensável colaboração nesta pesquisa, de um modo especial ao Prof. Dr. Hélio Humberto Angotti Carrara.

Ao Prof. Dr. Fernando de Queiróz Cunha pela disponibilização do método e dosagem das citocinas e a técnica de laboratório Giuliana Bertozi Francisco, pela sua excussão.

À bióloga Flávia Carneiro Bueno de Castro, por ter realizado todos os teste de espirometria com difusão e pela sua amizade.

À biomédica Elizabeth Sobrani, por ter coletado o sangue das voluntárias da pesquisa.

A estatística, Mayara Piani, ao Prof. Dr. Omero Benedito Poli Neto e ao Prof. e colega Anderson José, por toda a ajuda para realização das estatística do presente trabalho. 
No fim tudo dá certo, se não deu certo ainda é porque não chegou ao final.

(Fernando Sabino) 


\section{Resumo}

MIRANDA-CHAVES, A. A. Toxicidade pulmonar da radioterapia conformacional torácica em mulheres com câncer de mama. Repercussões funcionais, tomográficas, sistêmicas e seus reflexos na qualidade de vida. 2013. $183 \mathrm{f}$. Tese (Doutorado) - Faculdade de Medicina, Universidade de São Paulo, Ribeirão Preto - SP, 2013.

O tratamento radioterápico continua aperfeiçoando-se, porém ainda pode estar associado com toxicidade pulmonar. Objetivo: Estudar os efeitos locais e sistêmicos provocados pela radioterapia conformacional torácica adjuvante em mulheres portadoras de câncer de mama, sem fatores de riscos prévios para desenvolvimento de alterações pulmonares. Por meio da tomografia computadorizada de alta resolução; identificar as possíveis alterações radiológicas no parênquima pulmonar. Se presentes, correlacioná-las com parâmetros obtidos da exploração funcional dos pulmões, com os efeitos sistêmicos, pela dosagem de mediadores inflamatórios, IL-1 $\beta$, IL-6 e TNF- $\alpha$, e suas repercussões sobre a qualidade de vida. Material e Métodos: Em 25 pacientes saudáveis foram coletadas amostras de sangue para serem utilizadas apenas como referência de normalidade da IL-1 $\beta$, IL-6 e TNF- $\alpha$. Em decorrência dos rígidos critérios de inclusão e exclusão estabelecidos, das 157 pacientes entrevistadas apenas 24 foram selecionadas para o estudo. A avaliação funcional pulmonar foi abrangente e constou de: medida dos volumes e capacidade dos pulmões, sendo o volume residual obtido pelo método de diluição do hélio em circuito fechado; estudo dos fluxos expiratórios máximos (curva fluxo x volume e curva volume x tempo) e medida da capacidade de difusão pulmonar pela técnica de respiração única do $\mathrm{CO}$. A tomografia computadorizada de alta resolução (16 detectores) foi realizada no pré-planejamento da radioterapia conformacional do tórax, esta com dose total de 45-50 Gy em 25 
frações. Para as dosagens de citocinas plasmáticas foram empregadas as técnicas de imunoabsorção enzimáticas (ELISA). Na avaliação da qualidade de vida foi aplicado o questionário Saint George's Respiratory Questionnary traduzido e adaptado culturalmente ao Brasil. Todos estes procedimentos foram obtidos na fase pré e repedidos 3 meses após a radioterapia. Os resultados das duas fases foram comparados utilizando-se a versão exata do teste Wilcoxon e o teste de Correlação de Spearman, nível de significância $p \leq 0,05$. Resultados: Entre parâmetros funcionais houve queda significativa apenas na difusão e no fluxo expiratório a $50 \%$ da capacidade vital forçada. Mesmo comportamento observou-se para citocina IL-6, já que os mesmos encontravam-se aumentados pré-RT. Não ocorreram mudanças significativas em nenhum dos domínios do questionário de qualidade de vida. As alterações tomográficas ocorreram $60,87 \%$ das pacientes na fase pós-radioterapia, em sua maioria de graus leves a moderados e não correlacionaram-se com as alterações observadas em outros parâmetros estudados. Conclusão: $O$ aumento observado na IL-6 durante a fase pré-RT, parece ser um bom índice preditivo de alteração pulmonar. A capacidade de difusão foi a alteração mais evidente e parece ser o índice que melhor reflete as alterações pulmonares que afetam essas pacientes. Diante das discretas alterações tomográficas e funcionais observadas após a RT, é provável que para a redução observada na DLCO concorra uma combinação de fatores ao nível da membrana alvéolo-capilar. No conjunto, as alterações induzidas pela radioterapia conformacional nas pacientes estudadas foram de pequena monta, insuficientes para influenciar aspectos funcionais do pulmão e a qualidade de vida.

Palavras-chave: Radioterapia torácica. Tomografia. Qualidade de vida. IL-1ß. IL-6. TNF-a. Função Pulmonar. 


\begin{abstract}
MIRANDA-CHAVES, A. A. Pulmonary toxicity of thoracic conformal radiotherapy in women with breast cancer. Functional, tomographic and systemic impacts and its effects on quality of life. 2013. 183 leaves, Thesis (Ph.D.) - Faculdade de Medicina, Universidade de São Paulo, Ribeirão Preto - SP, 2013.
\end{abstract}

Radiotherapy continues to improve itself, but it may still be associated with pulmonary toxicity. Objective: To study the effects caused by local and systemic adjuvant thoracic conformal radiotherapy in women with breast cancer, without risk factors prior to the development of pulmonary alterations. Through high-resolution computed tomography, to identify the possible radiological alterations in the lung parenchyma. If positive identification occurs, correlates it with pulmonary functional parameters, its systemic effects, the dosage of inflammatory mediators IL-1 $1 \beta, \mathrm{IL}-6$ and TNF- $\alpha$, and their impact on quality of life. Material and Methods: Blood samples were collected from 25 healthy patients to be used as a normal reference for IL-1 $\beta, I L-6$ and TNF- $\alpha$ mediators. Due to the established strict inclusion and exclusion criteria, only 24 from the initial 157 interviewed patients were selected for this study. The evaluation of pulmonary function was comprehensive and included: Lung volume and capacity measurement through closed loop helium residual volume dilution method;Peak expiratory flow study (flow curve $x$ volume and volume vs. time curve) and CO diffusing capacity measurement through single breath technique. High-resolution computerized tomography (16 detectors) was performed in the pre-planning phase of thoracic conformal radiotherapy where 45-50 Gy total dose was applied in 25 fractions. For cytokines plasma measurement, the enzymatic immunosorbent techniques (ELISA) were used. For quality of life assessment, the Brazil's validated Saint George's Respiratory 
Questionnary was used. All these procedures were applied in the pre-phase and repeated three months later after radiotherapy sessions. The results of the two phases were compared using the exact version of the Wilcoxon test and Spearman correlation test with $p \leq 0.05$ significance level. Results: Among the functional parameters, there were a significant decrease in dissemination and expiratory flow at $50 \%$ of forced vital capacity. The same behavior was observed for cytokine IL-6, since they were already high at pre-RT. There were no significant changes in any of the aspects of quality of life questionnaire. The tomographic alterations occurred in $60,87 \%$ of patients in the post radiotherapy phase, mostly having low to moderate degree and not correlated with the observed changes in other parameters. Conclusion: The IL-6 increase in the pre-RT phase appears to be a reasonable predictive index of pulmonary alterations. The diffusing capacity alterations were the most evident and seem to be the index that best reflects the pulmonary alterations that affect these patients. Given the discrete tomographic and functional abnormalities observed after RT, it is likely that for the observed reduction in DLCO compete a combination of factors occurring at alveolarcapillary membrane level. Overall, the conformal radiotherapy induced changes in the studied patients were not expressive, insufficient to influence the pulmonary functional aspects and the quality of life of the patients.

Keywords: Thoracic Radiotherapy. Tomography. Quality of life. IL-1ß. IL-6. TNF- $\alpha$. Pulmonary Function. 


\section{LISTA DE ILUSTRAÇÕES}

Figura 1 - Distribuição dos valores da IL-1 $\beta$ em picograma por mililitro de cada paciente nos tempos de avaliação.

Figura 2 - Distribuição dos valores da IL-6 em picograma por mililitro de cada paciente nos tempos de avaliação.

Figura 3 - Distribuição dos valores do TNF- $\alpha$ em picograma por mililitro de cada paciente nos tempos de avaliação.

Figura 4 - Distribuição dos valores do total de pontos no SGRQ de cada paciente nas fases que foram submetidas à avaliação.

Figura 5 - Distribuição dos valores do Domínio Sintomas de cada paciente nos tempos de avaliação

Figura 6 - Distribuição dos valores do Domínio Atividade de cada paciente nos tempos de avaliação.

Figura 7 - Distribuição dos valores do Domínio Impacto de cada paciente nos tempos de avaliação.

Figura 8 - Distribuição dos valores da CVF em litros de cada paciente nos tempos de avaliação......

Figura 9 - Distribuição dos valores da VEF1 em litros de cada paciente nos tempos de avaliação...

Figura 10 - Distribuição dos valores da VEF1/CVF em porcentagem de cada paciente nos tempos de avaliação.

Figura 11 - Distribuição dos valores da FEF50\% de cada paciente nos tempos de avaliação........

Figura 12 - Distribuição dos valores da FEF75\% de cada paciente nos tempos de avaliação.......

Figura 13 - Distribuição dos valores da CPT de cada paciente nos tempos de avaliação...

Figura 14 - Distribuição dos valores da CRF de cada paciente nos tempos de avaliação. 93

Figura 15 - Distribuição dos valores da CV de cada paciente nos tempos de avaliação... 
Figura 16- Distribuição dos valores da VR de cada paciente nos tempos de avaliação..............................................................................................95

Figura 17 - Distribuição dos valores da DLCO $(\mathrm{ml} / \mathrm{min} / \mathrm{mmHg})$ de cada paciente nos tempos de avaliação

Figura 18 - Correlação das diferenças das fases pré-RT e pós-RT da Difusão em $\mathrm{ml} / \mathrm{min} / \mathrm{mmHg}$ e a diferenças das fases pré-RT e pós-RT do Domínio Sintoma do SGRQ.. 100

Figura 19 - Correlação das diferenças das fases pré-RT e pós-RT da Difusão $\mathrm{ml} / \mathrm{min} / \mathrm{mmHg}$ e a diferenças das fases pré-RT e pós-RT do Domínio Impacto do SGRQ ...........................................................................100 


\section{LISTA DE TABELAS}

Tabela 1 - Distribuição e motivos da não inclusão das pacientes no estudo...........71

Tabela 2 - Pacientes excluídas do estudo......................................................72

Tabela 3 - Estadiamento dos tumores das pacientes que concluíram a participação

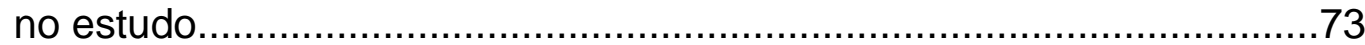

Tabela 4 - Distribuição das pacientes segundo o comportamento dos mediadores inflamatórios sistêmicos da fase pós-RT em relação a fase pré-RT.......76

Tabela 5 - Estatística descritiva das variáveis estudadas nos mediadores inflamatórios sistêmicos................................................................76

Tabela 6 - Estatística descritiva das variáveis estudadas no Saint George's Respiratory Questionnaire no grupo de pacientes que não realizou QT e

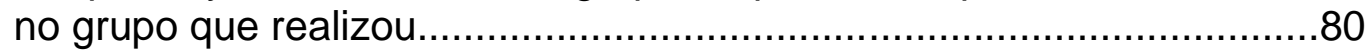

Tabela 7 - Estatística descritiva das variáveis estudadas no Saint George's Respiratory Questionnaire............................................................. 81

Tabela 8 - Estatística descritiva das variáveis estudadas na prova de função pulmonar. .86

Tabela 9 - Correlações de Sperman entre as diferenças pós-RT menos pré-RT das variáveis estudadas, que apresentaram p-valor significante. 


\section{LISTA DE ABREVIATURAS}

\begin{tabular}{ll} 
ATS & American Thoracic Society \\
BSA & Albumin from bovine serum \\
CM & Campo mediastinal \\
CO & Monóxido de carbono \\
CPT & Capacidade pulmonar total \\
CSC & Campo supraclavicular \\
CSE & Centro de Saúde Escola \\
CTM & Campo tangencial da mama \\
CV & Capacidade vital \\
CVF & Capacidade vital forçada \\
DLCO & Capacidade de difusão do monóxido de carbono \\
EBCTCG & Early breast cancer trialists' collaborative group \\
EORTC & Organização Europeia para Pesquisa e Tratamento do Câncer \\
FEF50\% & Fluxo expiratório forçado 50\% da CVF \\
FEF75\% & Fluxo expiratório forçado 75\% da CVF \\
FMRP & Faculdade de Medicina de Ribeirão Preto \\
FSC & Fossa supraclavicular \\
GC & Grupo controle \\
IL-1 3 & Interleucina $1 \beta$ \\
IL-6 & Interleucina 6 \\
INCA & Instituto Nacional de Câncer \\
PBS & Solução salina tamponada \\
\hline
\end{tabular}


PFP Prova de função pulmonar

QLQ-BR23 Questionário de QV relacionada a saúde para pacientes de mama com câncer da mama da EORTC

QLQ-C30 Questionário de QV relacionada a saúde para pacientes com câncer da EORTC

QT Quimioterapia

QV Qualidade de vida

RT Radioterapia

Rx Raio-x

SGRQ Saint George's Respiratory Questionnaire

TC Tomografia computadorizada

TCLE Termo de consentimento livre e esclarecido

TGF- $\beta \quad$ Fator- $\beta$ de crescimento

TNF- $\alpha \quad$ Fator- $\alpha$ de necrose tumoral

USP Universidade de São Paulo

VEF1 Volume expiratório forçado no primeiro segundo

VR Volume residual 


\section{LISTA DE ANEXOS}

ANEXO A Termo aprovado pelo Comitê de Ética e Pesquisa da Faculdade de Medicina de Ribeirão Preto da Universidade de São Paulo.

ANEXO B Termo aprovado do adendo de inclusão do grupo controle pelo Comitê de Ética e Pesquisa da Faculdade de Medicina de Ribeirão Preto da Universidade de São Paulo.

ANEXO C Termo de Consentimento Livre e Esclarecido - Grupo Radioterapia.

ANEXO D Termo de Consentimento Livre e Esclarecido - Grupo Controle.

ANEXO E Questionário do Hospital Saint George na Doença Respiratória (SGRQ) 162

ANEXO F Características da neoplasia mamária, tratamento cirúrgico, quimioterápico e complementares de cada paciente.

ANEXO G Características do tratamento radioterápico realizado em cada paciente.

Anexo $H$ Descrição dos achados qualitativos e quantitativos nas tomografias pré-RT e após-RT.

ANEXO I Valores observados na prova de função pulmonar.

ANEXO J Valores observados no Saint George's Respiratory Questionnary (SGRQ)

ANEXO $L$ Resultado da dosagem de alguns mediadores infamatórios sistêmicos.

ANEXO M Resultado da dosagem de alguns mediadores infamatórios sistêmicos (Grupo Controle).....

ANEXO N Resultado das Correlações de Sperman entre as diferenças pós-RT menos préRT do DLCO com as diferenças pós-RT menos pré-RT de todas as variáveis mensuradas no estudo.

ANEXO O - Continuação - Resultado das Correlações de Sperman entre as diferenças pós-RT menos pré-RT do FEF50\% com as diferenças pós-RT menos pré-RT de todas as variáveis mensuradas no estudo.

ANEXO P - Continuação - Resultado das Correlações de Sperman entre as diferenças pósRT menos pré-RT da IL-6 com as diferenças pós-RT menos pré-RT de todas as variáveis mensuradas no estudo. 


\section{SUMÁRIO}

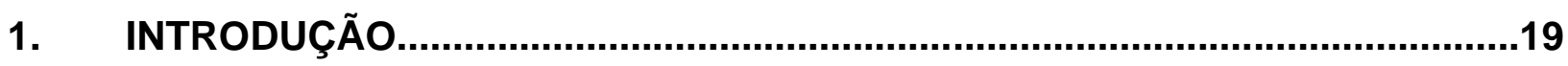

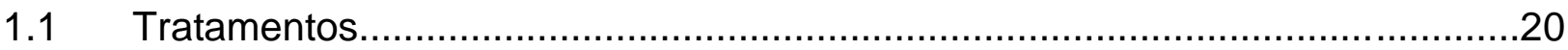

1.2 Radioterapia para Câncer de Mama $x$ Mediadores Inflamatórios

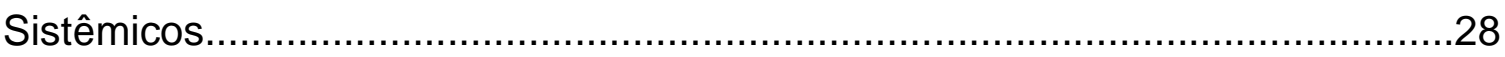

1.3 Radioterapia para Câncer de Mama x Qualidade de vida..................................31

1.4 Radioterapia para Câncer de Mama x FPP ..................................................

1.5 Radioterapia para Câncer de Mama x TC x PFP...........................................46

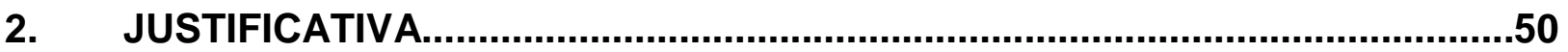

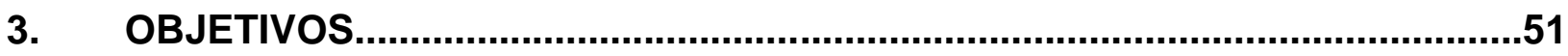

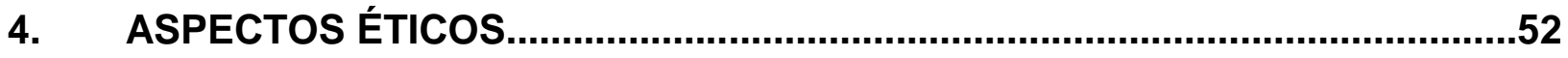

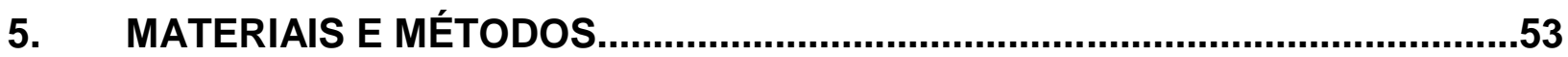

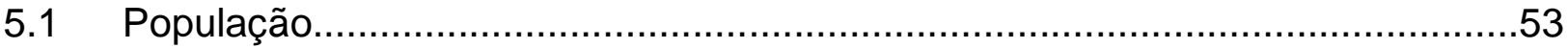

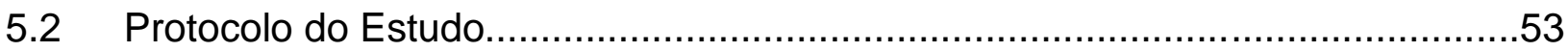

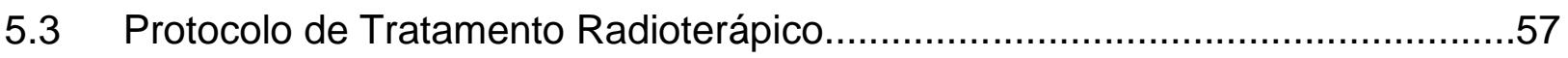

5.4 Mensuração dos Mediadores Inflamatórios.....................................................58

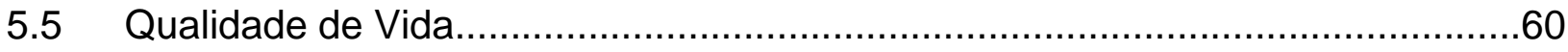

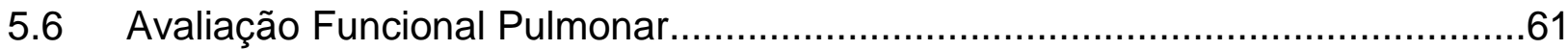

5.7 Tomografia Computadorizada de Alta Resolução...............................................65

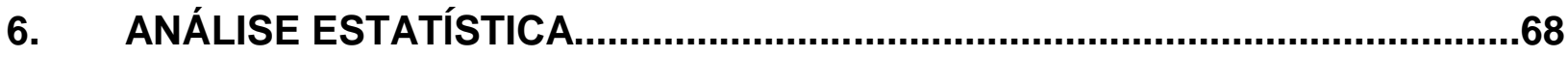

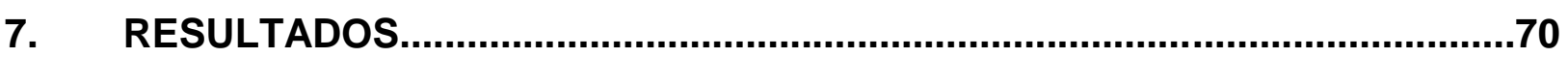

7.1 Características da População Estudada........................................................... 


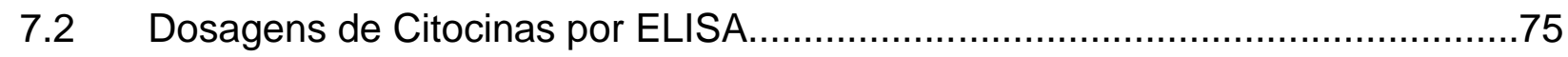

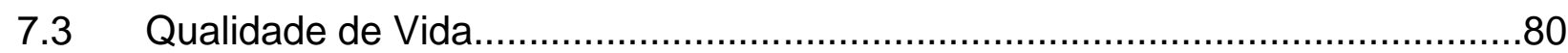

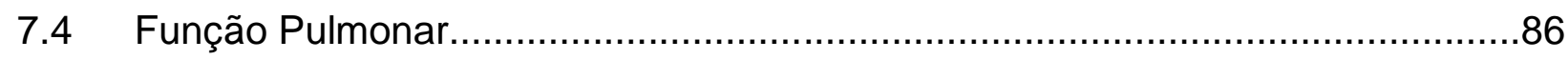

7.5 Tomografia Computadorizada de Alta Resolução........................................97

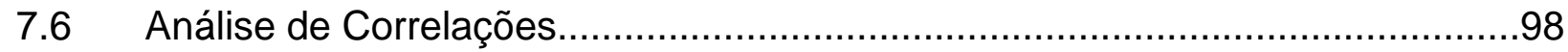

8. DISCUSSÃO

9. CONCLUSÕES.............................................................................................125

REFERÊNCIA BIBLIOGRÁFICA.....................................................................127

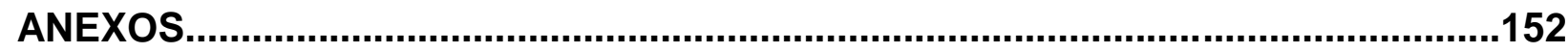




\section{INTRODUÇÃO}

O câncer de mama representa cerca $23 \%$ de todos os tipos de câncer, sendo o tipo que mais acomete as mulheres em todo o mundo (JEMAL et al., 2004). O Instituto Nacional de Câncer (INCA) apresenta estimativa de incidência para o ano de 2012 em 52.680 novos casos de câncer de mama no Brasil, apresentando um risco estimado de 52 casos a cada 100 mil mulheres (INCA, 2012a).

Como existem vários fatores de riscos e características genéticas que estão envolvidos na etiologia do câncer de mama, o diagnóstico precoce se faz através de estratégias de rastreamento. No Brasil é empregado programas de divulgação do autoexame mensal das mamas, exame clínico anual das mamas a partir dos 40 anos e um exame monográfico a cada dois anos para mulheres de 40 a 69 anos. No caso das mulheres que fazem parte do grupo de risco elevado para desenvolvimento de câncer de mama o exame clínico e a mamografia devem ser anuais a partir dos 35 anos. São considerados como riscos elevados: parentes de primeiro grau com história de câncer de mama antes dos 50 anos de idade; história familiar em parentes de primeiro grau com câncer de mama bilateral ou de ovário em qualquer idade; caso de câncer de mama masculina na família; ou mulheres com neoplasia lobular in situ ou lesão mamária proliferativa atípica (INCA, 2004).

Se diagnosticado e tratado precocemente apresenta bom prognostico, porém as taxas de mortalidade no Brasil ainda são elevadas, possivelmente devido aos diagnósticos tardios. Apresentando após cinco anos sobrevida média de cerca de 
$60 \%$, sendo que em países desenvolvidos a taxa está em torno de $85 \%$ (INCA, 2012a).

\subsection{Tratamentos}

A abordagem terapêutica do câncer de mama visa um tratamento integral da paciente. Este pode ser dividido em local, incluindo a cirurgia e a radioterapia (RT), e sistêmico, incluindo a quimioterapia (QT), hormonioterapia e terapia biológica (INCA, 2012b).

\subsubsection{Cirurgia}

A técnica cirúrgica depende das características da doença, como tipo histológico, tamanho do tumor em relação à mama, estadiamento e das características da paciente. Os tratamentos cirúrgicos podem ser divididos em conservadores (tumorectomia, tumorectomia alargada e a quadrantectomia, com retirada ou não dos gânglios axilares ou linfonodo sentinela) e não conservadora como a mastectomia (INCA, 2004). 
Quando indicada adequadamente, as cirurgias conservadoras, principalmente quando associadas à outra técnica de tratamento como QT, RT, hormonioterapia e terapia biológica, obtêm os mesmos resultados que as cirurgias mais agressivas, e por isso é sempre a terapia de escolha em casos de câncer de mama de estágio não avançado; a recidiva local e regional é um evento muito raro (BOTTERI et al., 2010).

Durantes as cirurgias, muito frequentemente são utilizadas a biópsia de linfonodos axilares; objetivando determinar o estadiamento, avaliar o prognóstico no que se refere à recidiva local e à distância e orientar a terapêutica complementar (INCA, 2012b; PAZ et al. 2001).

\subsubsection{Quimioterapia}

A QT tem por objetivo proporcionar à paciente aumento da sobrevida livre da doença através do controle da progressão da doença e de metástases (BERGH et al., 2001).

A terapia neoadjuvante é indicada em pacientes com tumores de mama localmente avançados, inicialmente, inoperáveis (ESTEVA; HORTOBAGYI, 1999). Porém, ultimamente vêm sendo muito empregada como alternativa de QT adjuvante, em tumores inicialmente já operáveis, tornando a cirurgia mais conservadora e com taxas de eficácia semelhantes (GIANNI, et al. 2009). Diversos especialistas, como os da Sociedade Brasileira de Mastologia, defendem que a QT neoadjuvante é muito efetiva devido ao melhor acesso das drogas às células tumorais, pela ausência de 
fibrose e pela integridade do sistema vascular e linfático da mama e da axila. E destacam como principal desvantagem retardar o tratamento, o que possibilita o crescimento tumoral local (SAMPAIO, 2011).

A QT adjuvante tem se mostrado muito importante para aumento da sobrevida livre de recidivas (SIMES; COATES, 2001). Estas variam de acordo com o risco prévio da paciente, a histologia do tumor e a presença de metástases (DURIC; STOCKLER, 2001).

Existem diversos esquemas quimioterápicos para auxiliar a melhor escolha da combinação de drogas, incluindo a recomendação do Consenso para Controle do Câncer de Mama de dois programas obtidos pela internet, http://www.adjuvantonline.com e http://www.mayoclinic.com/calcs (INCA, 2004). Atualmente, os quimioterápicos mais utilizados para câncer de mama são: Epirrubicina ou Doxorrubicina, Ciclofosfamida, Fluorouracil e Docetaxel, podendo estar essas drogas associadas também a um agente de bioterapia, no caso o anticorpo monoclonal anti-HER2, o Trastuzumab.

Diversos estudos como os de Crivellari et al. (2003) e Sartor et al. (2005) demostraram que a QT isoladamente não apresenta um bom controle local ou locorregional, fazendo-se necessário tratamento local, RT. 


\subsubsection{Terapia Biológica}

Devido à grande importância do câncer de mama existem constantes pesquisas buscando o aprimoramento dos tratamentos. Vem-se obtendo melhoria das técnicas cirúrgicas, otimização de QT, RT, hormônio terapia e, mais recentemente, o emprego do anticorpo monoclonal anti-HER-2 trastuzumab (Herceptin® Genentech, São Francisco, Estados Unidos da América), também conhecida como terapia biológica (INCA, 2012b).

HER-2 é o fator de crescimento epidérmico humano receptor-2, pertence à família de receptores transmembrânicos envolvidos nas vias de transdução de sinais que regulam o crescimento e diferenciação celular. Portanto, mulheres com câncer de mama que apresentem superexpressão / amplificação de HER2 têm pior prognóstico. Diminuindo a concentração de HER2 da superfície da célula ou inibindo a sua atividade enzimática intrínseca pode reduzir oncogênese (YARDEN, 2001). Os testes de HER2 e receptores hormonais são partes essenciais da avaliação clínica das pacientes com carcinoma de mama; resultados precisos são fundamentais na identificação de pacientes que podem ser beneficiadas por terapias específicas (WLUDARSKI, 2010). No entanto, é muito importante se considerar o elevado custo do tratamento (MARTINS; YAMAMOTO, 2008) e o fato de ter-se observado a ocorrência de cardiotoxicidade induzida pelo trastuzumab (SANCHES; SILVA, 2010). 


\subsubsection{Hormonioterapia}

Os benefícios da hormonioterapia adjuvante com tamoxifeno em pacientes com câncer de mama estão bem estabelecidos em estudos randomizados (EARLY BREAST CANCER TRIALISTS' COLLABORATIVE GROUP - EBCTCG, 1992; OVERGAARD et al., 1988).

O mecanismo de ação se dá devido ao tamoxifeno ser modulador do receptor seletivo de estrogênio com ação tanto agonista quanto antagonista do estrogênio e por isso só é indicado no tratamento de mulheres com tumor de mama que tenham receptores de estrogênio e progesterona, o que ocorre em torno $60 \%$ dos casos (OSBORNE, 1998).

Overgaard et al. (1999) observaram que o tratamento do câncer de mama em mulheres com alto risco de recidiva é mais efetivo se há a combinação de terapia locorregional e sistêmica. A RT adjuvante associada ao tamoxifeno é de extrema importância neste controle locorregional e aumenta a sobrevida livre do câncer nestas mulheres.

\subsubsection{Radioterapia}

A RT é uma radiação ionizante capaz de destruir células tumorais. Para cada paciente é calculada a dose, o tempo, o volume do tecido irradiado, visando erradicar 
todas as células tumorais locais, com o menor dano possível às células normais circunvizinhas. A eficácia depende da sensibilidade do tumor, da sua localização, da qualidade e da quantidade da radiação aplicada. Ela poderá ser a única forma de tratamento ou estar associada a outros métodos de tratamento como: cirurgia, QT, hormonioterapia, terapia biológica. A RT será fracionada em doses diárias visando atingir maior número de células neoplásicas e o menor de células sadias dos tecidos circunvizinhos e respeitar a tolerância destes. Assim, os efeitos colaterais são mínimos e bem tolerados. Os efeitos imediatos são mais evidentes em tecidos que apresentam maior capacidade proliferativa, como a epiderme, as gônadas, as mucosas dos tratos digestivo, urinário e genital, e a medula óssea e devem ser tratados sintomaticamente, pois geralmente são bem tolerados e reversíveis. Já os efeitos tardios só ocorrem quando são ultrapassadas as doses de tolerância dos tecidos normais, causando atrofias e fibroses (PRO-ONCO ${ }^{1}, 1993$ apud INCA, 2012c).

As técnicas de RT estão evoluindo muito, buscando realizar melhores distribuições de dose, isto é, a capacidade de reduzir o volume de tratamento em relação ao volume alvo e ainda garantir uma cobertura do volume alvo em todas as dimensões. Quando a RT é guiada por imagem, a radiação é entregue para a área mais específica e este fato tornou-se possível devido às melhorias recentes na tecnologia de informática, novas técnicas de RT e melhor compreensão morfológica

\footnotetext{
1 Pro-Onco. Controle do Câncer: uma proposta de integração ensino-serviço. Rev. Atual, Rio de Janeiro, 2 ed., 1993.
} 
e das informações funcionais do organismo do paciente (VERELLEN; DE RIDDER; STORME, 2008).

\subsubsection{Radioterapia para o Câncer de Mama}

Para muitas mulheres com câncer de mama em estágio inicial, acirurgia conservadora da mama pode remover a doença macroscópica, no entanto, alguns focos de tumor microscópico podem permanecer e, se não tratados, levar à recidiva locorregional ou metástases distantes, ou ambos, daí a imensa importância da RT (EBCTCG, 1995, 2000, 2005). Existem riscos de recidivas mesmo em cirurgias conservadoras associadas à linfonodos sentinelas negativos para a doença, sendo também nestes casos muito importante a RT adjuvante, pois a mesma diminui significativamente as taxas de recidivas (EBCTCG, 2000; FISHER et al., 2002).

A RT é também muito importante no controle dos casos de mastectomia associada ao esvaziamento axilar, mesmo com todos os linfonodos explorados negativos para a doença; há um risco considerável de recorrência locorregional, por exemplo, na parede torácica se houver envolvimento de algum linfonodo e, consequentemente, mais clara a indicação de RT (OVERGAARD et al., 1999; RAGAZ et al., 2005).

Outras importantes indicações da RT são as doenças locorregionalmente avançadas, muitas vezes tornando-as operáveis - RT neoadjuvante (KLEFSTROM et al., 1987; OLSON et al., 1997), ou utilizá-la como único tratamento, objetivando melhorar a qualidade de vida (QV) - RT paliativa (FARIA; LEITE, 1999). O controle da doença pela RT foi observado até mesmo em estudos mais antigos, época que os 
recursos técnicos eram inadequados em relação aos atuais (FOWBLE; GLICK; GOODMAN, 1988; PIERCE; LICHTER, 1996).

Em EBCTCG (2005) observaram que a RT adjuvante em cirurgia conservadora apresentaram alto controle local e pouca influência sobre a mortalidade nos primeiros anos, mas moderado controle nas taxas de mortalidade em 15 anos. O mesmo grupo de pesquisadores em 2000 já havia constatado, por metanálise, um importante controle na recidiva locorregional e uma significativa redução da mortalidade por câncer de mama, mas também observaram um aumento significativo do número de mortes por outras causas, principalmente de origem vascular. Quando analisaram a sobrevida global, observaram uma redução de 3,9\% na taxa de morte anual.

\subsection{Campos Irradiados}

A escolha dos campos de RT é geralmente baseada nos padrões da recidiva locorregional. (STROM; MCNEESE, 1999). A indicação de radiação axilar ou fossa supraclavicular vem da análise da invasão dos linfonodos axilares. Quando há ausência de comprometimento axilar ou a presença de um ou dois linfonodos comprometidos com esvaziamento axilar completo não há indicação de irradiar esse(s) campo(s); caso não seja possível esvaziamento axilar completo há a necessidade de irradiar estes campos. Outros casos em que há essa indicação são na presença de três ou mais linfonodos ou quando há a invasão de estruturas vizinhas. Em câncer de mama quase nunca é irradiada a cadeia da mamária interna, pois metástases para essa área são raras e há grande possibilidade de dano aos 
tecidos mediastinais, como o coração e o pulmão. Só estão indicados quando também há tumores mediais, maiores que três centímetros, ou tumores mediais ou centrais com axila comprometida. Já a RT em plastão mamário está indicada em tumores com alto risco de recidiva local (MIZIARA; PINTO, 2001).

Os efeitos colaterais mais comumente encontrados são: linfedema de membro superior, pneumonite/fibrose pulmonar e toxicidade cardíaca crônica, doenças isquêmicas cardíacas, eritema, telangiectasia e ulcerações de pele e necrose óssea em costelas e esterno (LANDBERG, 1995). Sendo que os efeitos colaterais são menos frequentes e com menor intensidade na RT conformacional por esta ser mais dirigida ao tecido acometido (BONAN et al., 2005).

\subsection{Radioterapia para Câncer de Mama x Mediadores Inflamatórios Sistêmicos}

Chen et al. (2001) sugeriam que o valor da interleucina 6 (IL-6) pré-RT é um bom índice preditivo de pneumonite induzida pela radiação. Estes autores mensuraram as citocinas em 24 pacientes que realizaram RT por câncer de mama, de pulmão, em linfomas e outras neoplasias do tórax e fizeram o acompanhamento clínico por mais de 12 meses. Foram analisadas pelo teste ELISA, a IL-6 e fator- $\alpha$ de necrose tumoral (TNF- $\alpha$ ) antes da RT, durante, e após a RT; a lesão por radiação pulmonar foi definida utilizando critérios do National Cancer Institute Common Toxicity (TROTTI et al., 2000). Não ocorreram casos de pneumonite grau 3 ou 4; observou-se 13 casos de pacientes que apresentaram grau 2 e 6 pacientes 
desenvolveram grau 1, essas alterações foram observadas de 8 a 12 semanas após a RT. O valor da IL-6 na avaliação pré-RT foi significativamente maior nas pacientes que desenvolveram pneumonite em todos os tempos avaliados, já os níveis de TNFa não apresentaram correlação com a ocorrência de pneumonite por radiação.

Por outro lado, Geinitz et al. (2001) não observaram alterações dos níveis de IL-1ß, IL-6 e TNF- $\alpha$ induzidos pela RT. Analisando outros parâmetros, os autores não consideraram as interleucinas como bons índices preditivos para a sensação de fadiga manifestada pelas pacientes durante as avaliações do estudo. Assim como também não observaram correlação da fadiga com a ansiedade, a depressão, ou declínio dos níveis de hemoglobina. Essa fadiga, que ocorreu durante a RT, voltou a níveis normais na avaliação dois meses após o término da mesma. Para chegar a essas conclusões, estes autores realizaram um estudo prospectivo em 41 mulheres que receberam RT adjuvante após a cirurgia conservadora da mama por câncer, nenhuma realizou QT concomitante. Foram realizadas avaliações pré-RT, 1, 2, 3, 4 e 5 semanas durante a RT e dois meses após o término da mesma. Foram utilizados os questionários de auto avaliação padronizado e de avaliação da fadiga, uma escala visual analógica para dimensionar a intensidade de fadiga e a do Hospital de Ansiedade e Depressão (GLAUS, 1998). Para mensurar os mediadores inflamatórios sistêmicos foi utilizado o método ELISA.

A grande maioria dos estudos realizados com mediadores inflamatórios sistêmicos foram com pacientes com câncer de pulmão, como o trabalho de Rube et al. (2008), estudaram 52 pacientes, no qual mensuraram os níveis de IL-6 e fator de crescimento (TGF)- $\beta 1$ nas biópsias tumorais que foram realizadas antes da RT e os níveis plasmáticos de citocinas (TNF- $\alpha$, IL-1 $\beta$, IL-6 e TGF- $\beta 1$ ) medidos antes e 
semanalmente durante a RT, e 1, 3, 6 e 9 meses pós-RT, e no início dos sintomas clínico de pneumonite por radiação. As lesões pulmonares induzidas pela radiação ocorreram em 21 pacientes. Não houve correlação dos níveis de citocinas plasmáticos antes, durante e após a RT com a incidência de lesões induzidas pela radiação, assim sendo os autores concluíram que a TNF- $\alpha$, IL-1 $1 \beta$, IL-6 e TGF- $\beta 1$ não seriam bons índices preditivos de risco para pneumonite por radiação. Estes autores acreditam que o tumor era a principal fonte produtora de IL-6 e TGF- $\beta 1$ circulantes nas pacientes que fizeram RT; chegaram a essa conclusão após analisarem a resposta individual do tumor.

ARPIN et al. (2005), estudaram os níveis de IL-6; TNF- $\alpha$ e IL-10 em 96 pacientes com diversos tipos de canceres que realizaram RT conformacional tridimensional. Avaliaram dosagem destes mediadores antes de iniciar a RT e semanalmente durante a RT, 8 semanas após término da mesma. Apresentaram aumento de IL-6 com pico em duas semanas após a RT estiveram associadas com o risco de pneumonia actínica, $(p=0,047)$, assim como, as que não apresentaram esse pico em 2 semanas estiveram associados com a sua ausência. Foram encontradas associações entre aumento dos níveis $\mathrm{IL}-10$ e menor risco de pneumonite por radiação e não houve correlação entre TNF- $\alpha$ e a incidência de pneumonia actínica.

Estudo realizado por Rube et al. (2004), do qual irradiaram com 12 Gy o tórax de camundongos do grupo tratados; nestes e no grupo controle foram avaliados a expressão de TNF-a, IL-1a e IL-6 no tecido pulmonar, 30 minutos; 1, 3, 6, 12, 24, 48, 72 horas e 1, 2, 4, 8, 16, e 24 semanas após a radiação. A análise permitiu observar que existem duas ondas de expressões das citocinas na fase precoce da resposta à 
radiação: a primeira onda ocorre nas primeiras horas após o a RT e volta aos níveis basais até 2 dias após a RT; a segunda onda ocorre de 8 até 16 semanas pós-RT. Essa segunda onda de aumento de citocinas correlacionou-se com a pneumonite por radiação.

\subsection{Câncer de Mama x Qualidade de Vida}

Mulheres com câncer de mama são naturalmente expostas à tensão relacionada ao diagnóstico, tratamento e prognóstico da doença, fatos que influenciam muito a QV destas pacientes (BJÖRNEKLETT et al., 2012; SVENSK et al., 2009). Essa piora na QV pode-se apresentar como piora física, fadiga, disfunção sexual, devido à alteração da imagem corporal e baixa autoestima que também é um dos efeitos psicologicos de quem sofre tratamento para câncer de mama (CULOSREED et al. 2006; CARPENTER et al., 2004; SAVARD et al., 2004).

Diversos autores estudaram a influência dos diferentes tratamentos para câncer de mama sobre a QV das pacientes submetidas a eles; como Arndt et al. (2008), que avaliaram a QV de 315 mulheres em estágios inicias de câncer de mama, durante cinco anos após a primeira cirurgia oncológica e compararam os resultados entre o grupo de mulheres que fizeram a cirurgia conservadora, $72 \%$, e as que fizeram mastectomia, $28 \%$. Utilizaram o questionário de QV para pacientes com câncer (QLQ-C30) da Organização Europeia para Pesquisa e Tratamento do Cancer 
(EORTC) (AARONSON et al., 1993) e o especifico para pacientes com câncer de mama (QLQ-BR23) (SPRANGERS et al. 1996), essas avaliações foram realizadas 1, 3 e 5 anos após a primeira cirurgia. $\mathrm{O}$ grupo que realizou cirurgia conservadora apresentou melhor atividade física e psicologica, eram sexualmente mais ativas e mais satisfeitas com sua imagem corporal já na avaliação um ano $(p<0,05$ em todas as variáveis avaliadas). Já a avaliação global da QV foi aumentando gradualmente ao longo do tempo e tornou-se estatisticamente significativa apenas em cinco anos.

Penttinen et al. (2011) observaram que a QV das pacientes logo após tratamentos adjuvantes para câncer de mama foi prejudicada, assim como o desempenho físico, em comparação com a população geral. Em particular, a depressão e fadiga foram relacionadas com prejuízo na QV. Desempenho físico e nível de atividade foram os únicos fatores que se correlacionaram positivamente a QV. Assim, o exercício físico pode ser útil na reabilitação de sobreviventes de câncer, especialmente para pacientes com depressão e fadiga.

QV das pacientes, a logo prazo, após tratamento por câncer de mama é comparável à da população geral; mesmo quando sofrem de substancial fadiga durante o tratamento. Porém, algumas pacientes apresentam fadiga persistente póstratamento que, pode levar a perda da QV em longo prazo (SCHMIDT et al., 2012). Outros autores também observaram que a QT apresenta maior impacto sobre a fadiga do que a RT; diversas pacientes relatam que a QT altera a QV através da indução de vários sintomas comportamentais e existem estudos que relatam essa sensação das pacientes (DAGNELIE et al., 2007; STONE et al., 2000).

Também existem muitos relatos de fadiga e diminuição da QV durante ou após a RT em pacientes que fazem tratamento para câncer de mama. Porém muitas 
destas também foram submetidas à QT adjuvante; na tentativa de esclarecer se a piora da QV foi influenciada mais pela QT ou pela RT, Noal et al. (2011), estudaram a QV e fadiga de 161 pacientes que realizaram QT adjuvante e RT e 141 que realizaram somente RT e compararam os resultados. Estes autores observaram que na avaliação antes do início da RT, o grupo de pacientes que realizaram a QT adjuvante ocorreu fadiga em $60 \%$ destas pacientes versus $33 \%$ do grupo as quais não se submeteram a QT, $(p<0,001)$. Já os valores após o término da RT foram estatisticamente semelhantes entre os grupos, $61 \%$ e $53 \%$, respectivamente. Após um ano do término de RT cerca de $40 \%$ das pacientes continuavam apresentando fadiga em ambos os grupos. Já a depressão na avaliação pré-RT foi significantemente menor no grupo que realizou somente a RT $(p=0,01)$. Ao final da RT ambos os grupos apresentavam sinais de depressão em $25 \%$ das pacientes. Após análise destes dados os autores concluíram que a fadiga é um dos sintomas mais frequente e que mais influencia a QV durante RT. E que após o término da RT a QV não é influenciada pela QT adjuvante, ou seja, a QT só influencia a QV logo após sua administração, antes do início da RT. A fadiga está altamente relacionada com o estado psicológico, de modo que devem ser rastreados para detectar pacientes que necessitam de apoio. Estes autores também dosaram IL-6, TNF- $\alpha$ e valores de proteína C reativa e não encontram correlação com a fadiga ou QV em nenhum dos tempos avaliados.

Reidunsdatter et al. (2013) avaliaram a fadiga de 250 mulheres que fizeram RT utilizando o questionário da EORTC e o QLQ-C30 (AARONSON et al., 1993). As avaliações foram realizadas antes da RT, 3, 6 e 12 meses após o término da mesma e também compararam com dados de 652 pessoas que foram o grupo controle, 
composto da população geral, ou seja, sem câncer. Estes autores concluíram que as comorbidades são determinantes mais importantes para o nível de fadiga que os tratamentos para o câncer. Em Karakoyun-Celik et al. (2010), observaram que a piora na QV após a RT estava correlacionada com a incidência de linfedema em membro superior.

Munshi et al. (2010) realizaram avaliação da QV em 255 mulheres submetidas a RT para tratamento de câncer de mama, todas estas já haviam se submetido à cirurgia para tratamento. Estes autores dividiram as pacientes em dois grupos, segundo a cirurgia a qual foram submetidas. Grupo de mastectomizadas composto por 113 pacientes e o grupo com as outras 142 pacientes no qual foi realizada cirurgia conservadora; compararam a QV destes grupos. As pacientes submetidas à mastectomia foram tratados com 45 Gray em 20 sessões durante quatro semanas. Pacientes que realizaram cirurgia conservadora foram tratados com dose de 45-50 Gray em 25 sessões durante cinco semanas e realizaram reforço no leito tumoral de mais 15 Gray em seis sessões diárias. As avaliações de QV foram realizadas antes, durante e após a RT, utilizando os questionários da EORTC, os QLQ-C30 (AARONSON et al., 1993) e o QLQ-BR23 (SPRANGERS et al. 1996), específico câncer de mama. A QV global observada antes do início da RT foi semelhante em ambos os grupos e não houve piora durante ou após o término da RT. Porém, houve diferença em alguns domínios; como no domínio função social, onde as pacientes que foram submetidas à mastectomia apresentaram melhor função social $(p=0,018)$, que as que fizeram cirurgia conservadora; já nos domínios prazer sexual e perspectiva de futuro as pacientes submetidas à cirurgia conservadora apresentaram-se melhor que as pacientes mastectomizadas, $(p=$ 
0,006) e $(p=0,036)$, respectivamente. Já outros domínios que avaliaram os efeitos colaterais na região da mama e do braço, assim como efeitos colaterais sistêmicos, não apresentaram diferença entre os grupos.

Arraras et al. (2008) avaliaram a QV antes do início da RT, ao final e seis semanas após o término da mesma, utilizando os questionários QLQ-C30 (AARONSON et al., 1993) e QLQ-BR23 (SPRANGERS et al. 1996), ambos da EORTC. Dividiram as pacientes em dois grupos de mulheres com câncer de mama: grupo de 65 a 84 anos de idade com 48 pacientes e o outro de 40 a 64 anos com 50 pacientes. Na avaliação logo após o término da RT ocorreram limitações leves e moderadas em algumas áreas emocionais, sexuais. Estas foram relacionadas com o tratamento, com a toxicidade, mas foram recuperadas durante o período de acompanhamento, ou seja, a RT não causou piora da QV na sexta semana após o seu término. Não houve diferença estatística na QV entre os grupos, portanto, concluiu que a idade era um parâmetro influente.

Versmessen et al. (2012) avaliaram 121 mulheres com câncer de mama estágio I-II e que se já haviam se submetido à cirurgia; estas foram randomizadas em dois grupos; um recebeu RT convencional e o outro recebeu tomoterapia hipofracionada. Realizaram avaliação antes da RT, logo após o término da mesma, três meses e 1, 2 e 3 anos pós-RT, aplicando os questionários da EORTC, o QLQC30 (AARONSON et al., 1993) e QLQ-BR23 (SPRANGERS et al. 1996), especifico para câncer de mama. Houve uma piora temporária no último dia da RT, nos escores de fadiga e global da saúde em ambos os grupos de tratamento e apresentou melhora durante o período de acompanhamento do estudo. 
Hopwood et al. (2010) observaram que as pacientes que receberam regimes de RT hipofracionada tiveram menos efeitos adversos que as pacientes receberam a RT tradicional para câncer de mama em estágios iniciais. Para estes autores chegarem a essa conclusão, os mesmos estudaram 4451 mulheres submetidas a RT por câncer de mama e avaliaram a QV através dos questionários EORTC, o QLQC30 (AARONSON et al., 1993) e o QLQ-BR23 (SPRANGERS et al. 1996). Também observaram que uma importante parcela de mulheres relataram alteração moderada da função braço / ombro ao longo de cinco anos após a RT.

A QV das pacientes submetidas ao tratamento por câncer de mama é influenciada pelos procedimentos aos quais são submetidas, por isso, diversos estudos foram realizados tentando avaliá-los e/ou mensurá-los e assim melhorar a QV destas pacientes (BANERJEE et al., 2007; DAGNELIE et al., 2007; MATTHEW et al., 2013; NUNES et al., 2007; HOFFMAN et al., 2012; REIDUNSDATTER et al., 2013; STONE et al., 2000; SVENSK et al., 2009).

O trabalho realizado por Vadiraja et al. (2009) avaliou a eficácia da ioga na melhora ou manutenção da QV das pacientes submetidas à RT adjuvante para tratamento de câncer de mama. Para isso dividiram 88 pacientes aleatoriamente para receber ioga $(n=44)$ ou terapia de suporte breve $(n=44)$ durante o tratamento radioterápico. O grupo intervenção realizou 18 sessões de ioga com duração de 60 minutos por dia, enquanto o grupo controle foi instituída a terapia de suporte breve constituída de aconselhamento com assistente social, uma vez a cada 10 dias, portanto, três ou quatro sessões durante a RT. As avaliações da QV foram realizadas utilizando o QLQ-C30 (AARONSON et al., 1993) da EORTC e a escala funcional Escala de Afeto Positivo e Negativo (WATSON; CLARK; TELLEGEN, 1988). Estas 
foram realizadas no início do estudo e após seis semanas de tratamento com RT. Houve melhora significativa no grupo ioga em relação ao grupo controle nos quesitos: efeitos positivos ( $p=0,007)$, função emocional $(p=0,001)$ e função cognitiva $(p=0,03)$, e queda em efeitos negativos $(p<0,001)$, ou seja, o grupo que realizou ioga apresentou melhora significante na QV em relação ao grupo controle.

Chandwani et al. (2010) também observaram que programas de ioga estão associados à significativa melhora na QV em mulheres com câncer de mama submetidas à RT. Estes autores compararam mulheres que fizeram RT e ioga e as que fizeram somente RT e observaram que após a RT que as pacientes do grupo de ioga relataram percepção de significativa melhora da saúde $(p=0,005)$ que 0 grupo que fez só RT.

Banerjee et al. (2007) avaliaram a QV de 68 pacientes nas fases pré e após o término da RT. Foram aplicados dois testes psicológicos: a Escala de Ansiedade e Depressão (AZIGMOND; SNAITH, 1983) e a Escala de Estresse Percebido (COHEN; WILLIAMSON,1988). As pacientes foram divididas em dois grupos; o grupo controle só realizou a RT e o grupo estudo realizou RT e ioga. Os autores observaram uma diminuição significativa nos escores na Escala de Ansiedade e Depressão no grupo que também realizou ioga, enquanto o grupo controle mostrou aumento destas pontuações. Já na Escala de Estresse Percebido houve diminuição no grupo que realizou ioga, enquanto o grupo controle manteve-se inalterado após a RT.

Hoffman et al. (2012) realizaram um estudo randomizado e controlado em 229 mulheres após a cirurgia, QT e RT para câncer de mama. Observaram que houve uma melhora estatisticamente significante na QV do grupo que realizou psicoterapia cognitiva comportamental em relação ao grupo controle, que não a realizou. 
Matthew et al. (2013) avaliaram a QV em estudo randomizado, controlado, em 117 pacientes com câncer avançado que receberam RT. Estas pacientes foram divididas em dois grupos; o grupo intervenção realizou seis sessões de psicoterapia e o outro não realizou, grupo controle. Observaram que participar desta intervenção foi eficaz na manutenção da QV destas pacientes.

Estudos realizados com terapias alternativas como a arteterapia empregada no estudo de Svensk et al. (2009), no qual avaliaram a QV de 41 pacientes com câncer de mama submetidas a RT e compararam o grupo intervenção, 20 pacientes, que fizeram arteterapia por 1 hora por semana durante a RT e grupo controle, no que só fizeram a RT. Aplicaram os questionários da EORTC o QLQ-BR23 (SPRANGERS et al. 1996) e o da World Health Organization Quality of Life (KUYKEN et al., 1995), antes do inicio da RT, dois e seis meses após o término da mesma. Estes autores concluiram que este estudo forneceu um forte apoio para o uso de terapia de arte para melhorar a QV de mulheres submetidas a tratamento de RT para câncer de mama.

Nunes et al. (2007), estudaram 34 pacientes submetidas a RT por câncer de mama, estas foram divididas aleatoriamente em dois grupos. $\mathrm{O}$ grupo controle que só realizou a RT e foi composto por 14 pacientes e o grupo experimental que realizou a RT e terapia de relaxamento visual. A QV destas pacientes através da mensuração do estresse, ansiedade e depressão por testes psicológicos com pontuação, realizados através avaliação clínica estruturada antes da RT e após o término da mesma. Observaram que houve uma melhora nos escores da QV no grupo experimental em relação ao grupo controle $(p<0,05)$, ou seja, o grupo que realizou somente RT apresentou piora nos escores avaliados. 
Em 2011, Duijts et al. (2011), realizaram metanálise para avaliar os efeitos de intervenções psico-comportamentais e exercícios sobre a fadiga, depressão, ansiedade, imagem corporal, estresse e QV em pacientes submetidas a tratamento por câncer de mama. Foram incluídos um total, 56 estudos. As análises dos estudos de utilizando técnicas psico-comportamentais sobre a fadiga apresentaram melhora significante $(p<0,001)$, assim como sobre a depressão $(p<0,001)$, sobre a ansiedade $(p<0,001)$ e sobre $o$ estresse $(p=0,038)$. Já na análise dos efeitos de exercícios físicos também foram estatisticamente significativos em relação à fadiga $(p=0,004)$, a depressão $(p=0,016)$, a imagem corporal $(p=0,007)$ e a QV geral $(p=$ 0,001), em relação ao grupo controle.

Na tentativa de mensurar a QV diversos questionários foram criados; há dois tipos de questionários para avaliar a QV: os genéricos e os específicos. Os instrumentos genéricos buscam avaliar, de forma holística, todos os aspectos importantes relacionados à QV. Como exemplos, destacam-se o Medical Out comes Study 36-item Short-Form Health Survey (WARE-Jr; SHERBOURNE, 1992), Nottingham Health Profile (HUNT et al.,1981), Quality of Well-being (KAPLAN; BUSH; BERRY, 1979), World Health Organization Quality of Life (KUYKEN et al., 1995) e o da EORTC, o QLQ-C30 (AARONSON et al., 1993). Já os específicos são capazes de avaliar, com maior acurácia, alguns aspectos específicos da QV, sendo mais sensíveis na deteç̧ão de alterações após uma intervenção (WIEBE et al., 2003). Os questionários específicos podem ser direcionados para avaliar a influência que determinada função tem sobre a QV. Por exemplo, a avaliar a influência da qualidade do sono, vida sexual, aspectos sociais, alterações pulmonares, entre muitos outros. (GUYATT; FEENEY; PATRICK, 1993). 
Entre esses instrumentos específicos que avaliam a influência dos aspectos respiratórios na QV encontra-se o questionário proposto por St. George's Hospital Medical School, conhecido com Saint George's Respiratory Questionnaire (SGRQ), que tem sido traduzido e validado em vários idiomas (JONES; QUIRK; BAVEYSTOCK, 1991).

No Brasil, o SGRQ foi traduzido e validado por Sousa; Jardim; Jones (2000). Este questionário apresentado no Anexo C, avalia domínios como sintomas (frequência e gravidade) através de perguntas alocadas na Parte 1, atividades diárias limitadas ou abolidas pela doença respiratória (Parte 2, seções 2 e 6) e os seus impactos nos aspectos profissionais, familiares, sociais e psicológicos dos indivíduos (Parte 2, seções 1, 3, 4, 5 e 7). Esses domínios possuem uma pontuação máxima possível. Os pontos de cada resposta são somados e o total é referido como uma porcentagem desse máximo. Valores acima de 10 refletem uma QV alterada naquele domínio. Alterações iguais ou superiores a 4 após uma intervenção, em qualquer domínio ou no total dos pontos, indicam uma mudança significativa na QV dos pacientes. Neste questionário, escores menores refletem uma QV melhor.

Devido à falta de um questionário validado específico para mensurar a influência do pulmão sobre a QV em mulheres submetidas a RT torácica foi optado pelo SGRQ, pois este atende as necessidades do presente estudo; por ser um questionário especifico para avaliar a influência do pulmão na QV e também devido ao mesmo já ser validado aqui no Brasil. 


\subsection{Radioterapia para Câncer de Mama x PFP}

As alterações pulmonares induzidos pela radiação torácica continuam sendo estudas por diversos autores, pois ainda não estão bem caracterizadas possivelmente por envolver múltiplos mecanismos, adicionam-se a esses fatos que estes trabalhos utilizam diversos métodos para tentar mensurar essas alterações e encontrar um bom índice preditivo, sendo que uns dos mais estudados são a prova de função (PFP) e tomografia computadorizada de alta resolução (TCAR). Marks et al. (2000) destacam a PFP como um dos promissores índices preditivos para alteração pulmonar induzida pela radiação. Estas alterações pulmonares podem ser divididas em danos agudos e tardios: os danos agudos caracterizam-se por ocorrer quatro semanas à três meses após a RT, período no qual a paciente apresenta frequentemente tosse e dispnéia. Quando leve a moderado costuma apresentar evolução favorável, enquanto, o dano mais intenso resulta em fibrose da área irradiada, iniciando entre seis a doze meses depois de tratamento - dano tardio (GROSS, 1981).

Theuws et al. (1998) avaliaram 81 pacientes com câncer de mama e linfoma torácico e observaram que há redução significativa no volume alveolar, capacidade vital (CV), volume expiratório forçada no primeiro segundo (VEF1), volume residual (VR) e capacidade de difusão do monóxido de carbono (DLCO) no $3^{\circ}$ ao $4^{\circ}$ mês após a RT quando comparado ao pré-RT e que este dano pode ser estimado previamente ao início do tratamento baseado na dose individual de cada paciente. $\mathrm{O}$ tabagismo e hábitos das pacientes podem tornar mais evidentes a diminuição destes parâmetros. 
Há diversos fatores que parecem influenciar as alterações pulmonares causadas pela RT. Para tentar entender melhor algumas das variáveis, Erven et al. (2012) avaliaram 75 mulheres submetidas a RT adjuvante e realizaram uma avaliação da PFP pré-RT, 3, 6 e 12 meses e 8 a 10 anos pós-RT. Realizaram comparações destes tempos com o exame da fase pré-RT. Todos os parâmetros da PFP estudados nesta pesquisa, CV, capacidade vital forçada (CVF), VEF1, capacidade pulmonar total (CPT) e DLCO apresentaram significante piora nos três e seis meses após a RT $(p<0,05)$. Já na avaliação com 12 meses, CVF, CV, VEF1 apresentaram recuperação quase aos valores basais, enquanto a CPT e a DLCO apresentaram discreta recuperação, ainda apresentavam uma diminuição significante $(p<0,05)$ em relação à linha de base. A análise dos resultados obtidos na PFP realizada em 8 a 10 anos pós-RT apresentavam reduções médias VEF1 de 4\% ( $p=$ $0,03)$ e em CV, DLCO e CPT de $5 \%$, $9 \%$ e $11 \%$, respectivamente, todos apresentaram $p<0,0001$. Os autores também observaram uma correlação do uso do tamoxifeno com uma redução da CPT na avaliação de 8 a 10 anos após a RT ( $p=$ 0,033). Estes autores relatam que um bom índice preditivo para alteração tardia do VEF1 e DLCO, foi a alteração na fase aguda destes parâmetros $(p=0,003$ e $p=$ 0,0009 , respectivamente).

Outra variável que apresenta grande influência nestas alterações pulmonares pós-RT é a o uso de QT neoadjuvante composta de doxorrubicina-ciclofosfamida, paclitaxel (Taxol), segundo a pesquisa realizada por Sánchez-Nieto et al. (2012). Para chegar a essa conclusão, os autores estudaram 66 mulheres com câncer de mama ou linfoma torácico, submetidas a RT e analisaram a correlação significante dos parâmetros dosimétricos (dose média de pulmão e a porcentagem do volume de 
pulmão irradiado) e alterações da PFP. Também foram consideradas como variáveis individuais a QT, idade, tabagismo, por análise multivariada. Nenhum dos parâmetros de dose-volume foi um perfeito preditor de alterações na PFP. A lesão aguda e tardia apresentaram as maiores correlações com volumes irradiados acima de 20 Gy (R2 máxima =0,28) e 40 Gy $(R 2$ máxima =0,21), respectivamente. $R T$ isoladamente induziu uma pequena alteração pulmonar restritiva e transitória ( $p$ = 0,013), sendo que a variável que mais influenciou na presença de restrição pulmonar foi QT neoadjuvante com uso de doxorrubicina-ciclofosfamida, paclitaxel (Taxol), independente de RT ( $p=0,031)$.

Por outro lado, autores como Theuws et al. (1999) observaram que a RT não gera uma diminuição significativa na CV, VEF1 e volume alveolar (VA) em pacientes com câncer de mama, porém gera na DLCO na fase inicial e reverte espontaneamente na fase tardia, independente do regime QT adotado. Para chegar a essa conclusão avaliaram 69 pacientes com câncer de mama e 41 com linfoma torácico. Realizaram PFP pré-RT, 3, 18 e 48 meses pós-RT isolada ou em combinação com a QT (mecloretamina, vincristina, procarbazina, prednisona, doxorrubicina, bleomicina, vinblastina, ciclofosfamida, epidoxorubicina, fluorouracil; ciclofosfamida, tiotepa, carboplatina; ciclofosfamida, metotrexato, fluorouracilo). Foi observado nos pacientes com linfoma uma redução na ventilação alveolar, CV e VEF1 aos 3 meses, houve uma recuperação significativa em 18 meses para todos os pacientes. Porém, nenhuma recuperação adicional foi observada na avaliação realizada com 48 meses. Já nas pacientes com câncer de mama não houve alteração significativa, nestes parâmetros. A DLCO apresentou uma redução significativa no $3^{\circ}$ e $18^{\circ}$ mês e recuperou-se espontaneamente até o $48^{\circ}$ mês após o 
término de RT, tanto nos pacientes com câncer de mama, como nos com linfoma torácico. Este parâmetro comportou-se da mesma forma independente do regimes de QT aplicado. Porém, foi importante o momento de aplicação da QT; a realizada antes $\mathrm{RT}$ reduz os valores da linha de base, enquanto que a QT após ou durante a RT é responsável por uma redução extra na avaliação realizada 3 meses após o tratamento.

A modalidade e a técnica de RT empregada parece interferir na ocorrência e intensidade destas alterações pulmonares. Há fortes indícios de que a lesão pulmonar está associada à maior área pulmonar irradiada (OOI et al., 2000).

Verbanck et al. (2012) realizaram avaliação da função das pequenas vias aéreas e os efeitos agudos da RT em pacientes com câncer de mama sem doença respiratória ou histórico de tabagismo pesado, porém a população do estudo foi composta por mulheres com histórico de tabagismo insignificante, segundo o conceito destes autores, menor que 10 maços/ano. Avaliaram 60 pacientes, com PFP pré-RT e três meses após a avaliação inicial, sendo que 26 mulheres receberam RT convencional e 34 RT hipofracionada. Todas estas mulheres apresentavam PFP normal na fase pré-RT. Na fase pós-RT houve significativa diminuição da DLCO e dos fluxos tele-expiratórios e heterogeneidade da ventilação alveolar no grupo que realizou RT tradicional, porém não foi observado no grupo que realizou RT hipofracionada.

Lind et al. (1998) consideraram consenso que a RT adjuvante em câncer de mama está associada às complicações nos pulmões, porém a frequência e o grau desses efeitos colaterais são, no entanto, ainda debatidos. 
O tipo de cirurgia parece interferir nos valores da PFP, pois no estudo de Jaén et al. (2012), as mulheres mastectomizadas apresentaram valores basais da PFP menor do que as mulheres tratadas com cirurgia conservadora. Neste estudo os autores realizaram avaliação da PFP pré-RT, 6 meses, 1 ano, 2 anos e 7 anos após término da RT, em 41 mulheres, com câncer de mama e idade média de 55 anos; os valores basais da avaliação da PFP pré-RT não apresentaram diferenças significativas para os parâmetros idade, tabagismo e QT prévia, só apresentaram diferenças em relação ao tipo cirúrgico. Mulheres com mastectomia apresentaram menores valores em relação às tratadas com cirurgia conservadora. A dose de RT pós-operatória foi de 50 Gy, sendo fracionada em 2 Gy/dia, 5 dias / semana. Todos os valores estudados da PFP (CVF, VEF1, DLCO, ventilação e perfusão) mostraram redução aos 6 meses. A partir de então, a CVF e VFE1 começaram sua recuperação até atingir, e mesmo ultrapassar, os valores de referência de 7 anos. A DLCO, a ventilação e a perfusão começaram a diminuir durante 24 meses e, em seguida, recuperaram parcialmente os respectivos valores da linha de base $(-3,5 \%,-3,8 \%$ e $5,5 \%$, respectivamente). Apenas uma paciente teve pneumonia sintomática. Houve correlação entre parâmetros somente para o índice ventilação, apenas na avaliação de 7 anos. Outras variáveis, como idade, tabagismo, QT e tamoxifeno não mostraram relação significativa com as mudanças nos valores da PFP em nenhuma das avaliações em 7 anos. A extensão da redução nos valores de PFP foi pequena, e não houve associação clara com vários parâmetros dosimétricos e clínicos. Os autores relatam que não temos sido capazes de encontrar um modelo claramente preditivo para estas reduções, mesmo levando-se em consideração a longa série de parâmetros dosimétricos e clínicos já analisados. Estes dados dão ideia da sua 
complexidade fisiopatológica provavelmente com o envolvimento de outros fatores, tais como mediadores bioquímicos.

Por outro lado, outros autores como Ozturk et al. (2004), já estão estudando tratamentos para a prevenção da radiotoxicidade. Estes autores realizaram um estudo duplo cego e aleatório para avaliar o uso profilático de pentoxifilina para impedir os danos agudos e crônicos causados ao tecido normal do pulmão. Avaliaram 40 pacientes com câncer de mama ou de pulmão antes de iniciarem a RT, 3 e 6 meses após a RT, para isso utilizaram exames de cintilografia, Raio-x (Rx) e TCAR de tórax e PFP. Na PFP foram analisados CVF, VEF1, CV, CPT, VR, DLCO. Foi observada uma diminuição estatisticamente significativa entre os grupos de 3 e 6 meses na DLCO e nos resultados da perfusão das regiões irradiada. Fundamentado nestas observações os autores acreditaram no efeito protetor da pentoxifilina contra radiotoxicidade pulmonar precoce e tardia e recomendam o uso profilático, considerando o mesmo seguro e eficaz.

\subsection{Radioterapia para Câncer de Mama x TCAR x PFP}

Para melhor compreensão do mecanismo de ação da RT sobre o pulmão, diversos autores estão estudando a PFP e a TCAR, como Tokatli et al. (2005), que avaliaram 20 pacientes com câncer de mama, sendo que em 10 irradiaram o lado direito e as outras 10 o esquerdo. Realizaram a PFP, TCAR, teste de depuração pulmonar com ácido dietilenotriamina pentacético e cintilografia pulmonar, pré-RT, 6 , 
16, 52 semanas após a RT. Os parâmetros VEF1 e volume corrente (VC) apresentaram redução significativa em todas as avaliações, já CVF e a DLCO foram significativamente reduzidas apenas nas avaliações de 6 e 16 semanas após a RT; não surgiram diferenças estatisticamente significativas em relação à lateralidade da radiação. Porém, no teste de depuração pulmonar houve uma significativa diferença em relação à lateralidade da radiação durante o período avaliado, houve diminuição estatisticamente significativa, nas pacientes irradiadas à esquerda, mas a direita a diminuição não foi significativa. As alterações pulmonares nas TCAR foram mais evidentes na avaliação de 16 semanas e apresentaram uma recuperação parcial na avaliação realizada em 52 semanas pós-RT. Estes autores concluíram que a RT por câncer de mama pode causar uma diminuição irreversível na TCAR, na cintilografia e na PFP, mesmo sem sintomas clínicos associados.

Já Marks et al. (2000) avaliaram 175 pacientes que tiveram o tórax irradiado devido a qualquer tipo de câncer, investigaram alterações na TCAR incluindo as de perfusão, sintomas pulmonares induzidos pela radiação e alteração na PFP. Das pacientes avaliadas 34 apresentaram sintomas pulmonares induzidos pela radiação em até 6 meses após a RT. Não houve associação entre a presença ou ausência de sintomas pulmonares induzidos radiação e alterações na TCAR $(p=0,53)$, ou na curva de dose-resposta da perfusão regional. A avaliação 6 meses após a RT apresentou diminuição da DLCO em $81 \%$ das pacientes e do VEF1 redução em $73 \%$ das pacientes; a diminuição foi mais importante no DLCO que no VEF1. Estes autores concluíram que a TCAR no estudo da densidade do tecido pulmonar ou na avaliação da perfusão tecidual não são bons preditores de alterações pulmonares induzidas pela radiação, uma vez os sintomas pulmonares são semelhantes em 
pacientes com e sem alterações RT induzidas. Este autores consideraram a PFP o melhor preditor de alterações pulmonares induzidos pela radiação, um vez que houve maior declínio dos parâmetros da PFP nas pacientes sintomáticas e estas já apresentavam valores menores que o esperado na fase pré-RT.

Em estudo realizado por Krengli et al. (2008), foram avaliadas 41 mulheres que haviam se submetido à cirurgia conservadora para ressecção do câncer de mama; avaliaram pré-RT, 3 e 9 meses após a RT a PFP, TCAR e a correlação destas com a dose de RT. Houve uma diminuição significativa em três meses da CVF, VEF1, CPT, fluxo expiratório forçado 50\% da CVF (FEF50\%), fluxo expiratório forçado 75\% da CVF (FEF75\%) e DLCO com recuperação parcial em 9 meses. Não houve diferença na espirometria das pacientes que receberam hormonioterapia e as que não a receberam. As alterações tomográficas também foram maiores na avaliação após 3 meses que a de 9 meses. Segundo esses autores, essas alterações estão relacionadas, principalmente, aos danos à barreira alvéolo-capilar e ramificações das vias aéreas menores e que, minimizando-se o volume pulmonar irradiado e dose $\leq 25$ Gy, poder-se-ia reduzir a toxicidade pulmonar.

Ooi et al. (2001) realizaram PFP, Rx e TCAR pré-RT, 1, 3, 6 e 12 meses após a RT em 30 pacientes com câncer de mama. Sessenta e três por cento apresentaram sintomas respiratórios (dispnéia, tosse seca ou produtiva e diminuição da capacidade aeróbia) no primeiro mês, resolvendo-se completamente no sexto mês. No terceiro mês, $80 \%$ das pacientes apresentaram alteração no Rx e $100 \%$ nas TCARs, estas alterações permaneceram até a última avaliação deste estudo. Os índices da PFP como VEF1, CVF, CPT e DLCO apresentaram declínio no terceiro 
mês após a RT e reversão espontânea dentro de 12 meses. Não houve diferença entre as pacientes que realizam a QT e as que não realizaram.

Wennberg et al. (2002), demonstraram que a técnica de RT empregada altera ou não o pulmão da paciente, pois dependo da técnica de RT houve ou não a alteração na densidade média na TCAR para chegar a essa conclusão avaliaram em 121 pacientes com câncer de mama tratadas com quatro diferentes técnicas de RT. Estes autores não encontraram associação entre alterações na densidade pulmonar do pós-RT em relação ao pré-RT ou pré-RT em relação à QT ou a ingestão do tamoxifeno, ou ao tabagismo. 


\section{JUSTIFICATIVA}

A RT adjuvante como tratamento do câncer de mama envolve parte do parênquima pulmonar, com potencial efeito deletério sobre este tecido, com reflexos sobre a reserva funcional pulmonar. Tal efeito merece ser estudado em profundidade, considerando-se a longa expectativa de vida dessas mulheres (KRENGLI et al., 2008).

As alterações agudas e tardias da RT sobre o parênquima pulmonar, apesar de terem sido exploradas por diversos autores, continuam relativamente pouco compreendidas. Isso ocorre devido aos dados disponíveis muitas vezes terem sido obtidos de populações não uniformes, frequentemente sem informações a respeito da função pulmonar prévia ao tratamento, além da não padronização das técnicas de RT utilizadas (LIND et al., 2001).

Na tentativa de amenizar esses vieses, melhor controle dessas variáveis poderia favorecer o entendimento da complexidade desse processo, aumentando a confiabilidade dos resultados obtidos.

O presente estudo justifica-se pela importância e interesse do assunto face ao papel da RT torácica na abordagem de diversas doenças. A compreensão das alterações ocorridas em decorrência deste tratamento é de fundamental importância para a terapia e/ou prevenção destas. Também é relevante a busca da correlação entre as possíveis alterações pulmonares identificáveis funcionalmente e radiologicamente e as modificações em alguns mediadores inflamatórios sistêmicos e na QV identificáveis pelo SGRQ. 


\section{OBJETIVOS}

Estudar os efeitos locais e sistêmicos provocado pela RT conformacional torácica adjuvante em mulheres portadoras de câncer de mama, sem fator de risco prévio para desenvolvimento de alterações pulmonares.

1) Por meio de TCAR identificar as alterações no parênquima pulmonar;

2) Correlacionar as possíveis alterações radiológicas àquelas observadas em parâmetros obtidas pela avaliação da função pulmonar;

3) Identificar a presença de efeitos sistêmicos provocados pela RT, analisando as possíveis alterações em medidores inflamatórios sanguíneos (IL-1ß, IL-6 e TNF- $\alpha$ ).

4) Avaliar através do questionário de QV/sintomas respiratórios, SGRQ, se há alteração devido à RT. 


\section{ASPECTOS ÉTICOS}

Este projeto e o Termo de Consentimento Livre e Esclarecido (TCLE) foram submetidos e aprovados pelo Comitê de Ética e Pesquisa da Faculdade de Medicina de Ribeirão Preto da Universidade de São Paulo, em sua $307^{\text {a }}$ Reunião Ordinária realizada em 10/05/2010, por estar de acordo com o Processo HCRP n³116/2010; Ofício n 1449/2010 CEP/MGV, cópia Anexo A. Já o anexo B é aprovação do adendo referente à inclusão de Grupo Controle (GC), bem como o TCLE deste grupo. Este foi aprovado pelo Comitê de Ética e Pesquisa da Faculdade de Medicina de Ribeirão Preto da Universidade de São Paulo, em sua $338^{a}$ Reunião Ordinária realizada em 07/12/2011, por estar de acordo com o Processo HCRP n³116/2010; Ofício $n^{\circ}$ 4506/2011 CEP/MGV. 


\section{MATERIAIS E MÉTODOS}

\subsection{População}

As voluntárias foram recrutadas da população de pacientes atendidas no Ambulatório de Mastologia e Ambulatório de Radioterapia do Hospital das Clínicas da Faculdade de Medicina de Ribeirão Preto (FMRP) - Universidade de São Paulo (USP) - com a autorização e colaboração dos respectivos responsáveis. Não houve distinção de classe socioeconômica, estatura, etnia, crenças ou religiões.

\subsection{Protocolo do Estudo}

Este estudo foi realizado pela pesquisadora com a colaboração das equipes dos Serviços de: Radioterapia, Radiologia, Função Pulmonar do Hospital das Clínicas da Faculdade de Medicina da USP - Campus de Ribeirão Preto. A pesquisadora comparecia quase diariamente no Serviço de Radiologia para avaliar os Pedidos de Interconsultas das pacientes que iriam submeter-se à avaliação do médico radioterapeuta. Nos Pedidos de Interconsultas das pacientes que envolviam terapêutica da mama, a pesquisadora anexava um lembrete solicitando para que o profissional médico ao atendê-la abordasse a respeito da participação na presente 
pesquisa. Esta rápida conversa destes profissionais aumentou a aceitabilidade das paciente em relação à pesquisa. Após anuência, a pesquisadora checava os critérios de inclusão e exclusão no estudo, descritos abaixo.

\section{Critérios de inclusão}

1) Mulheres entre 18 e 65 anos de idade, portadoras de carcinoma mamário primário, com confirmação histopatológica ou citológica;

2) Já submetidas a tratamento cirúrgico para sua doença de base (tumorectomia; quadrantectomia com axilectomia; mastectomia radical e axilectomia);

3) Necessidade de ter complementação do tratamento oncológico com RT locorregional, pelo protocolo de tratamento do referido Serviço;

4) Intervalo de tempo entre o último tratamento e início de RT maior que quatro semanas;

5) Ser capaz de compreender e considerar-se capaz de realizar os procedimentos do protocolo do estudo;

6) Ter assinado o TCLE (Anexo C).

\section{Critérios de exclusão}

1) Pacientes que realizaram RT previamente;

2) Pacientes que realizaram QT ou qualquer outro tratamento oncológico planejado no intervalo entre as avaliações do estudo, exceto hormonioterapia; 
3) Pacientes que apresentaram envolvimento da parede torácica pelo tumor primário;

4) Pacientes que ainda não tenham se recuperado dos eventos adversos agudos de tratamentos prévios (QT, cirurgia ou outros);

5) Uso de drogas (agentes citotóxico ou não) com efeitos pneumotóxicos importantes;

6) Pacientes fumantes ou ex-fumantes;

7) Portadoras de doença de vias aéreas crônicas ou mesmo agudas há menos de dois meses;

8) Pacientes cardiopatas;

9) Pacientes grávidas;

10)Pacientes que não foram capazes de realizar os procedimentos de estudo.

As pacientes que não tinham nenhum dos critérios de exclusão e tinham todos os de inclusão formaram o Grupo da Radioterapia (GRT). Já o GC foi constituído de 25 voluntárias sadias da mesma faixa etária do GRT, do qual foram mensurados alguns mediadores inflamatórios sistêmicos, IL-1 $1 \beta$, IL-6 e TNF- $\alpha$. Estes resultados foram usados como parâmetros de normalidade para comparação da fase pré-RT do GRT.

No GRT, foram dosados os mesmos mediadores inflamatórios sistêmicos do GC. No GRT foram obtidos adicionalmente o questionário de QV relacionado a saúde; a TCAR; e o estudo funcional pulmonar realizados antes do início da RT e três meses mais ou menos sete dias após o término da mesma. Estes testes foram 
realizados sempre seguindo a ordem: questionário de QV, coleta de sangue, TCAR e a PFP, em um único dia e horário em cada fase da avaliação; a execão foi o questionário de QV na fase pré-RT que foi aplicado logo após a anuência da paciente. Cada paciente foi controle dela mesma e a única intervenção efetuada entre as avaliações foi a RT torácica adjuvante para o câncer de mama.

Todas as pacientes do GRT realizaram a RT no Ambulatório de Radioterapia do Hospital das Clínicas de Ribeirão Preto. A TCAR foi realizada no tomógrafo Big Bore para o planejamento da RT conformacional, a qual estas pacientes seriam submetidas para tratamento de sua doença de base; o mesmo sistema e os mesmos critérios de obtenção de imagens foram utilizados nas fases pré e pós-RT - Serviço de Imaginologia Hospital das Clínicas da FMRP - USP. Todas as TCAR foram avaliadas pelo mesmo examinador, médico experiente e especialista na área. Já o estudo funcional pulmonar, questionário de QV relacionada a saúde e a coleta do sangue do GRT, para dosagem dos mediadores inflamatórios sistêmicos, IL-1 1 , IL-6 e TNF- $\alpha$, foram realizados no Laboratório de Função Pulmonar do Hospital das Clínicas da FMRP - USP, pelos mesmos examinadores. A coleta do sangue do GC, voluntárias sadias, foi realizada no Centro de Saúde Escola (CSE) da mesma Faculdade. A mensuração dos mediadores inflamatórios sistêmicos estudados foi realizada no Laboratório de Inflamação e Dor do Departamento de Farmacologia da FMRP - USP. 


\subsection{Protocolo do Tratamento Radioterápico}

As pacientes realizaram radioterapia conformacional em mama residual ou plastão torácico e fossa supraclavicular (FSC), quando indicado o tratamento das regiões de drenagem linfática. Para este planejamento, as imagens realizadas por TCAR (Brilliance Big Bore, Philips Medical Systems; Best, Holanda) foram enviadas via protocolo DICOM ao sistema de planejamento CMS/XIO versão 4.51 .02 (Elekta Inc., Stockholm, Sweden). Quando necessário o co-registro de imagens com ressonância magnética, foram realizadas na mesma semana de planejamento em ressonância de três tesla (Intera $3 \mathrm{~T}$, Philips Medical Systems, Best, The Netherlands). Foi realizada a segmentação das estruturas anatômicas normais próximas, denominadas órgãos de risco, e os volumes alvo, definida pelo volume tumoral grosseiro e margens para o volume tumoral planejado.

A RT foi planejada com técnica de campos tangentes paralelos e opostos em mama residual ou plastão, e campo direto em FSC, quando indicado tratamento das regiões de drenagem linfática. Foi avaliada e escolhida aquela composição que apresentou melhor gradiente de dose, respeitando-se os limites de doses em órgãos de risco próximos ao volume alvo.

O fracionamento foi de 1,8 a 2,0 Gy/ fração (1 fração dia / 5 dias por semana), utilizando doses totais na primeira fase de tratamento de 45 a 50,4 Gy em 25 frações, prescritas a uma profundidade correspondente a linha media da mama 
residual ou plastão e na dose de máximo para o campo da FSC. No reforço do leito tumoral, foi prescrito dose de 9 a 10 Gy em 5 frações, também com 1,8 a 2,0 Gy/ fração ( 1 fração dia / 5 dias em uma semana) envolvendo apenas o volume alvo ou quadrante previamente acometido pelo tumor.

Os controles de qualidade foram analisados individualmente por sistema de arranjos de câmaras de ionização (MATRIXX, MULTICube QA Software) (IBA Dosimetry, Bartlett, EUA). O aceite do tratamento foi permitido quando a função gama estava abaixo de $3 \%$. Os tratamentos foram realizados em Acelerador Linear (ONCOR ou PRIMUS, Siemens, Alemanha), energia $6 \mathrm{MV}$, com multilâminas de 1 cm de espessura (MLC) do Serviço de Radioterapia do Hospital das Clínicas da FMRP-USP.

\subsection{Mensuração dos Mediadores Inflamatórios}

As amostras de sangue foram obtidas juntamente com a coleta deste material para exames de rotina vinculadas ao tratamento, portanto não acrescentou risco adicional algum à paciente. No GC, o sangue foi coletado no CSE das próprias voluntárias do setor. O sangue foi coletado em tubos a vácuo e imediatamente transferido para a centrífuga refrigerada (BECKMAN - ALLEGRA TM 21R). As amostras foram centrifugadas a uma velocidade de 5000 rotações por minuto, por 5 minutos. O plasma obtido foi colocado em tubos de Ependorff designados para 
dosagens específicas, sendo mantido estocados em freezer a $-80^{\circ} \mathrm{C}$ até o momento da realização das medidas.

No Departamento de Farmacologia da FMRP - USP foram as efetuadas as dosagens dos valores plasmáticos das citocinas: IL-1 $\beta$, IL-6 e TNF- $\alpha$. Para a medida desses fatores foram empregadas as técnicas de imunoabsorção enzimática (ELISA), sendo zero o limite inferior de detecção do método (ABRAMS et al., 1992).

As placas usadas de 96 poços (NUNC) foram recobertas e incubadas com anticorpos purificados anti-IL-1 $\beta$, anti-IL-6 e anti-TNF- $\alpha$, diluído em tampão fosfato de cálcio a $4^{\circ} \mathrm{C}$ durante toda a noite. Após esse tempo de incubação, as placas foram lavadas com solução salina tamponada (PBS) contendo 5\% de Tween 20 e bloqueadas durante 2 horas, em temperatura ambiente com uma solução de PBS contendo $1 \%$ de albumina sérica bovina (BSA). Após esse período as placas foram lavadas, incubadas com plasma de sangue periférico das pacientes do GRT e do GC e as curvas padrões das interleucinas recombinantes específicas foram feitas a partir de diluições seriadas na concentração de 2000pg/ml. Após esse tempo de incubação, as placas foram lavadas e novamente incubadas em temperatura ambiente durante 1 horas com anticorpo anti-IL-1 $\beta$, anti-TNF- $\alpha$ e anti-IL- 6 biotinilado diluído na concentração final de $1 \mu \mathrm{g} / \mathrm{ml}$ em PBS contendo $1 \%$ de BSA e $0.5 \%$ de Tween 20. A seguir as placas foram lavadas e incubadas por 30 minutos com avidina peroxidase 1:5000 em PBS contendo 1\% de BSA e 0,5\% de Tween 20, em temperatura ambiente. Após nova lavagem, as placas foram reveladas com tetramethylbenzidine diluído em tampão diluente próprio. A reação foi bloqueada com ácido sulfúrico e, em seguida, feita a leitura em 450nm. 


\subsection{Qualidade de Vida}

Após a assinatura do TCLE, as pacientes foram convidadas a responder o questionário de QV relacionado a saúde (SGRQ) em local calmo e privativo, antes de qualquer procedimento da pesquisa. Na fase pós-RT, esse questionário foi respondido imediatamente antes dos procedimentos dessa etapa.

No Brasil, o SGRQ foi traduzido para o português e validado por Sousa; Jardim; Jones (2000). Este questionário avalia domínios como sintomas (frequência e gravidade) através de perguntas alocadas na Parte 1, atividades diárias limitadas ou abolidas pela doença respiratória (Parte 2, seções 2 e 6) e os seus impactos nos aspectos profissionais, familiares, sociais e psicológicos dos indivíduos (Parte 2, seções 1, 3, 4, 5 e 7). Esses domínios possuem uma pontuação máxima possível. Os pontos de cada resposta foram somados e o total foi referido como uma porcentagem desse máximo. Valores acima de 10 refletem uma alteração na QV naquele domínio ou no total. Alterações iguais ou superiores a 4 após uma intervenção, em qualquer domínio ou no total dos pontos, indicam uma mudança significativa na QV dos pacientes. Neste questionário, escores menores refletem uma QV melhor. 


\subsection{Avaliação Funcional Pulmonar}

Durante a execução das provas, as pacientes permaneceram sentadas, mantendo o tórax ereto. A temperatura da sala foi mantida estável por volta de $22^{\circ} \mathrm{C}$. Durante todos os exames, as pacientes usaram pinça nasal. Os volumes foram corrigidos pelo BTPS. Todos os testes foram realizados pela mesma Bióloga/Técnica.

\subsubsection{Medidas dos Volumes e Capacidades Pulmonares}

Os volumes e capacidades pulmonares foram obtidos em espirômetro de deslocamento volumétrico de nove litros - GS Plus da Collins. Critérios e valores preditivos utilizados foram compilados de vários autores (CRAPO; MORRIS, 1981; KNUDSON et al., 1983; MORRIS; KOSKI; JOHNSON, 1971). Para medida da capacidade residual funcional foi utilizado o método da diluição do hélio $(\mathrm{He})$ em circuito fechado (MENNELY; KALTREIDER, 1949). 


\subsubsection{Estudo da Capacidade Vital Forçada}

O mesmo equipamento permitiu o registro simultâneo das variáveis fluxos expiratórios x volumes pulmonares (curva fluxo-volume) e volumes pulmonares $\mathrm{x}$ tempo. Após alguns ciclos ventilatórios em VC era solicitado à paciente que realizasse uma inspiração máxima até a CPT, seguida de uma breve apnéia, e ao comando da Bióloga iniciava a manobra expiratória forçada até atingir o VR, seguindo o protocolo utilizado por Crapo; Morris, (1981); Knudson et al. (1983); Morris; Koski; Johnson, (1971). Foram obtidas, pelo menos três, medidas tecnicamente corretas. Para o cálculo foi utilizado o traçado correspondente ao melhor desempenho em relação à CVF e ao VEF1 (AMERICAN THORACIC SOCIETY - ATS, 1987). Os critérios de reprodutibilidade e aceitabilidade utilizados foram os preconizados pela ATS (1995). Foram determinados:

- Capacidade Vital Forçada (CVF)

- Volume Expiratório Forçado no Primeiro Segundo (VEF1)

- Fluxos Expiratórios Forçado entre 25-75\% (FEF25-75) da CVF

- Relação VEF1/CVF

- Pico do Fluxo Expiratório (PFE)

- Fluxo Instantâneo Máximo a 50\% (Vmax 50) e a 75\% (Vmax 75) da CVF 


\subsubsection{Medida da Capacidade de Difusão Pulmonar}

A DLCO foi obtida pela técnica da respiração única de monóxido de carbono (CO). A paciente inspirava, a partir do VR, uma mistura gasosa, contendo muito baixa concentração de $\mathrm{CO}(0,3 \%)$ e um gás quimicamente inerte e insolúvel, o hélio, até atingir volume pulmonar próximo a CPT. Este volume era retido dentro dos pulmões por, aproximadamente, 10 (dez) segundos, intervalo suficiente para permitir a difusão com concentração alveolar média de $\mathrm{CO}$ em níveis adequados relativamente ao tempo de exposição (ATS, 1995; CRAPO; MORRIS, 1981).

Ao término de 10 segundos, a paciente expirava rapidamente até o VR. Do gás expirado, a parte inicial era desprezada (lavagem do espaço morto anatômico de 500 a $1.000 \mathrm{ml}$ ) e parte era coletada para análise da composição do gás alveolar (concentração final de CO). Para cálculo da DLCO são necessários três valores:

$\mathrm{D}_{\mathrm{LCO}}=\frac{\mathrm{ml} \text { de CO transferido do gás alveolar/min }}{\text { Pressão alveolar média do CO - pressão capilar média do CO }}$

1 - O volume de CO transferido do gás alveolar pode ser calculado a partir da porcentagem de CO no gás alveolar, no início e no final do período de retenção da mistura inspirada, isto se o volume do gás alveolar for conhecido.

2- A pressão capilar média do CO é tão pequena que pode ser negligenciada.

3 - A pressão alveolar média do CO pode ser conhecida pelo cálculo do volume alveolar existente no início da retenção da respiração (diluição no gás alveolar das 
moléculas de He inspirado) e pelo cálculo da concentração do $\mathrm{CO}$ no volume amostrado no final do período de retenção da respiração.

Rearranjando e integrando a equação para um determinado instante t, teremos:

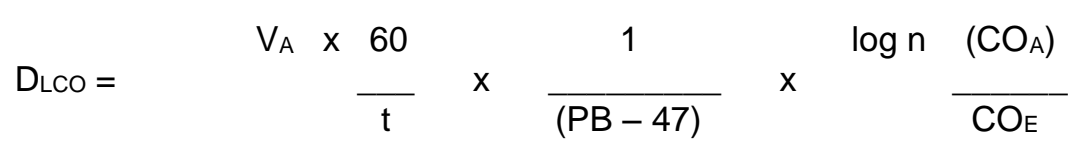

$V_{A}=$ volume alveolar em nível de inspiração máxima mantida

$V_{A}=(C V+V R) x$ fator correção (STP)

$\mathrm{t}=$ tempo de retenção

PB = pressão barométrica

47 = pressão de saturação de vapor de água

$\mathrm{CO}_{\mathrm{A}}=$ concentração alveolar de $\mathrm{CO}$, expressa em porcentagem do $\mathrm{CO}$ inspirado

$\mathrm{CO}=\mathrm{CO}$ inspirado

[He] expirado

$\mathrm{CO}_{\mathrm{A}}=\mathrm{CO} \mathrm{X}$

[He] inspirado

$\mathrm{CO}=$ concentração de $\mathrm{CO}$ expirado, expresso em porcentagem do $\mathrm{CO}$ inspirado

Este método propicia resultados confiáveis, com a vantagem de ser de simples execução, de requerer pouca colaboração do paciente e de poder ser repetido até três vezes (ATS, 1995). 
Os valores previstos de normalidade para a DLCO foram derivadas das equações de regressão de Bates; Macklem; Christie (1971) e McGrath; Thomson (1959) que leva em consideração o sexo, a altura, a idade, e o valor de hemoglobina em g/100ml (VAN-KESSEL, 1984).

Não existiram riscos para as pacientes, pois a concentração de $\mathrm{CO}$ é muito baixa, não trazendo repercussões para as mesmas, bem como a inalação do gás He, gás quimicamente inerte. Já o benefício foi uma avaliação adicional da função pulmonar da paciente possibilitando um melhor entendimento das possíveis alterações.

\subsection{Tomografia Computadorizada de Alta Resolução - TCAR}

As TCAR não representaram riscos adicionais as pacientes, uma vez que seriam realizadas em decorrência de suas inclusões no protocolo de rotina clínica da RT. Esse protocolo segue as recomendações da National Comprehensive Cancer Network - Clinical Practice Guidelines in Oncology: Breast Cancer; versão 3.2013 (THERIAULT, et al. 2013). O benefício foi a possibilidade de um melhor entendimento das possíveis alterações das imagens radiológicas e futuramente prevenção ou tratamento das mesmas.

Todos os exames de TCAR foram realizados em aparelho de 16-detectores (Brilliance Big Bore, Philips Medical Systems; Best, Holanda). Foi utilizado o seguinte 
protocolo de aquisição de imagens: paciente em posição supina com os braços levantados e mãos atrás da cabeça, cortes obtidos em inspiração profunda desde o nível dos ápices pulmonares até o abdome superior infradiafragmático, voltagem padrão do tubo de $120 \mathrm{KvP}$, valores de referência para corrente do tubo de $180 \mathrm{a}$ 250 mas, espessura de corte de $3-5 \mathrm{~mm}$, intervalo de reconstrução de $3-5 \mathrm{~mm}$, Pitch 1 e reconstrução com algoritmo padrão, janelas de mediastino e de pulmão. Os exames foram realizados somente sem a administração endovenosa de meio de contraste iodado.

Foi realizada reconstrução tridimensional de cada pulmão na estação de trabalho Extended Brilliance Workspace, da marca Philips, com obtenção de renderização com algoritmo "Airways" e cálculo automático do volume de cada pulmão em ml.

Obtido o coeficiente de atenuação pulmonar (unidades Hounsfield) de cada pulmão utilizando região de interesse oval entre 18 e $22 \mathrm{~cm}^{2}$, em corte ao nível da carina, evitando-se incluir vasos hilares pulmonares ou estruturas de parede torácica. Essa avaliação foi realizada por um observador.

As avaliações descritas foram realizadas em ambos os pulmões de cada paciente antes do início da RT e três meses, mais ou menos sete dias, após o término do tratamento radioterápico para a neoplasia de mama. Para a avaliação do volume pulmonar pela TCAR foi também calculada a diferença do obtido pós-RT do pré-RT para cada pulmão, a fim de se pesquisar eventuais diferenças na expansão de cada pulmão considerando o lado irradiado. 
O exame de TCAR pré-RT foi utilizada como referência para a avaliação e pontuação das alterações induzidas pela radiação no período pós-RT. As imagens obtidas na TCAR após a RT foram co-registradas com as imagens do sistema de planejamento de RT para correlacionar as alterações pulmonares com as curvas de isodose usando um programa de software dedicado (Xio-CMS). A fusão das imagens foi realizada por um método interativo com três dimensões e a precisão do procedimento foi verificada por correspondência das estruturas ósseas e tecidos moles das imagens dos tomógrafos nos diferentes tempos de análise.

Além da análise objetiva de volumes e densidades, foi realizada uma análise subjetiva das alterações pulmonares relacionadas à RT. Um médico radiologista torácico com cinco anos de experiência avaliou os exames de TCAR pré e pós-RT, sem conhecimento dos resultados das PFP. As alterações pulmonares foram categorizadas de maneira similar a previamente descrita por Nishioka et al. (1999) e Ooi et al. (2000), levando em consideração a localização, extensão e tipo de opacidades pulmonares identificáveis. As alterações foram definidas como Grau 0, se ausentes nos campos de radiação; Grau 1, quando presente apenas espessamento pleural nos campos de radiação; Grau 2, quando presentes opacidades pulmonares discretas predominantemente intersticiais em $<50 \%$ de área irradiada; Grau 3, quando as opacidades pulmonares estiverem presentes em $\geq 50 \%$ e $<75 \%$ de área de radiação e Grau 4, quando da presença de opacidades pulmonares grosseiras ou alveolares identificadas inclusive nos campos pulmonares profundos, em $\geq 75 \%$ da área irradiada. Os campos de radiação considerados na análise foram o Campo Tangencial a Mama (CTM), Campos Supraclaviculares (CSC) e Campo Mediastinal (CM). 


\section{ANÁLISE ESTATÍSTICA}

Para comparar os tempos (pré e pós) em relação às variáveis de interesse, foi proposto o teste de Wilcoxon para amostras dependentes, que é uma técnica não paramétrica utilizada para comparar dois grupos pareados. Sendo assim, ela não requer suposições quanto à distribuição dos dados. Os resultados foram obtidos com o auxílio do software R.

Já para avaliar se houve correlação das diferença entre pré-RT e pós-RT entre as variáveis, foi proposto o coeficiente de correlação de Spearman ( $r$ ho $=\rho$ ), que quantifica a associação entre duas variáveis quantitativas. Este coeficiente varia entre os valores -1 e 1 . O valor 0 (zero) significa que não há relação, o valor 1 indica uma relação perfeita e o valor -1 também indica uma relação perfeita, mas inversa, ou seja, quando uma das variáveis aumenta a outra diminui. Quanto mais próximo estiver de 1 ou -1 , mais forte é a associação entre as duas variáveis. Os resultados foram obtidos com o auxílio do software R.

E para comparar os tempos em relação à variável volume pulmonar, foi utilizado o modelo de regressão linear com efeitos mistos (efeitos aleatórios e fixos). Os modelos lineares de efeitos mistos são utilizados na análise de dados em que as respostas estão agrupadas (medidas repetidas para um mesmo indivíduo) e a suposição de independência entre as observações num mesmo grupo não é adequada (Schall, 1991). Tal modelo tem como pressuposto que o resíduo obtido através da diferença entre os valores preditos pelo modelo e os valores observados 
tenha distribuição normal com média 0 e variância constante. Nas situações onde tal pressuposto não foi observado, transformações logarítmicas na variável resposta foram utilizadas. O ajuste do modelo foi feito através do software SAS versão 9.2.

Foram considerados significativos um valor de $p<0,05$. 


\section{RESULTADOS}

\subsection{Características da População Estudada}

A idade das pacientes estudadas variaram de 25 a 65 anos (média de 52,7 anos) e eram pertencentes a diferentes classes socioeconômicas, estaturas, etnias, crenças e religiões. Estas pacientes foram oriundas do Ambulatório de Mastologia do Departamento de Ginecologia e Obstetrícia da FMRP-USP. Os critérios de inclusão e exclusão foram avaliados através de entrevista com as pacientes e análises dos prontuários médicos, imediatamente antes de iniciarem a RT.

Entre Junho de 2009 e Setembro de 2011 foram entrevistadas 157 pacientes com câncer de mama. Apenas 33 pacientes $(21,02 \%)$ preencheram os critérios para serem admitidas no estudo, fato que não ocorreu com as outras $124(78,98 \%)$ entrevistadas. A distribuição das 124 pacientes e os motivos que justificaram a não inclusão, estão apresentada na Tabela 1, abaixo. 
Tabela 1 - Distribuição e motivos da não inclusão das pacientes no estudo.

Critérios para não inclusão

n

$\%$ de pacientes não inclusas

RT torácica prévia

10

8,06

Mulheres com mais de 65 anos de idade

11

8,87

Envolvimento da parede torácica pelo tumor primário ou metástase

8

6,45

Não tinham se recuperado de efeitos adversos agudos de tratamentos prévios

3

2,42

Uso de drogas (agentes citotóxico ou não) com efeitos pneumotóxicos

Tabagistas ou ex-tabagistas

41

33,06

Portadoras de doença de vias aéreas crônicas ou mesmo agudas há menos de dois meses

6

Presença de cardiopatias

Encaminhadas a outro serviço de RT

3

2,42

Pacientes que não foram capazes de compreender ou não consideraram-se capazes de realizar os procedimentos do protocolo do estudo ou não quiseram participar, ou não quiseram assinar o TCLE

Porém, das 33 pacientes incluídas no estudo, 27,27\% destas tiveram que ser excluídas do protocolo de pesquisa. $\mathrm{Na}$ Tabela 2, apresenta-se a distribuição das pacientes excluídas com os respectivos motivos. 
Tabela 2- Pacientes excluídas do estudo.

\begin{tabular}{lcc}
\hline \multicolumn{1}{c}{ Motivo } & $\mathrm{n}$ & $\%$ \\
\hline $\begin{array}{l}\text { Dificuldades incontornáveis para realizar os } \\
\text { procedimentos de estudo }\end{array}$ & 5 & 55,55 \\
$\begin{array}{l}\text { Necessidade de realizar QT entre as avaliações } \\
\text { (Descoberta de novo tumor primário) }\end{array}$ & 1 & 11,11 \\
$\begin{array}{l}\text { Não comparecimento para a avaliação inicial, } \\
\text { mesmo após ter assinado TCLE }\end{array}$ & 3 & 33,33 \\
\hline
\end{tabular}

Das 24 pacientes que terminaram o protocolo de pesquisa, duas recusaram doar sangue para a fase pós-RT e 1 recusou-se a fazer a PFP na mesma fase.

Já a coleta das amostras de sangue do GC foram realizadas no CSE da FMRP- USP. Estas 25 voluntárias eram hígidas com idade entre 25 e 64 anos (média de 49,36 anos) pertencentes a diferentes classes socioeconômicas, estaturas, etnias, crenças e religiões.

Metade da população estudada tinha câncer de mama à direita, as outras 12 pacientes à esquerda. Os tipos histológicos encontrados foram: Carcinoma Lobular Invasivo grau I em uma paciente $(4,17 \%)$ e Carcinoma Ductal em 23 pacientes $(95,83 \%)$. Sendo que duas destas pacientes (8,33\%) com Carcinoma Ductal in situ e as outras 21 pacientes (87,5\%) com Carcinoma Ductal Invasivo: uma paciente (4,17\%) grau I, 13 pacientes (54,17\%) grau II e 7 pacientes $(29,17 \%)$ grau III. A Tabela 3 apresenta a distribuição das pacientes nos estadiamentos tumorais. 
Tabela 3 - Estadiamento dos tumores das pacientes que concluíram a participação no estudo.

\begin{tabular}{llc}
\hline $\begin{array}{c}\text { Estadiamento } \\
\text { TNM }\end{array}$ & $\mathrm{n}$ & $\%$ \\
\hline T1N0M0 & 7 & 29,17 \\
T1N1M0 & 1 & 4,17 \\
T1N2M0 & 1 & 4,17 \\
T2N0M0 & 5 & 20,83 \\
T2N1M0 & 2 & 8,33 \\
T2N1M0 & 2 & 8,33 \\
T3N1M0 & 1 & 4,17 \\
T4N0M0 & 2 & 8,33 \\
T4N2M0 & 3 & 12,50 \\
\hline
\end{tabular}

Já os tratamentos cirúrgicos realizados nestas pacientes foram: em 8,33\% a tumorectomia; em 25\% a tumorectomia associada à biópsia do linfonodo sentinela; em $41,66 \%$ tumorectomia associada ao esvaziamento axilar e em $25 \%$ a mastectomia associada ao esvaziamento axilar.

Oito pacientes $(33,33 \%)$ não realizaram QT, portanto, 16 pacientes $(66,66 \%)$ a realizaram. Das pacientes que realizaram QT, 10 (62,5\%) realizaram QT neoadjuvante e adjuvante e as outras 6 pacientes (37,5\%) realizaram só QT 
adjuvante. O esquema quimioterápico adotado para as pacientes que realizaram Neoadjuvância e Adjuvância foi quatro ciclos de Epirrubicina + Ciclofosfamida na fase Neoadjuvante e quatro ciclos de Docetaxel na fase Adjuvante. Cinquenta por cento das pacientes que realizaram somente QT adjuvante, ou seja, três pacientes fizeram uso de quatro ciclos de Epirrubicina + Ciclofosfamida, seguidos de outros quatro ciclos de Docetaxel e as outras três pacientes fizeram uso de seis ciclos de Epirrubicina + Ciclofosfamida

Também foi utilizado como tratamento complementar em $25 \%$ da população estudada (6 pacientes) o Herceptin, por apresentarem tumor com Her positivo e as outras 18 pacientes (75\%) não utilizaram, pois apresentavam Her negativo. Já o Tamoxifeno foi empregado no tratamento de 21 pacientes $(87,50 \%)$, já que os tumores destas apresentavam receptores de estrogênio e/ou progesterona, as outras três pacientes não fizeram uso, pois seus tumores não apresentavam esses receptores. As características da neoplasia mamária, tratamento cirúrgico, quimioterápico e tratamentos complementares de cada paciente estão descritos no Anexo F.

A modalidade de RT utilizada, doses e campos irradiados foi prescrita e realizada pela equipe médica do Setor de RT, sendo que todas as pacientes completaram o programa estabelecido. A dose de 5040 cGy foi administrada em 28 sessões de 180 cGy/dia em 13 pacientes (54,16\%), as outras 11 pacientes (45,83\%) receberam dose de 5000 cGy em 25 sessões de 200 cGy/dia. Cinquenta por cento da população fizeram radiação também da FSC por apresentarem linfonodo positivo. E o reforço na cicatriz cirúrgica foi utilizado em 22 mulheres $(91,66 \%)$, com dose de 
1000 cGy, entregue em cinco sessões com 200 cGy cada. A descrição das doses e dos campos de radiação para cada paciente encontra-se no Anexo G.

\subsection{Dosagens de Citocinas por ELISA}

O GC, constituído de 25 voluntárias sadias na mesma faixa etária do GRT. Neste GC foram mensurados os mediadores inflamatórios sistêmicos, IL-1ß, IL-6 e TNF- $\alpha$, usando-se o método ELISA. Estes resultados foram úteis como parâmetros de normalidade na comparação da fase pré-RT do GRT. No Anexo M estão os valores apresentados pelas voluntária do GC. A média e o primeiro e o terceiro quartil estão descritos a seguir: IL-1 $\beta, 0$ (0; 0); IL-6 4,77(0; 0) e o TNF- $\alpha$ 7,39 (0; 14,2).

Das 24 pacientes do GRT que completaram o protocolo do estudo, duas negaram-se a coletar sangue para a pesquisa na fase pós-RT, uma vez que as mesmas não precisavam de coletá-los para exames de rotina. Portanto, os mediadores inflamatórios sistêmicos foram analisados em 22 pacientes do GRT e os resultados são apresentados no Anexo L.

Quando analisadas separadamente, as pacientes que realizaram QT e as que não a realizaram, observou-se uma distribuição semelhante para IL-1ß, IL-6 e TNF- $\alpha$, como demonstrado na Tabela 4. Devido a essa semelhança na distribuição dos resultados e ao tamanho da amostra, decidiu-se não dividi-los em dois grupos 
para fins de análise estatística, decisão calcada no conjunto de informações, dados, que assim permitiram.

Tabela 4 - Distribuição das pacientes segundo o comportamento dos mediadores inflamatórios sistêmicos da fase pós-RT em relação à fase pré-RT.

\begin{tabular}{cccccccccc}
\hline Grupo & \multicolumn{3}{c}{ Não Alterou } & \multicolumn{3}{c}{ Diminuiu } & \multicolumn{3}{c}{ Aumentou } \\
& IL-1 $\beta$ & IL-6 & TNF- $\alpha$ & IL-1 $\beta$ & IL-6 & TNF- $\alpha$ & IL-1 $\beta$ & IL-6 & TNF- $\alpha$ \\
\hline Sem QT & 6 & 1 & 2 & 0 & 6 & 2 & 1 & 0 & 3 \\
Com QT & 10 & 2 & 3 & 2 & 9 & 6 & 3 & 4 & 6 \\
Estudo & 16 & 3 & 5 & 2 & 15 & 8 & 4 & 4 & 9 \\
\hline
\end{tabular}

Os resultados medianos obtidos nesta avaliação de mediadores inflamatórios sistêmicos encontram-se descritos na Tabela 5.

Tabela 5 - Estatística descritiva das variáveis estudadas nos mediadores inflamatórios sistêmicos.

\begin{tabular}{lccc}
\hline Parâmetros & pré-RT & pós-RT & p-valor \\
& mediana $\left(\mathrm{Q} 1^{*} ; \mathrm{Q}^{* *}\right)$ & mediana $\left(\mathrm{Q} 1^{*} ; \mathrm{Q} 3^{* *}\right)$ & \\
\hline $\mathrm{IL}-1 \beta(\mathrm{pg} / \mathrm{ml})$ & $0(0 ; 0)$ & $0(0 ; 0)$ & 0,11 \\
$\mathrm{IL}-6(\mathrm{pg} / \mathrm{ml})$ & $40,12(9,52 ; 65,96)$ & $12,3(0 ; 30,68)$ & 0,01 \\
TNF- $\alpha(\mathrm{pg} / \mathrm{ml})$ & $16,84(0 ; 46,20)$ & $0(0 ; 29,04)$ & 0,16 \\
\hline
\end{tabular}

Não houve alteração significativa dos parâmetros IL-1ß e TNF-a. Mas a IL-6, diminuiu significativamente da fase pós-RT em relação à fase pré-RT. Nas figuras de 1 a 3, observam-se os resultados dos parâmetros individuais das pacientes estudadas. 


\subsubsection{Interleucina $1 \beta$}

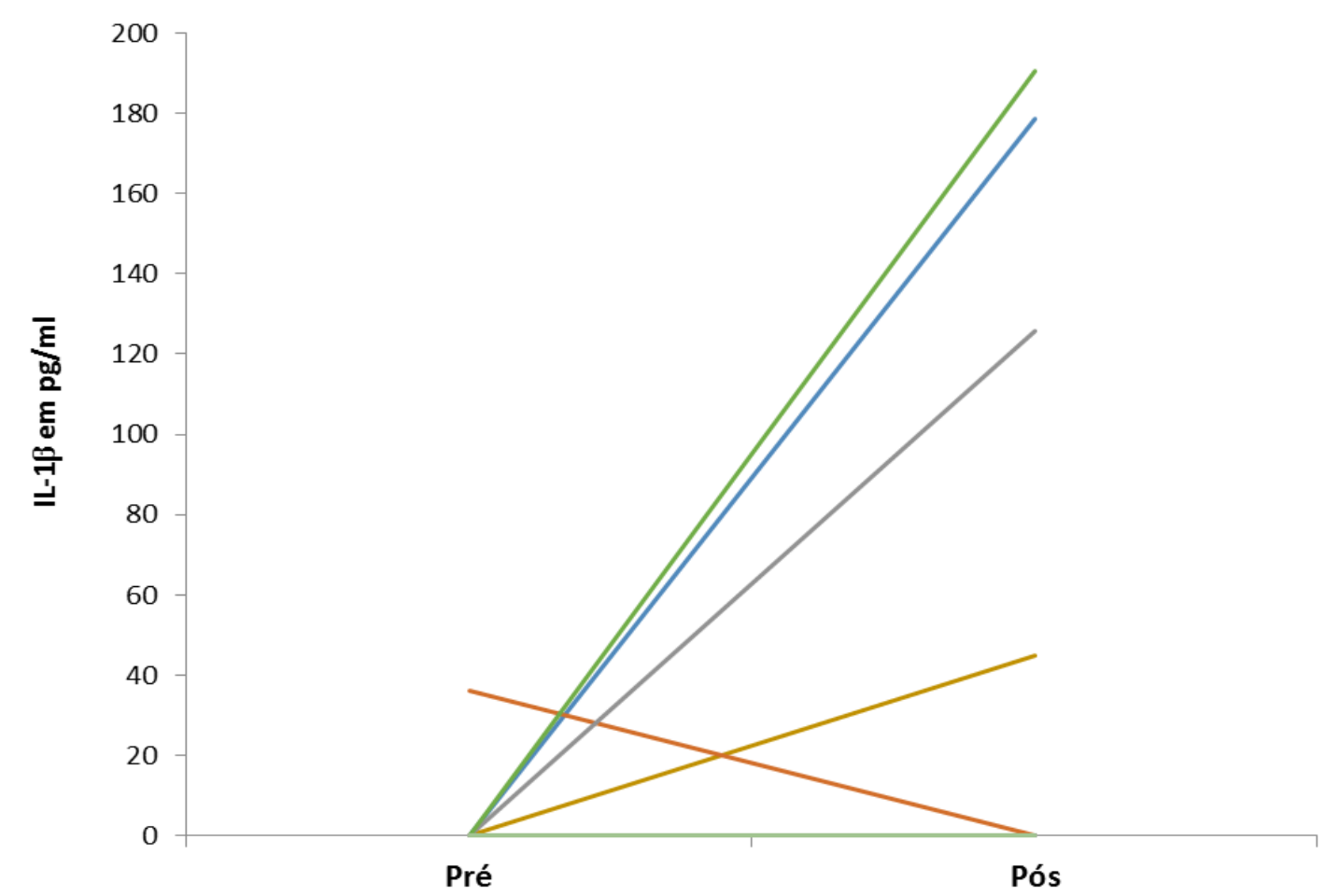

Figura 1 - Distribuição dos valores da IL-1 $\beta$ em picograma por mililitro de cada paciente nos períodos Pré e Pós-RT, 17 pacientes apresentavam valor 0 em ambas as fases $(p=0,11)$.

Destaca-se o fato que 17 pacientes apresentavam valor de IL-1 $\beta$ de 0 picograma por mililitro tanto na fase pré-RT como na fase pós-RT, por isso, só aparece no gráfico as 5 pacientes que se comportaram de forma diferente. Uma paciente apresentava $36 \mathrm{pg} / \mathrm{ml}$ na fase pré-RT e apresentou $0 \mathrm{pg} / \mathrm{ml}$ na fase pós-RT. Outras 4 pacientes apresentaram nível 0 na fase pré-RT e aumentaram na fase pósRT, porém a análise do GRT não demonstrou variação significativa com o uso da RT. 


\subsubsection{Interleucina 6}

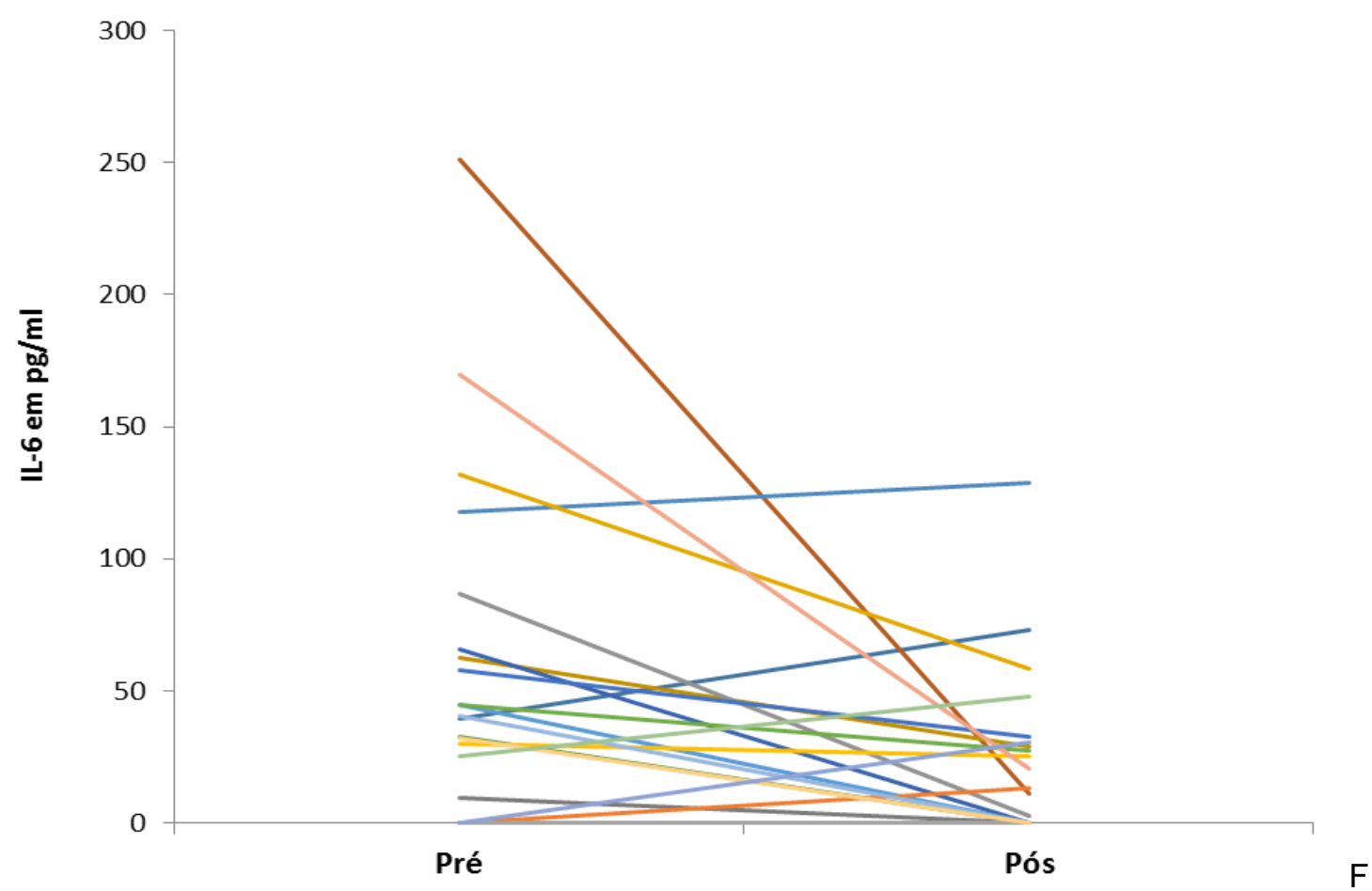

igura 2 - Distribuição dos valores da IL-6 em picograma por mililitro de cada paciente nas fases pré e pós-RT, 3 pacientes apresentavam valor 0 em ambas as fases $(p=0,01)$.

A maioria das pacientes (63,63\%) apresentou queda, mas $22,7 \%$ das pacientes apresentaram aumento após a RT e 13,63\% a RT não afetou o comportamento da IL-6. O comportamento do GRT foi uma queda significativa deste parâmetro na fase pós-RT $(p<0,05)$. 


\subsubsection{Fator de Necrose Tumoral - $\alpha$}

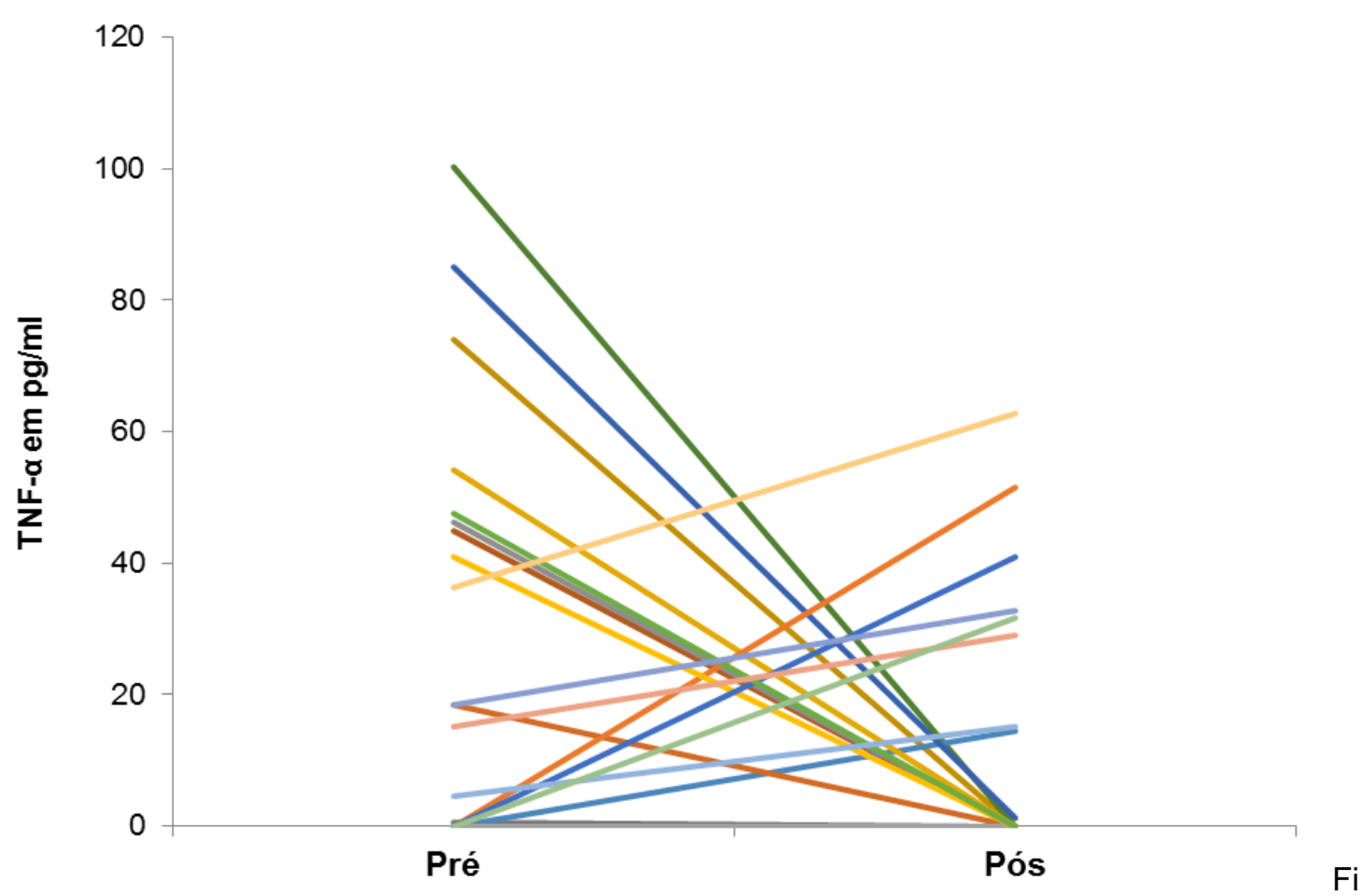

gura 3 - Distribuição dos valores do TNF- $\alpha$ em picograma por mililitro de cada paciente nas fases em que foram submetidas à avaliação pré e pós-RT, 4 pacientes apresentavam valor 0 em ambas as fases $(p=0,16)$.

Houve discreta tendência à queda do TNF- $\alpha$ na fase pós-RT, em relação à pré-RT, porém essa alteração não atingiu significância estatística $(p=0,16)$. 


\subsection{Qualidade de Vida}

Na análise do GRT não foram identificadas alterações na QV após a RT através do SGRQ, independente da administração prévia de QT. Para ser considerado alteração significativa após algum evento teria que ter apresentado um aumento superior ou igual a 4, neste caso, após a RT; segundo definição do próprio questionário (SOUSA; JARDIM; JONES, 2000). E para algum domínio ser considerado alterado tem de apresentar 10 ou mais, portanto, o Domínio Atividade já encontrava-se alterado antes do início da RT e manteve-se após, como demonstrado na Tabela 6 e 7, independente se analisado o grupo de pacientes que fizeram QT e as que não fizeram ou todas as pacientes do estudo.

Tabela 6 - Resultados das variáveis estudadas aplicando-se o Saint George's Respiratory Questionnaire no grupo de pacientes que não realizou QT e no grupo que realizou.

\begin{tabular}{|c|c|c|c|c|}
\hline & Parâmetros & $\begin{array}{c}\text { pré-RT } \\
\text { média/mediana } \\
\left(\mathrm{Q} 1^{\star} ; \mathrm{Q} 3^{\star *}\right)\end{array}$ & $\begin{array}{c}\text { pós-RT } \\
\text { média/mediana } \\
\left(\mathrm{Q} 1^{\star} ; \mathrm{Q3}^{* \star}\right)\end{array}$ & $\begin{array}{l}\text { Diferença da média } \\
\text { pós-RT menos a } \\
\text { média Pré-RT }\end{array}$ \\
\hline \multirow{4}{*}{$\begin{array}{l}\text { Com } \\
\text { QT }\end{array}$} & Sintomas & $4,43 / 0(0 ; 2,21)$ & $4,49 / 0(0 ; 4,4)$ & 0,06 \\
\hline & Atividade & $24,31 / 14,86(0 ; 50,69)$ & $21,66 / 3,74(0 ; 48,47)$ & $-2,65$ \\
\hline & Impacto & $4,71 / 4,71(0 ; 6,05)$ & $4,37 / 4,37(0 ; 1,53)$ & $-0,34$ \\
\hline & Total & 10,65 / 4,56 (0; 18,28) & 9,63 / 3,18 $(0 ; 24,1)$ & $-1,02$ \\
\hline \multirow{4}{*}{$\begin{array}{c}\text { Sem } \\
\text { QT }\end{array}$} & Sintomas & $2,07 / 0(0 ; 2,21)$ & 5,19 / 2,12 (0; 11,5) & 3,12 \\
\hline & Atividade & 18,48 / 11,64 $(0 ; 38,43)$ & $17,43 / 0(0 ; 44,70)$ & $-1,05$ \\
\hline & Impacto & 3,22 / 3,06 (0; 5,88) & 2,39 / $0(0 ; 5,51)$ & $-0,83$ \\
\hline & Total & 7,65 / 8,65 (0; 13,69) & 7,42 / 1,08 $(0 ; 17,7)$ & $-0,23$ \\
\hline
\end{tabular}


Quando analisados separadamente, o grupo de pacientes que fizeram QT com o grupo de pacientes que não a fizeram, observa-se que estas variáveis comportaram-se de forma semelhante, assim sendo pode-se analisá-las como um único grupo como apresentado na tabela 7.

Tabela 7 - Resultados das variáveis estudadas aplicando-se o Saint George's Respiratory Questionnaire.

\begin{tabular}{lccc}
\hline Parâmetros & $\begin{array}{c}\text { pré-RT } \\
\text { média/mediana } \\
\left(\mathrm{Q} 1^{*} ; \mathrm{Q} 3^{* *}\right)\end{array}$ & $\begin{array}{c}\text { pós-RT } \\
\text { média/mediana } \\
\left(\mathrm{Q} 1^{*} ; \mathrm{Q} 3^{* *}\right)\end{array}$ & $\begin{array}{c}\text { Diferença da } \\
\text { média pós-RT } \\
\text { menos a } \\
\text { média Pré-RT }\end{array}$ \\
\hline Sintomas & $3,64 / 0(0 ; 2,21)$ & $4,72 / 0(0 ; 6,68)$ & 1,08 \\
Atividade & $22,37 / 14,86(0 ; 44,54)$ & $20,26 / 0(0 ; 44,7)$ & $-2,11$ \\
Impacto & $4,21 / 0(0 ; 5,97)$ & $3,71 / 0(0 ; 3,06)$ & $-0,5$ \\
Total & $9,65 / 5,08(0 ; 14,11)$ & $8,89 / 2,01(0 ; 17,02)$ & $-0,76$ \\
\hline
\end{tabular}

A seguir, nas figuras de 4 a 7, demonstram-se o comportamento dos resultados obtidos de cada paciente em cada Domínio e no Total do questionário do SGRQ. 


\subsubsection{Total do Saint George’s Respiratory Questionnaire}

Não foram evidenciadas alterações significativas antes de iniciar a RT e nem pós-RT, pois a pontuação média inicial era de 9,65\% e manteve-se semelhante após a RT, 9,35\%, portanto, o GRT não apresentou alteração entre as avaliações. Sendo que 7 pacientes apresentaram pontuação 0 na fase pré-RT e na fase pós-RT.

Já o comportamento individual apresentou-se com piora nas pacientes $4,5,6$, 16, 17 e 21 (25\%) e as pacientes 9, 10, 12, 18, 19 e 20 (25\%) apresentaram melhoras significativas e as outras 12 pacientes (50\%) não demonstraram modificação após a RT.

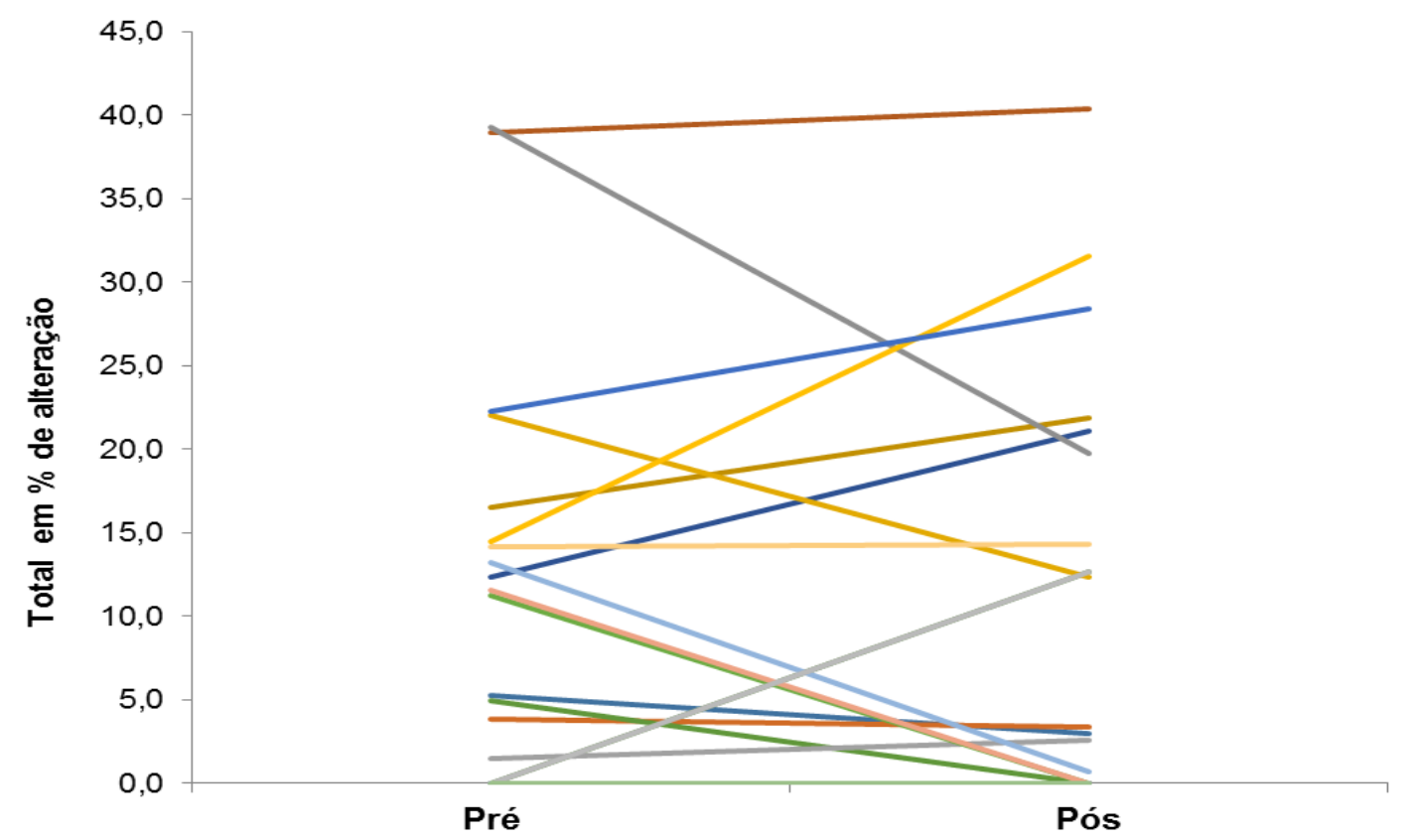

Figura 4 - Distribuição dos valores do total de pontos no SGRQ de cada paciente nas fases que foram submetidas à avaliação, 12 pacientes apresentavam valor 0 em ambas as fases. 


\subsubsection{Domínio Sintomas}

$\mathrm{Na}$ análise do GRT pode-se observar que não havia alterações pré-RT e que estas não surgiram no pós-RT, havendo pontuação de 3,64 na fase pré-RT, com alteração inferior a 4 na fase pós-RT. Destaca-se que 11 pacientes apresentaram pontuação 0 e a mantiveram na fase pós-RT.

Entretanto, tratando-se de sintomas, é necessário que se façam considerações individuais. Assim, observou-se que as pacientes 1, 2, 4, 5, 6, 15, 16 e 17 (33,33\%) tiveram piora neste domínio; por outro lado, as pacientes 9,18 e 19 $(12,50 \%)$ apresentaram melhora significativa e as outras 13 pacientes $(54,17 \%)$ não modificaram seus sintomas.

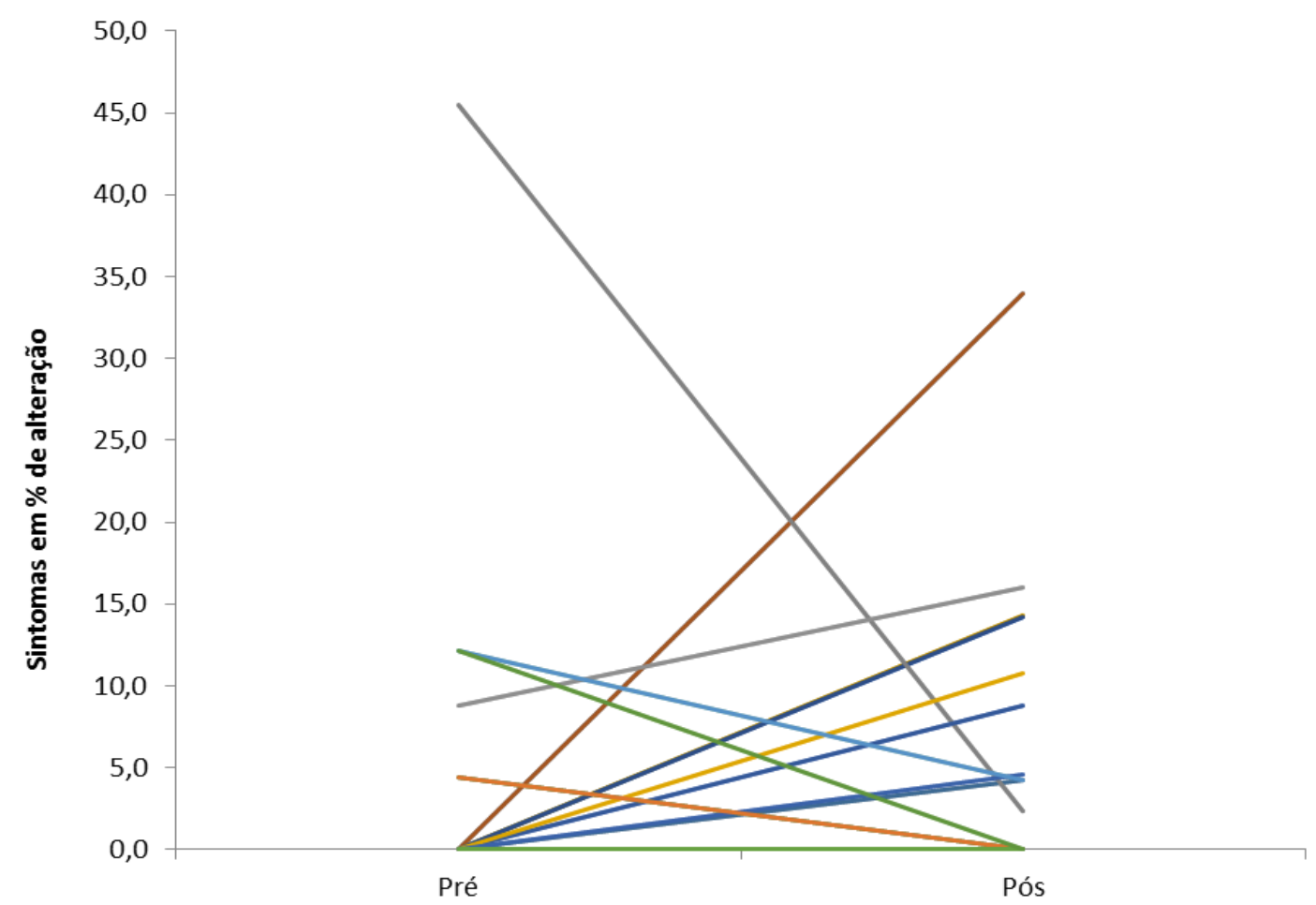

Figura 5 - Distribuição dos valores do Domínio Sintomas de cada paciente nas duas fases que foram submetidas às avaliações, 10 pacientes apresentavam valor $0 \mathrm{em}$ ambas as fases. 


\subsubsection{Domínio Atividades}

Pacientes já apresentavam alteração neste domínio antes da RT e não houve piora após, ao contrário apresentaram até uma melhora, porém não significativa, pois, houve diminuição na pontuação após a RT em relação ao pré-RT em 2,11 pontos. Neste domínio houve 10 pacientes que apresentaram pontuação 0 na fase pré-RT e a mantiveram na fase pós-RT.

Em análise do comportamento individual observou-se que as pacientes 5, 9, 16 e $21(16,66 \%)$ apresentaram piora e as pacientes 1, 2, 10, 18, 19 e 20 (25\%) apresentaram melhoras significativas e as outras 14 pacientes $(58,33 \%)$ não apresentaram modificação com RT.

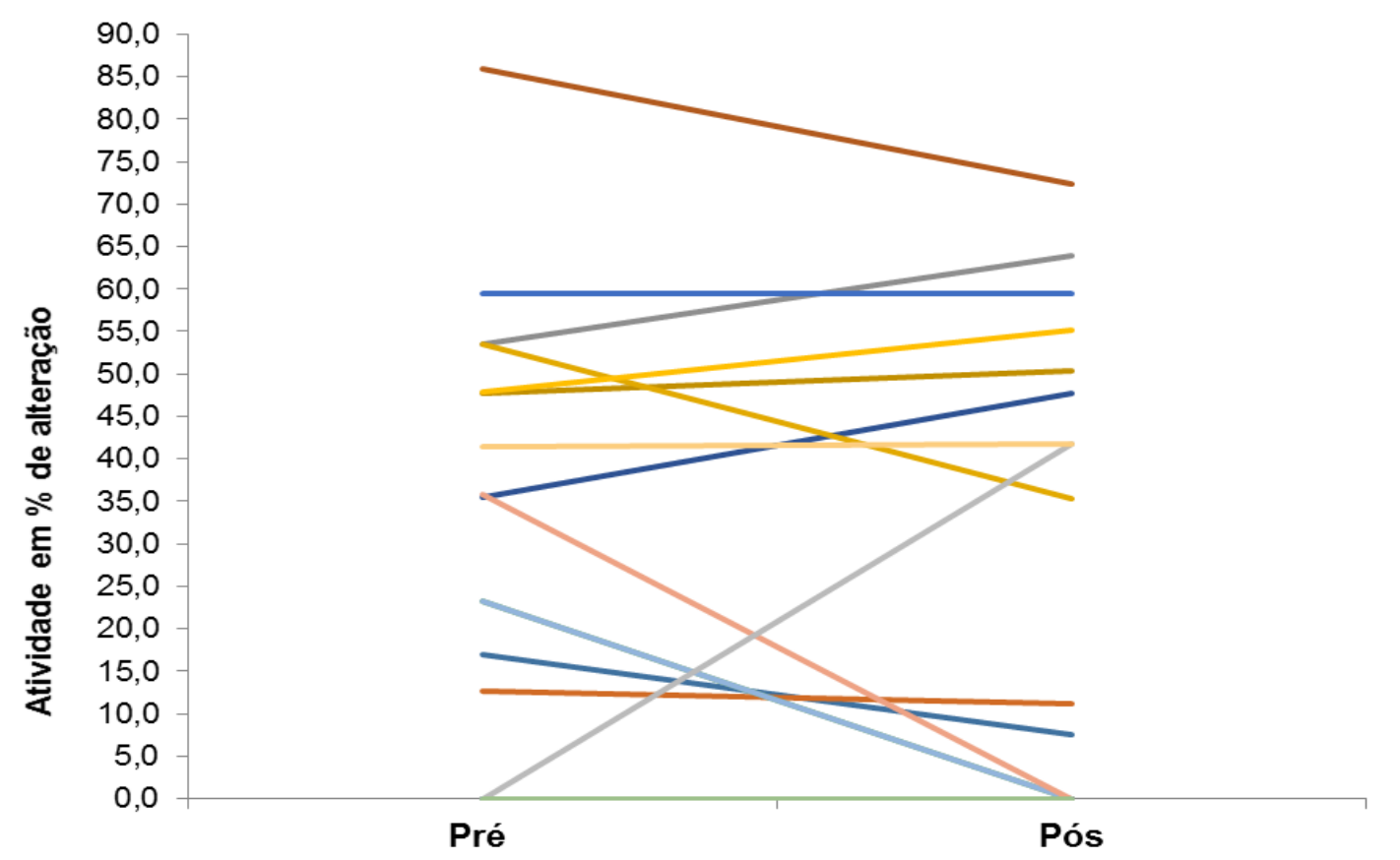

Figura 6 - Distribuição dos valores do Domínio Atividade de cada paciente nas fases que foram submetidas à avaliação, 10 pacientes apresentavam valor 0 em ambas as fases. 


\subsubsection{Domínio Impactos}

Como no Domínio Sintomas, o Domínio Impactos, a análise do GRT também não evidenciou alterações em ambas as fases das avaliações, com média de 4,21 na fase pré-RT e na fase após a média foi 3,71\%, portanto, uma alteração inferior a 4 \% após a intervenção, ou seja, não significante. Neste domínio 13 pacientes apresentaram pontuação 0 em ambas as fases das avaliações.

Já o comportamento individual observou-se que as pacientes 4, 5, 16 e 17 $(16,66 \%)$ apresentaram piora e as pacientes $9,10,12,18$ e $19(20,83 \%)$ apresentaram melhoras significativas e as outras 15 pacientes $(62,50 \%)$ não demonstraram modificação após a RT.

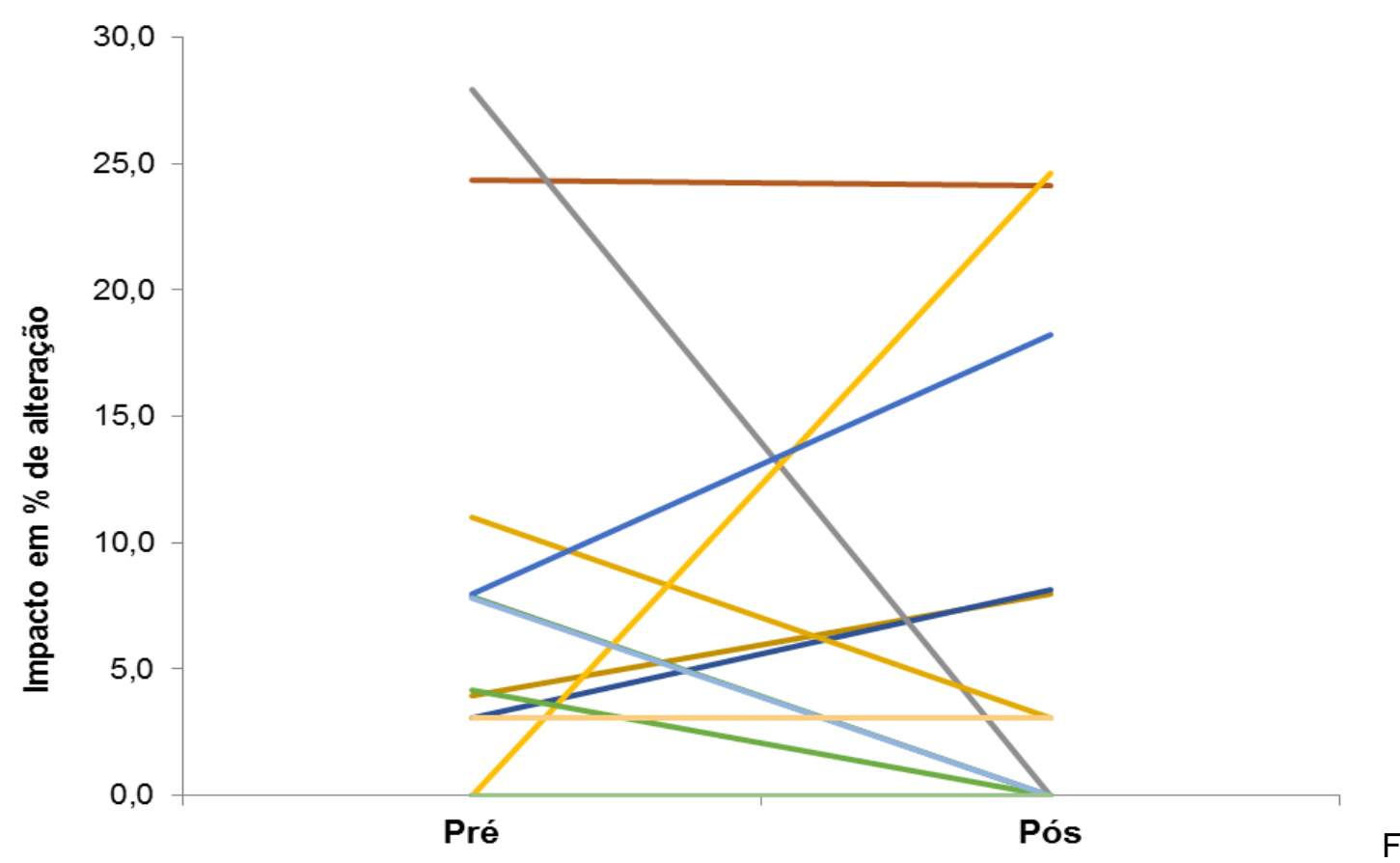

gura 7 - Distribuição dos valores do Domínio Impacto de cada paciente nas fases que foram submetidas à avaliação. 


\subsection{Função Pulmonar}

Do total de pacientes que completaram o protocolo do estudo, uma negou-se a realizar a PFP na fase pós-RT, por ter achado o teste desagradável. No Anexo F são apresentados os valores individualizados observados na PFP. As medianas, primeiro e terceiro quartil e o p-valor estão na Tabela 8.

Tabela 8 - Estatística descritiva das variáveis estudadas na prova de função pulmonar.

\begin{tabular}{lccc}
\hline \multicolumn{1}{c}{ Parâmetros } & pré-RT & pós-RT & p-valor \\
& Mediana $\left(\mathrm{Q1}^{*} ; \mathrm{Q}^{* *}\right)$ & Mediana $\left(\mathrm{Q} 1^{*} ; \mathrm{Q} 3^{* *}\right)$ & \\
\hline CVF (litros) & $2,91(2,48 ; 3,38)$ & $2,99(2,5 ; 3,37)$ & 0,57 \\
VEF1 (litros) & $2,33(1,92 ; 2,76)$ & $2,41(1,95 ; 2,63)$ & 0,14 \\
VEF1/CVF (\%) & $80(80 ; 84)$ & $80(80 ; 83)$ & 0,17 \\
FEF50\% (I/seg) & $3,34(2,92 ; 5,0)$ & $3,16(2,36 ; 4,07)$ & 0,04 \\
FEF75\% (I/seg) & $0,76(0,55 ; 1,23)$ & $0,97(0,37 ; 1,18)$ & 0,97 \\
CPT (litros) & $4,89(4,24 ; 5,57)$ & $4,83(4,46 ; 5,15)$ & 0,26 \\
CRF (litros) & $2,54(2,01 ; 3,03)$ & $2,38(2,02 ; 3,02)$ & 0,32 \\
CV (litros) & $2,95(2,39 ; 3,21)$ & $2,88(2,57 ; 3,24)$ & 0,86 \\
VR (litros) & $1,79(1,58 ; 2,47)$ & $1,82(1,48 ; 1,92)$ & 0,14 \\
$\begin{array}{l}\text { DLCO } \\
\text { (ml/min/mmHg) }\end{array}$ & $19,50(17,12 ; 22,37)$ & $17,48(14,71 ; 21,28)$ & 0,01 \\
\hline
\end{tabular}

${ }^{*} \mathrm{Q} 1$ é o primeiro quartil; ${ }^{* *} \mathrm{Q} 3$ é o terceiro quartil.

As únicas variáveis que apresentaram diminuição significativa da fase pós-RT em relação à fase pré-RT foi a DLCO e FEF50\%. Já a CVF, VEF1, CPT, FEF75\%, CRF, CV e VR não apresentaram alteração significativa dos parâmetros entre as avaliações. Nas figuras de 8 a 17, observam-se os resultados dos parâmetros individuais das mulheres estudadas. 


\subsubsection{Capacidade Vital Forçada}

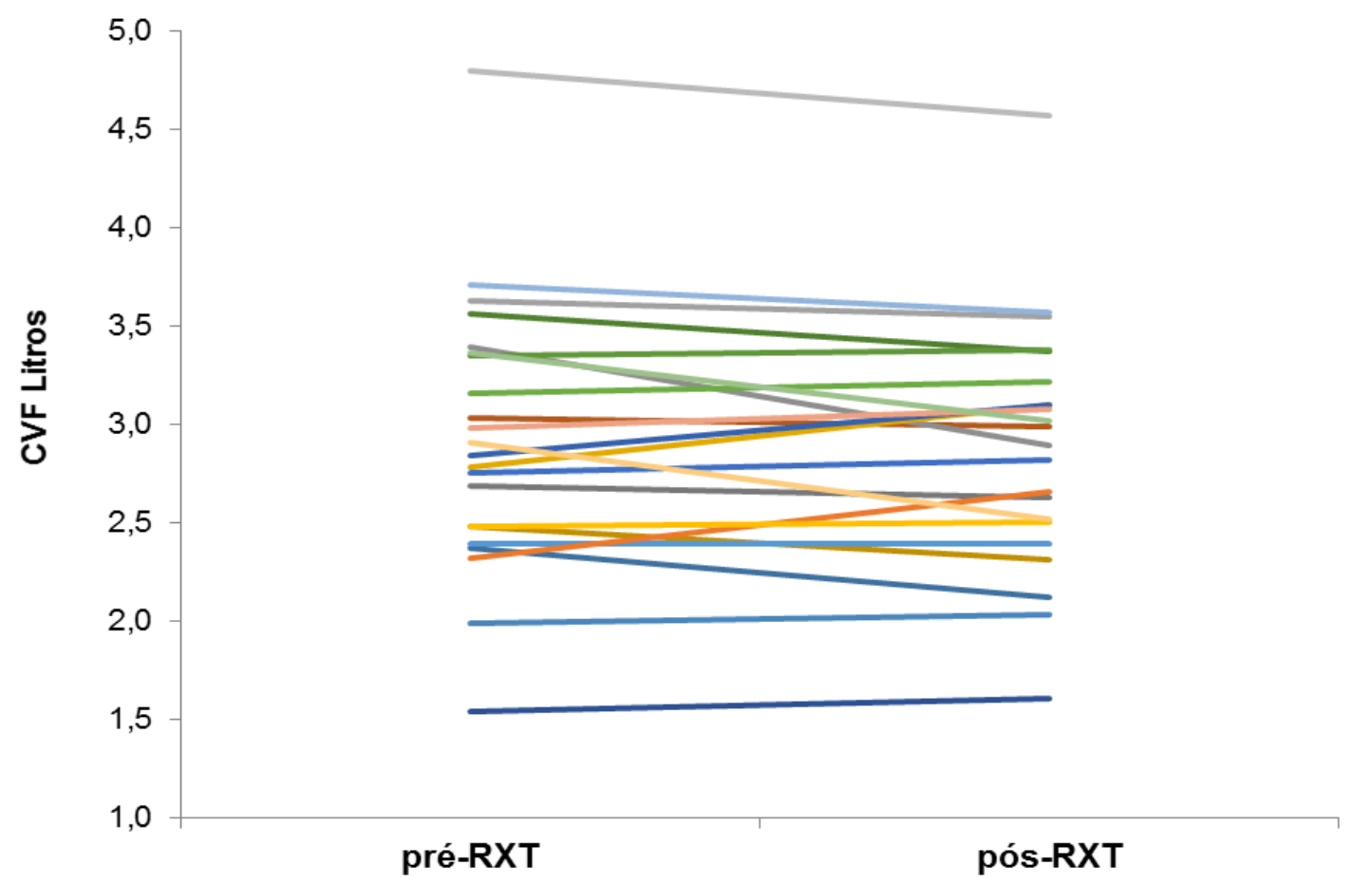

Figura 8 - Distribuição dos valores da CVF em litros de cada paciente nas fases Pré e Pós-RT ( $p=$ $0,57)$.

Destaca-se a paciente número 21 que apresentou na fase pré-RT 4,8 litros (112\% do previsto para ela) e na fase após a RT 4,57 litros (108\%). Das 23 pacientes que completaram o protocolo da PFP, 52\% não apresentaram alteração da CVF após a RT, 30,4\% apresentaram uma diminuição e 17,4\% um aumento, ou seja, não houve tendência clara no comportamento deste parâmetro $(p=0,57)$. 


\subsubsection{Volume Expiratório Forçado no Primeiro Segundo}

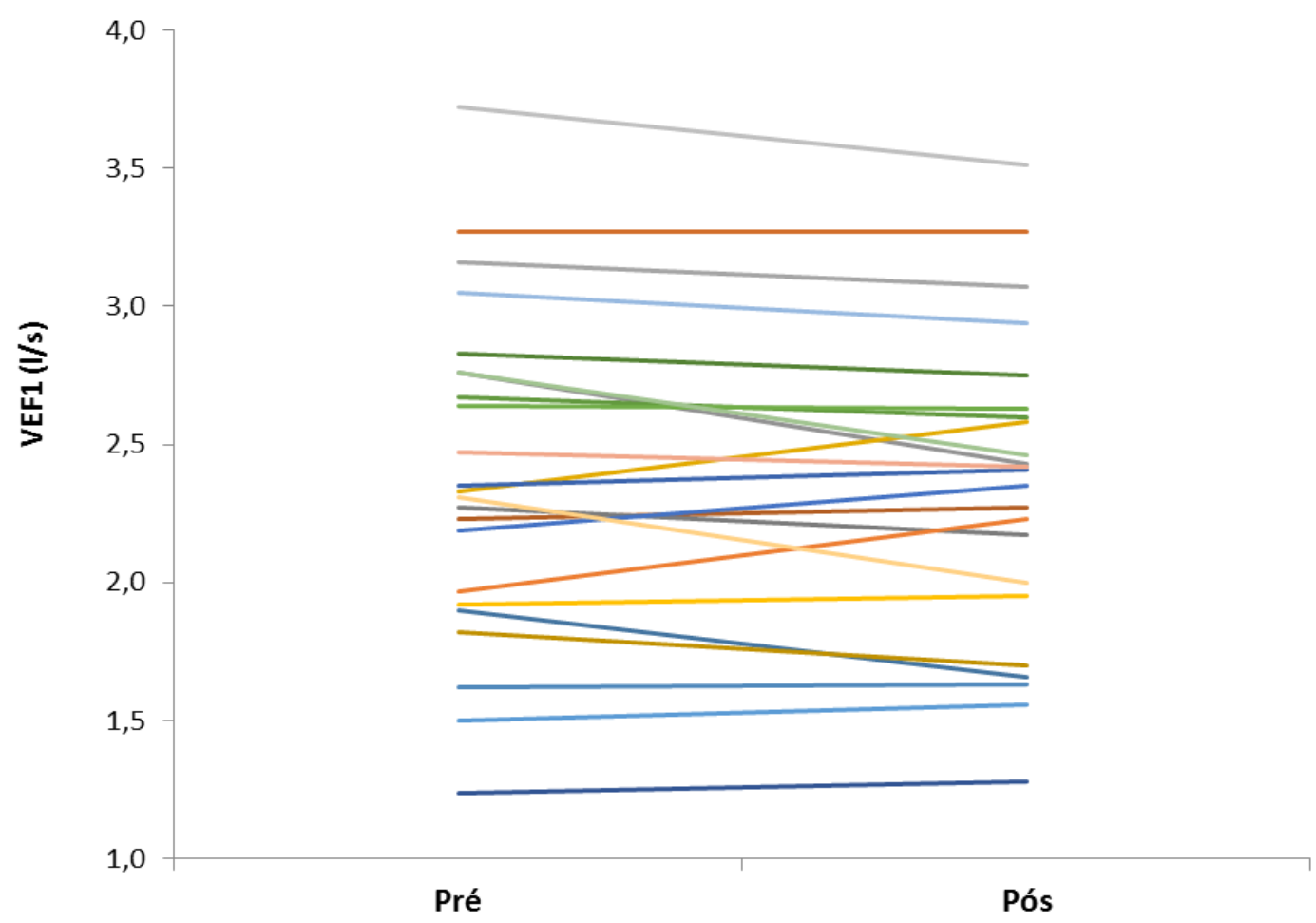

Figura 9 - Distribuição dos valores do VEF1 (litros) das pacientes estudadas nas fases Pré e Pós-RT $(p=0,14)$.

Não houve diferença significativa após a RT $(p=0,14)$. Sendo que $56,5 \%$ das pacientes não apresentaram alterações, 26,1\% tiveram diminuição e 17,4\% aumento. 


\subsubsection{Relação do Volume Expiratório Forçado no Primeiro Segundo e a Capacidade Vital Forçada}

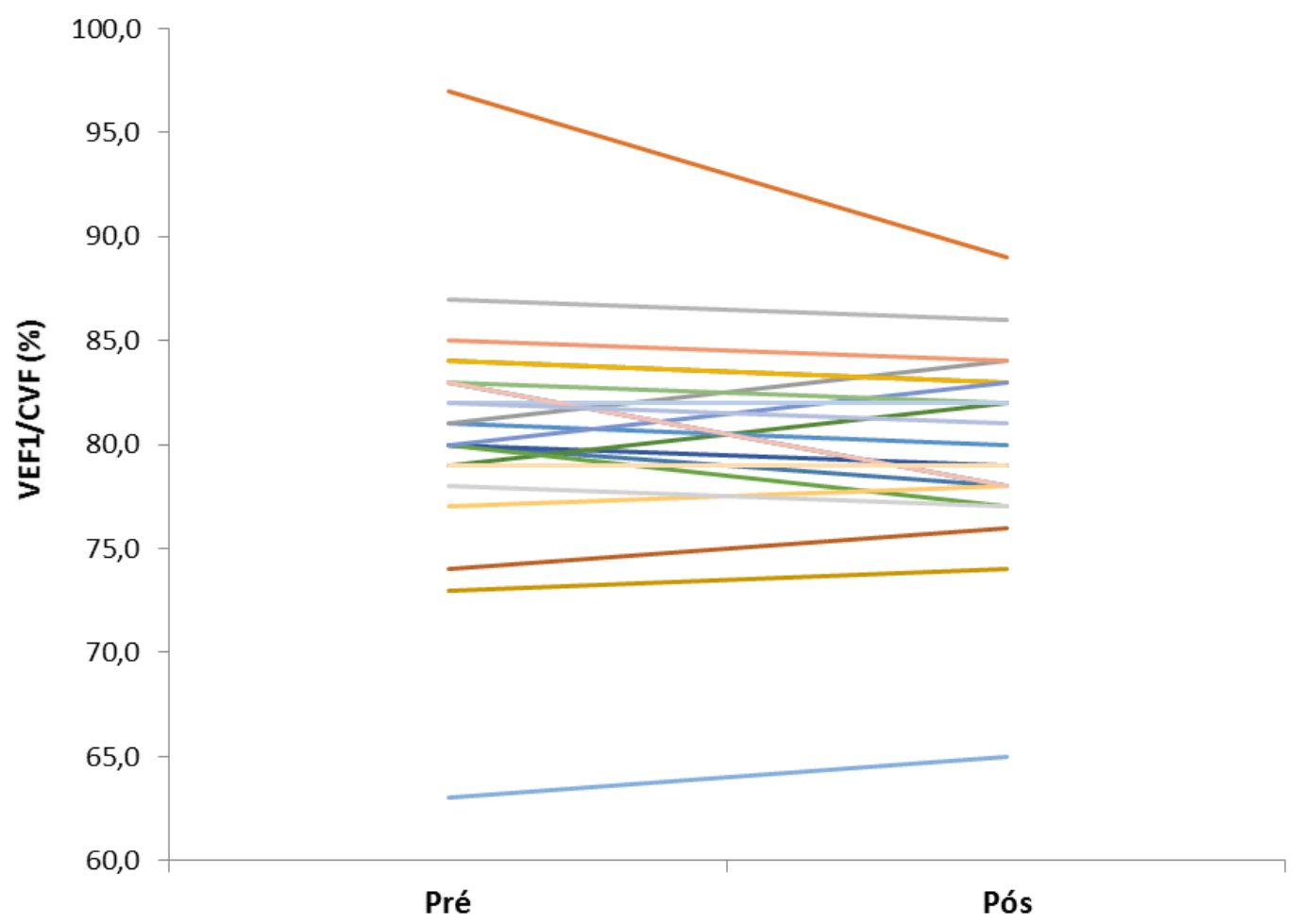

Figura 10 - Distribuição dos valores da relação VEF1/CVF (porcentagem) das pacientes estudadas na fase Pré e Pós-RT $(p=0,17)$.

Destaca-se a paciente número 13 pelo baixo valor da relação que apresentou tanto na fase pré-RT $65 \%$ como na fase pós-RT $63 \%$, porém se comportou de forma semelhante ao GRT, ou seja, não apresentou alteração importante após a RT variando de 1 a $5 \%$ em relação à fase pré-RT; também destaca-se a paciente número 8, que apresentou a relação na fase pré-RT 97\% e na fase pós-RT $89 \%$, variação um pouco maior que as demais (8\%). Assim sendo, não houve diferença significativa após a RT $(p=0,17)$. 


\subsubsection{Fluxo Expiratório Forçado a $50 \%$ da Capacidade Vital Forçada}

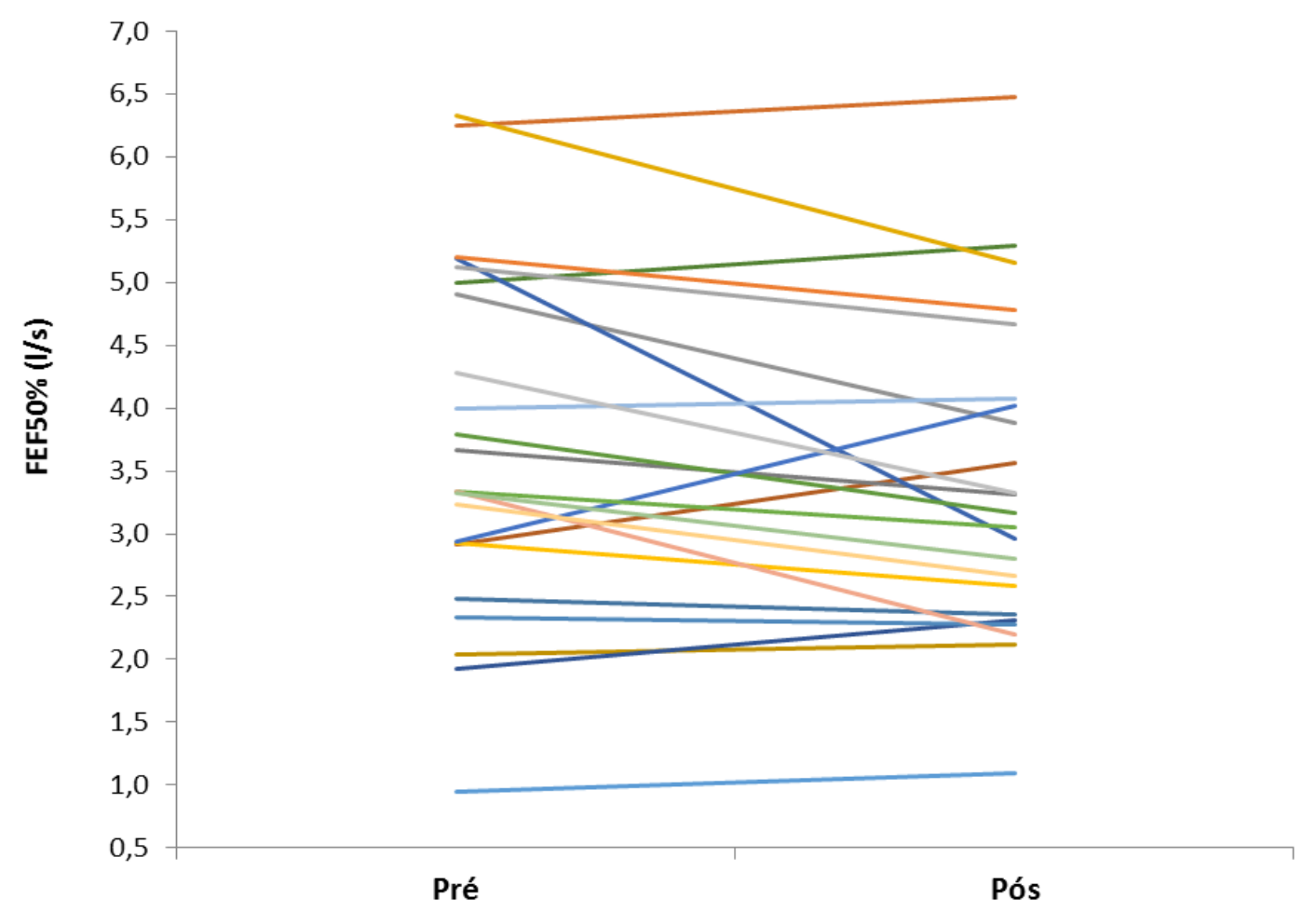

Figura 11 - Distribuição dos valores do FEF50\% das pacientes que participaram do estudo nas fases Pré e Pós-RT $(p=0,04)$.

Aqui também destaca-se a paciente número 13, que apresentou na fase préRT $0,95 \mathrm{l} / \mathrm{s}$ e na fase pós-RT $1,10 \mathrm{l} / \mathrm{s}$, sugerindo existência prévia de distúrbio ventilatório obstrutivo. O comportamento desta paciente assemelha-se a de outras cino pacientes, ou seja, $26,1 \%$ da população estudada apresentaram aumento da FEF50\%. Entretanto este comportamento foi destoante do comportamento do GRT, $56,52 \%$ das pacientes apresentaram queda significativa deste paramento na fase pós-RT $(p<0,05)$. Cerca de 17,4\% das pacientes não apresentaram alterações após a RT. 


\subsubsection{Fluxo Expiratório Forçado nos $75 \%$ da Capacidade Vital Forçada}

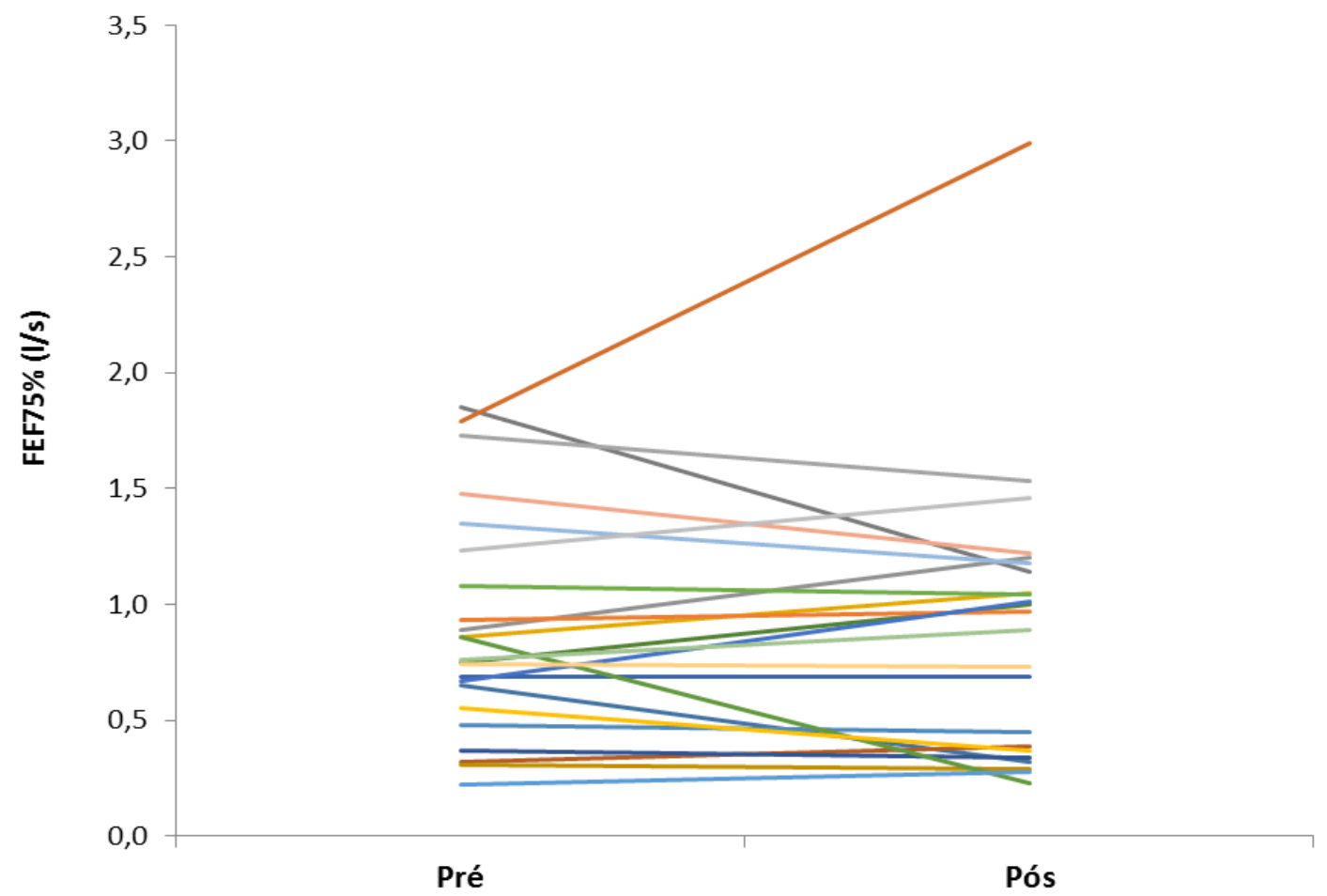

Figura 12 - Distribuição dos valores do FEF75\% das pacientes que participaram do estudo nas fases Pré e Pós-RT ( $p=0,97)$.

Destaca-se a paciente número 8 que apresentou na fase pré-RT 1,79 I/s e na fase pós-RT apresentou 2,99 I/s, valores que representam $86 \%$ e $141 \%$ do previsto para esta paciente, respectivamente. Outras sete pacientes também apresentaram aumento após a RT, ou seja, 34,78\% do GRT; outras $39,13 \%$ apresentaram diminuição após a RT e 26,09\% não alteraram. Na análise do comportamento do GRT foi observado que não houve alteração significativa após a $\operatorname{RT}(p=0,97)$. 


\subsubsection{Capacidade Pulmonar Total}

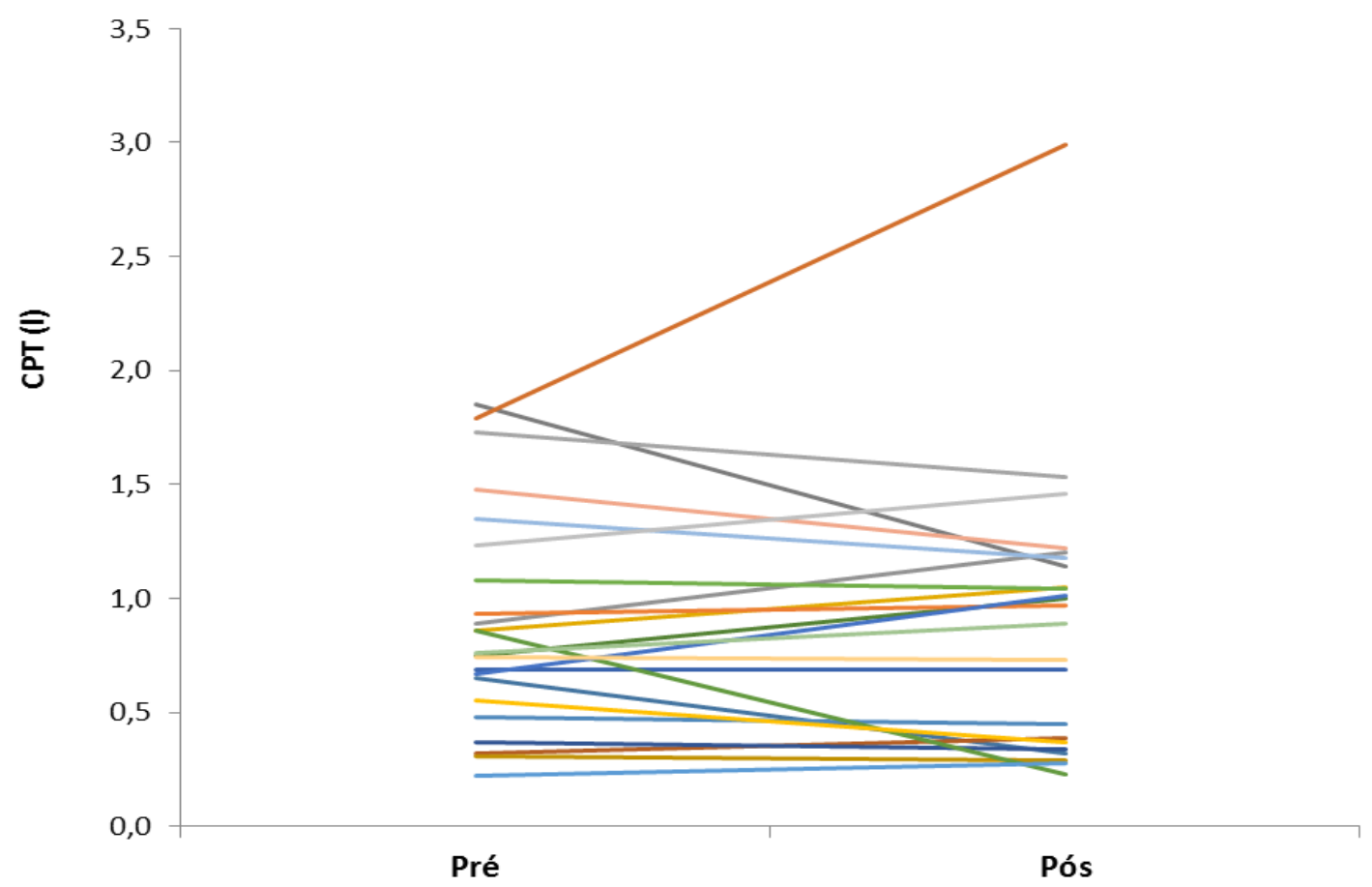

Figura 13 - Distribuição dos valores da CPT das pacientes que participaram do estudo nas fases Pré e Pós-RT $(p=0,26)$.

$\mathrm{Na}$ medida da CPT houve uma paciente que se também destacou das demais, paciente 21, apresentando um aumento significativo da CPT após a RT, assim como outras sete pacientes, ou seja, 34,7\% das pacientes estudadas; $13,1 \%$ não apresentaram alterações e 52,2\% apresentaram diminuição. Apesar de a redução ser a tendência da maioria das pacientes, não houve diferença significativa entre as fases pré-RT e após a RT $(p=0,26)$. 


\subsubsection{Capacidade Residual Funcional}

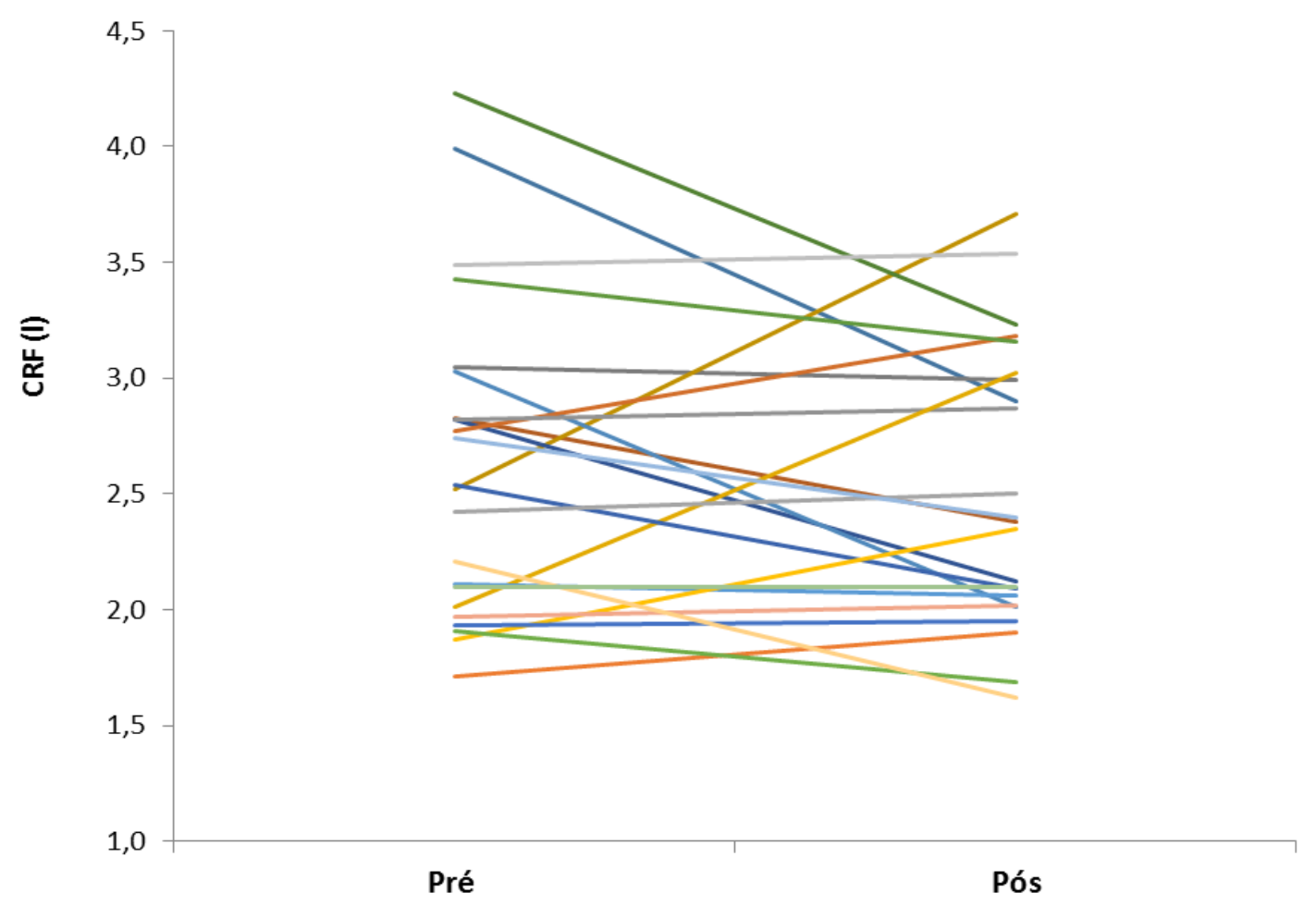

Figura 14 - Distribuição dos valores da CRF das pacientes que participaram do estudo nas fases Pré e Pós-RT $(p=0,32)$.

Na medida da CRF houve flutuação dos resultados: diminuição na fase após a RT em 47,8\% das pacientes, ausência de modificações em 30,4\% e aumento em 21,7\%; não apresentando alteração significativa após a RT $(p=0,32)$. 


\subsubsection{Capacidade Vital}

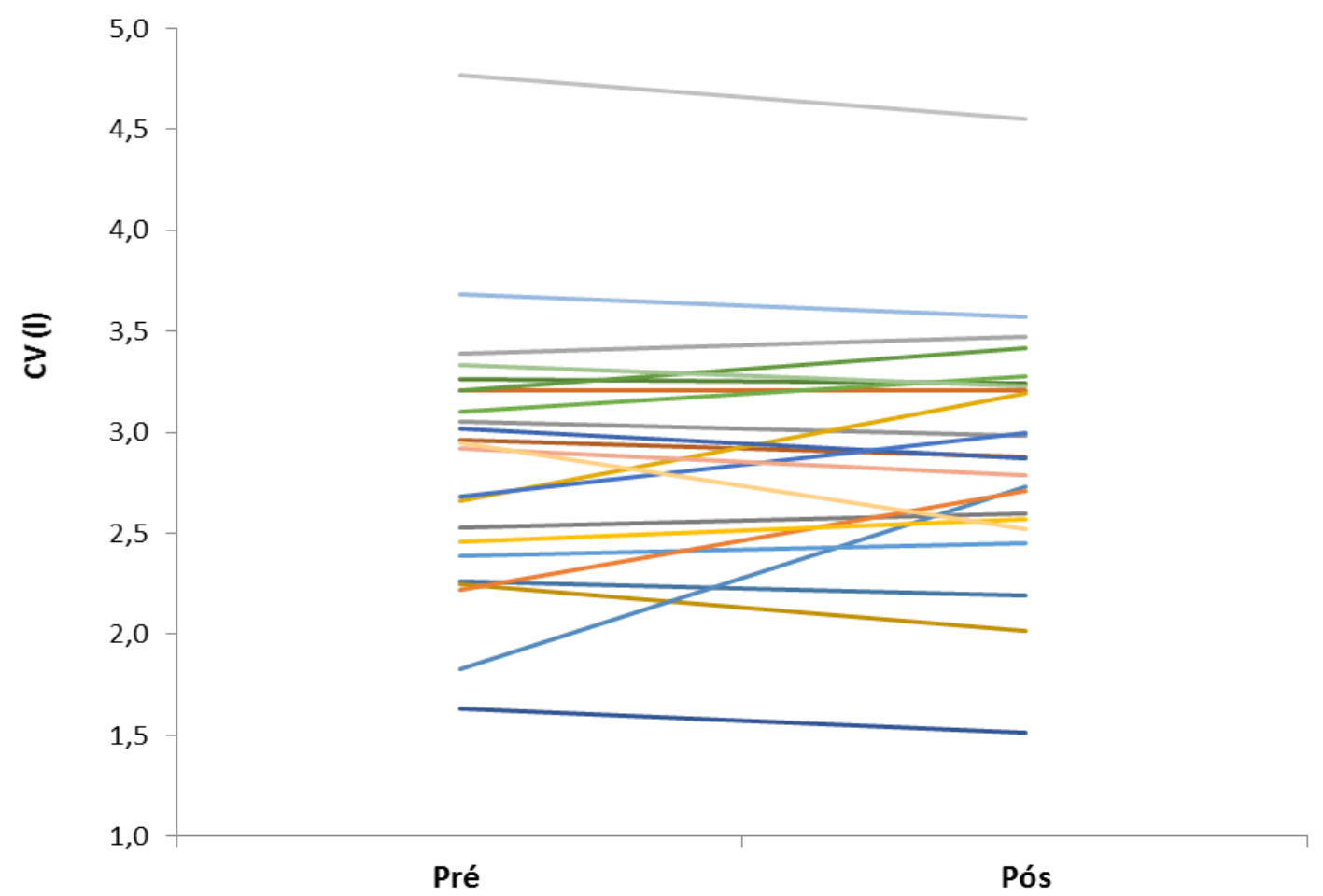

Figura 15 - Distribuição dos valores da CV das pacientes que participaram do estudo nas fases Pré e Pós-RT $(p=0,86)$.

Destaque para a paciente número 21 , que apresentou CV na fase pré-RT de 4,77 litros (112\%) e na após a RT de 4,55 litros (107), valores maiores que as demais pacientes, mas comportou-se de forma semelhante ao GRT após a intervenção com RT. Na análise do GRT não houve diferença significante após a RT $(p=0,86)$. 


\subsubsection{Volume Residual}

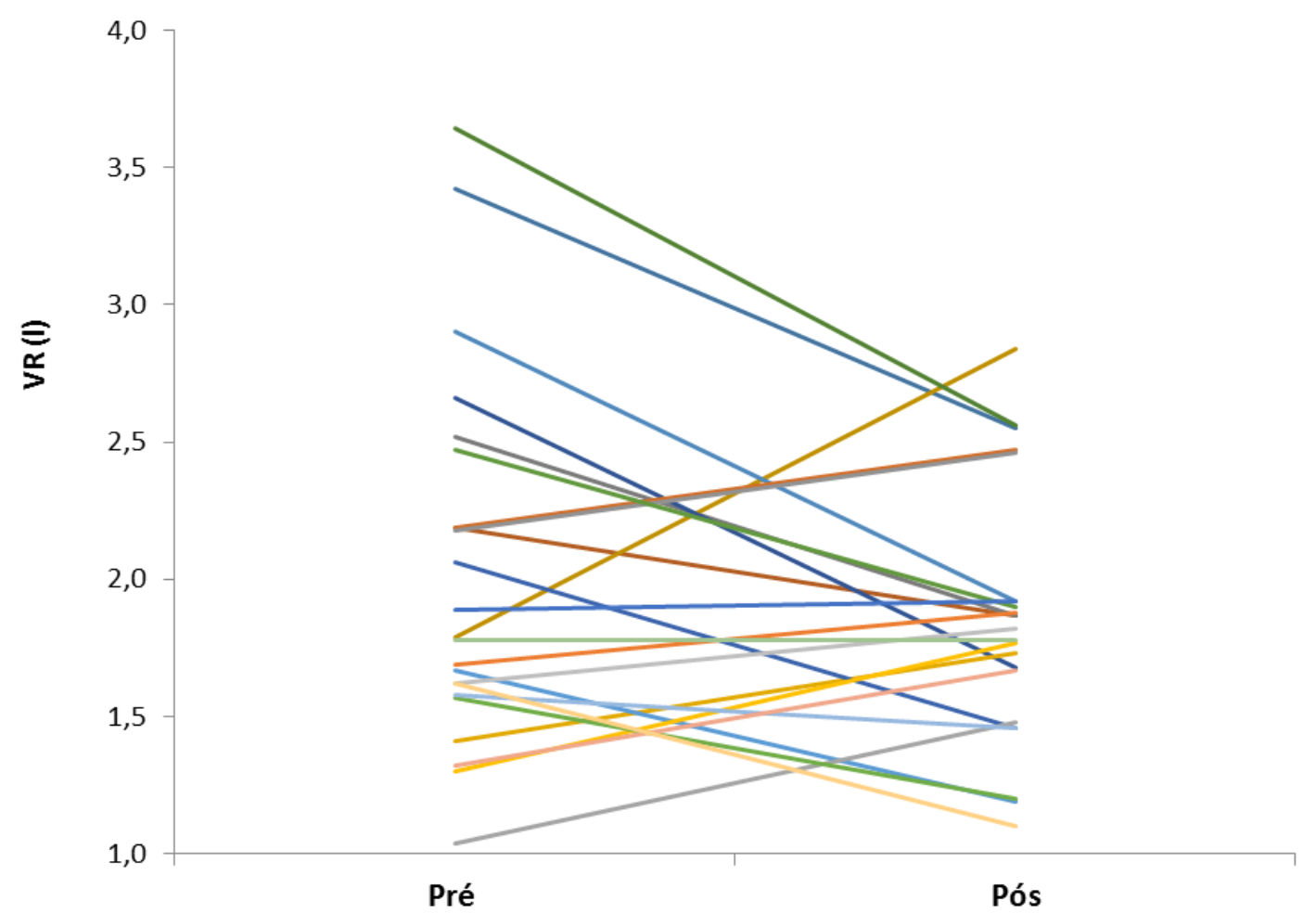

Figura 16- Distribuição dos valores do VR das pacientes que participaram do estudo nas fases Pré e Pós-RT $(p=0,14)$.

Após a RT 56,5\% das pacientes apresentaram redução do valor de VR, entretanto esta tendência não apresentou queda suficiente para atingir significância estatística $(p=0,14)$. Ainda, $8,7 \%$ das pacientes não apresentaram alteração na fase pós-RT em relação à fase pré-RT e 34,7\% tiveram um aumento. 


\subsubsection{Capacidade de Difusão Pulmonar}

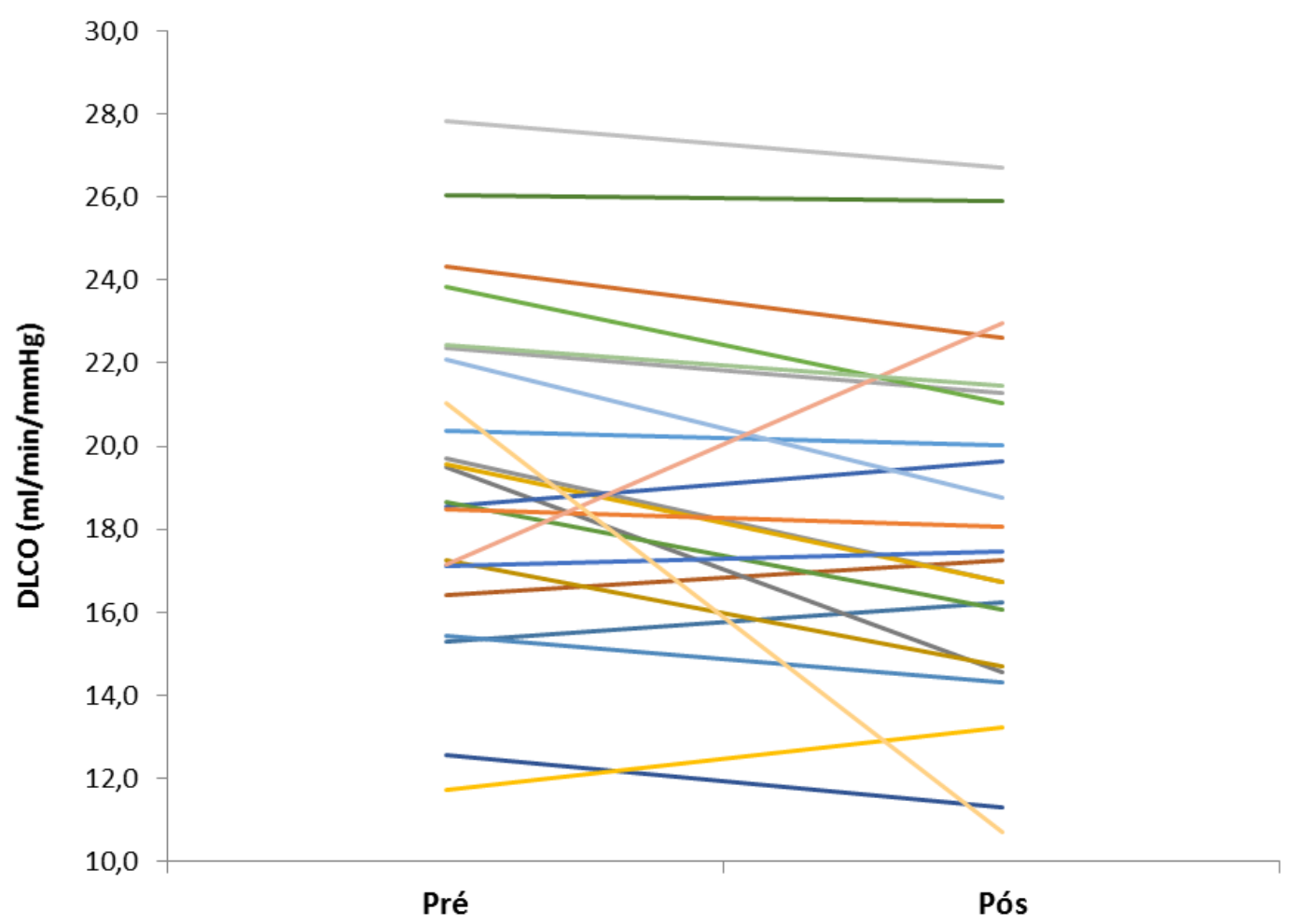

Figura 17 - Distribuição dos valores da DLCO $(\mathrm{ml} / \mathrm{min} / \mathrm{mmHg})$ das pacientes que participaram do estudo nas fases Pré e Pós-RT ( $p=0,01)$.

Houve queda significativa da DLCO pós-RT $(p=0,01)$, sendo que $65,2 \%$ das pacientes apresentaram essa queda, que foi o comportamento característico do GRT. Porém, 13,1\% não apresentaram alteração e 21,7\% tiveram aumento. 


\subsection{Tomografia Computadorizada de Alta Resolução}

Todas as 24 pacientes realizaram TCAR pré-RT e após a RT, porém os exames de três pacientes na fase pós-RT não foram passíveis de avaliação. A TCAR da paciente número 7 perdeu o registro imaginológico e as TCARs das pacientes número 8 e 9 não apresentaram qualidade técnica para a mensuração volumétrica quantitativa, mas apresentaram para a análise qualitativa. A análise quantitativa dos volumes pulmonares das pacientes do presente estudo foi realizada em 21 pacientes, as quais não apresentaram alterações significativas na fase pósRT em relação ao pré-RT $(p=0,99)$, independentemente se a análise foi realizado no pulmão esquerdo ou direito. Também não houve alteração significativa na fase pós-RT em relação ao fase pré-RT do volume pulmonar do lado irradiado $(p=0,13)$ e do lado não irradiado $(p=0,65)$.

Já a análise qualitativa foi realizada em 23 pacientes, por um médico experiente e especialista em Imaginologia, cujas descrições são apresentadas no Anexo H. Em 60,87\% das pacientes apareceram alterações após a RT e destas pacientes, $71,43 \%$ apresentaram opacidade pulmonar. Este médico também utilizou a escala de Nishioka et al. (1999) que apresenta a seguinte classificação: Grau 0, sem alterações nos campos de radiação; Grau 1, espessamento pleural nos campos de radiação; Grau 2, opacidades pulmonares discretas predominantemente intersticiais menor que $50 \%$ de área irradiada; Grau 3, opacidades pulmonares estiverem presentes em mais que $50 \%$ e menos que $75 \%$ da área de radiação e Grau 4, as opacidades pulmonares grosseiras ou alveolares identificadas inclusive nos campos pulmonares profundos, maior que $75 \%$ da área irradiada. Os campos de 
radiação considerados na análise foram o CTM, CSC e CM. Nas análises por campos foram descritas: no CTM, ou seja, o lobo superior e médio/língula, observouse somente alteração grau 3 na paciente número 3; cinco apresentaram grau 2; três pacientes apresentaram grau 1 e outras 14 não apresentaram alterações. No CSC, ou seja, ápices pulmonares, não houve alteração em nenhuma das 12 pacientes que não tiveram a FSC irradiada; das outras 11 pacientes que tiveram a FSC irradiada, somente uma paciente apresentou alteração grau 3; seis pacientes apresentaram grau 2 e quatro pacientes não apresentaram alteração em ápice pulmonar apesar de ter sofrido radiação neste campo. $\mathrm{Na}$ análise da região central, $\mathrm{CM}$, região central para hilar, somente a paciente número 10 apresentou alteração, caracterizada como grau 2, possivelmente devido à localização do seu tumor primário.

\subsection{Análise de Correlações}

Foram avaliadas as possíveis correlações entre as diferenças das variáveis que apresentaram alterações estatisticamente significante entre as duas fases do estudo: DLCO, FEF50\% e IL-6 e delas com as diferenças de todas as variáveis estudadas. Nos Anexos N, O, P estão expostos todos os resultados das Correlações de Sperman. A Tabela 9 apresenta os resultados das Correlações de Sperman que atingiram níveis de significância estatística. Observa-se que mesmo nestes casos as correlações não foram muito fortes, pois valores de rho mais próximos de um refletem as correlações mais fortes, que não foram observados na presente análise. 
Tabela 9 - Correlações de Sperman entre as diferenças pós-RT menos pré-RT das variáveis estudadas, que apresentaram $\mathrm{p}$-valor significante.

\begin{tabular}{lcc}
\hline Variáveis avaliadas & Correlação rho & p-valor \\
\hline DLCO x Sintomas & $+0,46$ & 0,03 \\
DLCO x Impacto & $+0,45$ & 0,03 \\
\hline
\end{tabular}

\subsubsection{Correlação da Alteração após a RT na DLCO}

A DLCO foi uma das principais variáveis estudadas que se correlacionaram com alterações no questinário de QV, atingindo significância estatística em dois domínios: Sintomas e Impacto (Figura 18 e 19). Na soma total dos pontos do SGRQ, o resultado da correlação $(p=0,11)$ aproximou-se da significância estatística, dado que sugere que a alteração na DLCO após a RT foi o principal fator influenciador na piora da QV das pacientes. 


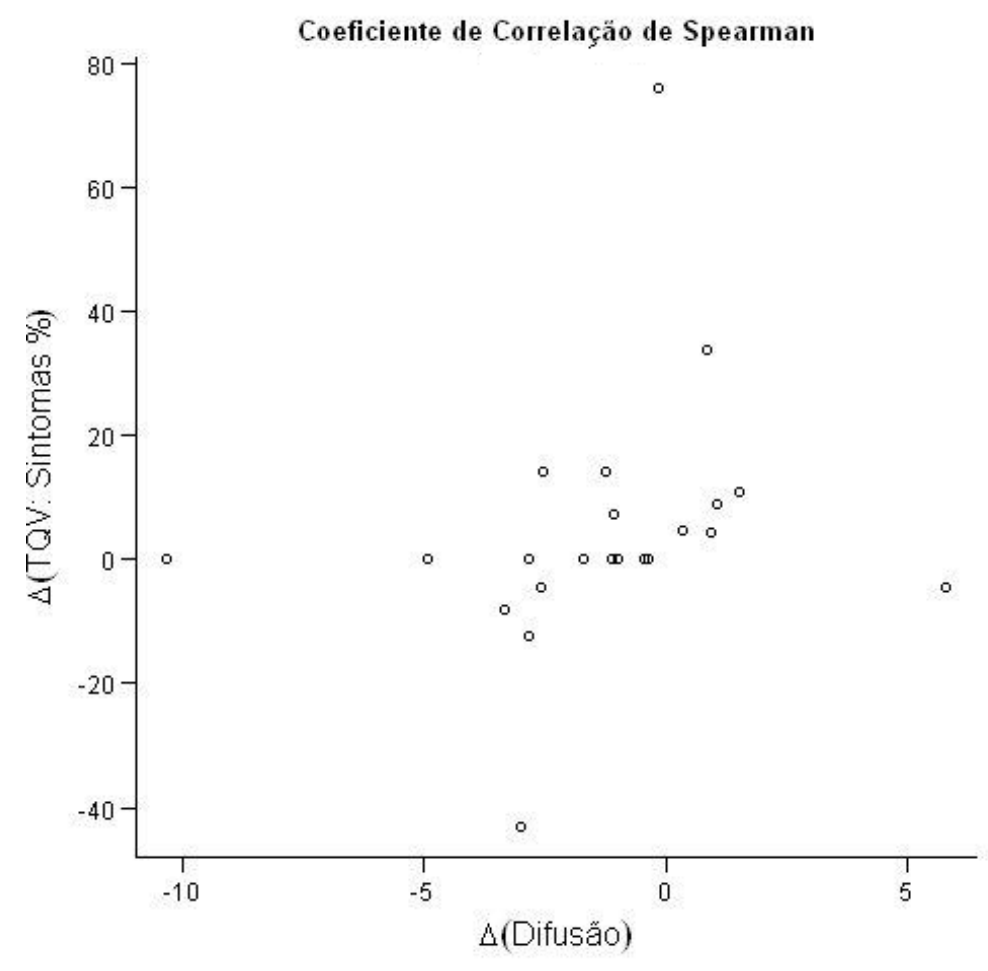

Figura 18 - Correlação das diferenças das fases pré-RT e pós-RT das medidas de Difusão $(\mathrm{ml} / \mathrm{min} / \mathrm{mmHg})$ e as diferenças das fases pré-RT e pós-RT do Domínio Sintoma do SGRQ, $(p=0,03$ e rho $=0,46)$.

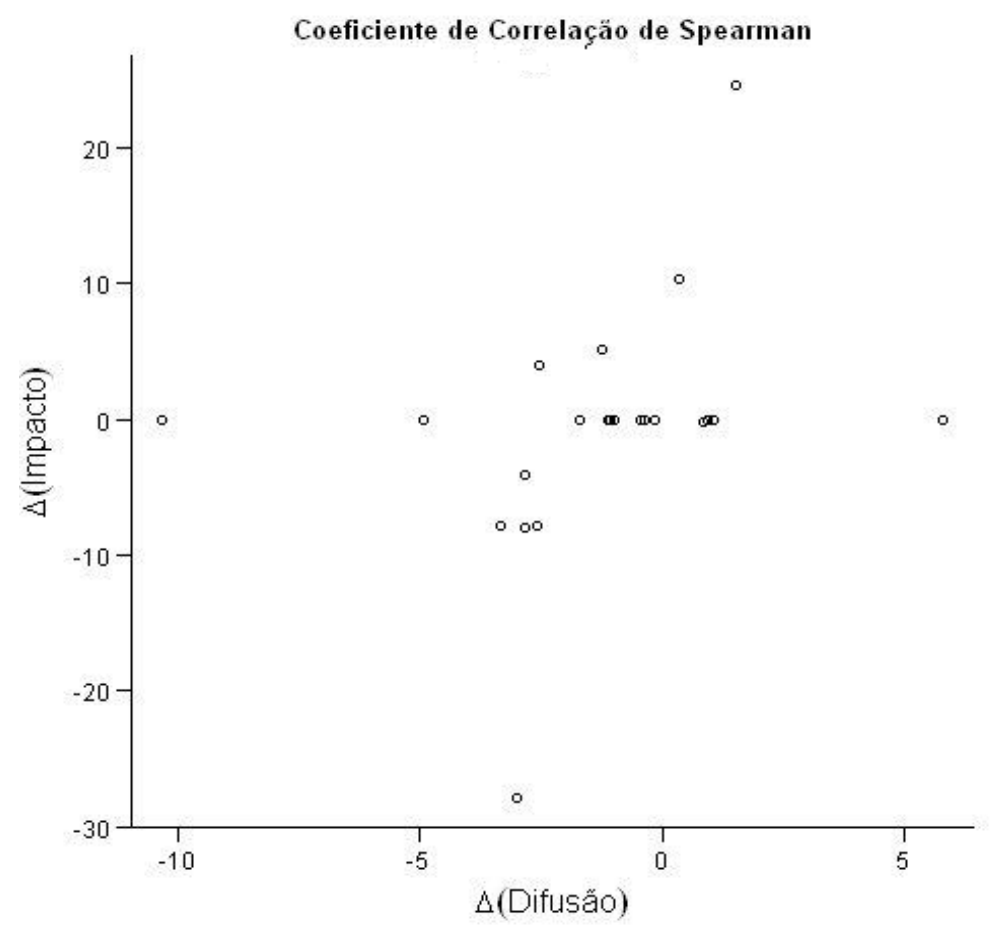

Figura 19 - Correlação das diferenças das fases pré-RT e pós-RT das medidas de Difusão $(\mathrm{ml} / \mathrm{min} / \mathrm{mmHg})$ e a diferenças das fases pré-RT e pós-RT do Domínio Impacto do SGRQ, $(p=0,03$ e rho $=0,45)$. 


\section{DISCUSSÃO}

Diversos autores, como Lind et al. (1998) consideraram consensual que a RT em câncer de mama estava associada às complicações pulmonares, porém a frequência e o grau desses efeitos colaterais são temas ainda em debate. A magnitude das alterações tomográficas, dos mediadores inflamatórios sistêmicos, dos questionários de QV e quais parâmetros das PFP são alterados é um assunto complexo, pois existem muitas variáveis que influenciam essas alterações, entre elas, o perfil das pacientes estudadas, hábitos como tabagismo, doenças pulmonares prévias, tratamento realizado; como qual quimioterápico utilizado e em qual momento foi realizado (THEUWS et al., 1999), técnica cirúrgica empregada (JAÉN et al., 2012), técnica de RT utilizada (VERBANCK et al., 2012) e campos irradiados (LIND et al., 1998). Tal diversidade de condições proporcionam o aparecimento de trabalhos que aparentemente apresentam resultados divergentes.

Jaén et al. (2012) relatam que até hoje não foi possível encontrar um modelo claramente preditivo para a redução observada de alguns parâmetros na PFP, mesmo levando-se em consideração uma longa série de critérios dosimétricos e clínicos. Tal consideração permite imaginar a complexidade fisiopatológica do processo em pauta, com envolvimento de muitos outros fatores, tais como diversos mediadores bioquímicos. Existe uma ampla área de pesquisa envolvendo todas essas variáveis que necessitam ser melhor exploradas para um melhor entendimento destas alterações induzidas em pacientes submetidas a tratamento radioterápico por câncer de mama. 
O presente estudo foi realizado na tentativa de enriquecer a compreensão das alterações pulmonares sofridas por pacientes submetidas a RT por câncer de mama; por isso, foram adotados rígidos critérios de inclusão e exclusão, a fim de evitar a inclusão de pacientes que já tivessem fatores de risco prévios para alterações pulmonares, situação indesejável considerando-se a complexidade do assunto.

A literatura relata que em algumas pacientes a radiação causa pneumonite actínica. Após a RT parece ocorrer uma sequência temporal e de progressão continua de eventos moleculares que resultam na lesão pulmonar induzida pela radiação. Porém, ainda é incerto se esta resposta é normal ou patológica. Uma hipótese, e mais aceita por diversos pesquisadores, é a de que a lesão pulmonar induzida pela radiação seja resultado de uma resposta de cicatrização anormal, seja pelo grau e/ou pela duração (ZHAO; ROBBINS, 2009; GRAVES et al., 2010).

A primeira fase da lesão pulmonar induzida pela radiação parece ser a ativação de neutrófilos que geram espécies reativas de oxigênio e / ou de nitrogênio, que podem induzir danos oxidativos no DNA resultando em morte celular (ISRAEL; PEEK, 2001). Outra característica da lesão pulmonar induzida pela radiação é a perda da função de barreira, devido à lise de células do epitélio ou endotélio. Estas lesões estimulam o recrutamento de uma variedade de células inflamatórias para iniciar os processos de reparação; e também reduz a densidade microvascular e perfusão pulmonar, promovendo hipóxia (FLECKENSTEIN; ZGONJANIN; CHEN, 2007). E essas células inflamatórias, por sua vez, secretam mais quimiocinas, citocinas e fatores de crescimento que ativam células de reparação tecidual (TROTT; HERRMANN; KASPER, 2004; RUBE; RODEMANN; RUBE, 2004; TSOUTSOU; 
KOUKOURAKIS, 2006). O processo de inflamação também controla a proliferação celular excessiva (WYNN, 2008).

Segundo Rube et al. (2004) existem duas ondas de expressão das citocinas na fase precoce da resposta à radiação: a onda inicial ocorre nas primeiras horas após a RT e que retorna aos níveis basais até aos dois dias subsequentes; a segunda onda ocorre de 8 até 16 semanas pós-RT. Essa segunda onda de aumento de citocinas correlaciona-se com a lesão pulmonar induzida pela radiação. Porém, deve-se considerar que estas observações foram feitas de avaliações realizadas em ratos. Após essa fase inicial há a fase tardia, fase de reparação, na qual pode ocorre a fibrose e que é observada entre 24 a 32 semanas após a RT. Uma discussão aprofundada sobre as alterações observadas na fase tardia foge do objetivo do presente estudo.

Diversas pacientes podem não apresentar nenhum sintoma clínico de lesão pulmonar induzida pela radiação; porém, a manifestação clinica mais comumente observada na lesão pulmonar induzida pela radiação é a dispnéia de intensidade leve à acentuada; a tosse é observada em $40 \%$ dos casos; febres baixas e transitórias ocorrem em menos de 10\%. Porém, em alguns casos graves as pacientes podem apresentar até insuficiência respiratória com hipoxemia grave levando à hipertensão pulmonar e cor pulmonale agudo (GRAVES et al., 2010).

Diversos estudos tentam entender os mecanismos envolvidos na lesão induzida pela RT (FLECKENSTEIN; ZGONJANIN; CHEN, 2007; ISRAEL; PEEK, 2001; RUBE et al., 2004). Os autores acreditam que células inflamatórias possam estar envolvidas neste processo, sendo que as citocinas mais estudadas são IL-1 IL-6 e TNF-a (CHEN et al., 2001, 2005; GEINITZ et al., 2001; RUBE et al., 2004, 
2008; ARPIN et al., 2005), por isso estes mediadores foram escolhidos para serem avaliados no presente estudo.

Porém, é importante ressaltar que as citocinas e fatores de crescimento têm uma ampla gama de atividades, estando presente em qualquer tipo de lesão tecidual (ROBBINS; COTRAN, 2007), e portanto, não são específicas para as lesões causadas pela radiação. As medições dos níveis de citocinas podem, eventualmente, serem úteis em predizer o risco de complicações induzidas pela RT (CHEN et al., 2001; 2005). No entanto, as citocinas também podem ser derivadas do tumor e assim confundirem os resultados quando se investiga um marcador para lesão induzida pela RT (TSOUTSOU; KOUKOURAKIS, 2006; RUBE, RODEMANN, RUBE, 2004; VUJASKOVIC; GROEN, 2000).

Diversos trabalhos descrevem as moléculas envolvidas na inflamação relacionada ao câncer; sendo que as principais citocinas inflamatórias envolvidas são a IL-1, IL-6, IL-23 e TNF-a (GRIVENNIKOV; KARIN, 2008; KARIN, 2006; LANGOWSKI et al., 2006; SZLOSAREK; BALKWILL, 2003; VORONOV et al., 2003; YU, KORTYLEWSKI; PARDOLL, 2007). Outros autores afirmam que há correlação positiva entre a capacidade invasiva das células malignas com a presença de citocinas inflamatórias, tais como TNF- $\alpha$, IL-1 $\beta$, IL-6 e TGF- $\beta 1$ (AUGUSTE et al., 2007; BALKWILL; MANTOVANI, 2001; BALKWIL; CHARLES; MANTOVANI, 2005; CALIGIURI; LOTZE, 2007; DRANOFF, 2004; MANTOVANI et al., 2008; RUBE et al., 2008).

As citocinas aparentemente desempenham um papel importante na promoção do crescimento de células tumorais, atenuando a apoptose, facilitando a invasão, a angiogênese e a metástase; o aumento da produção destas em tecidos 
de tumor, e que são introduzidas na circulação sanguínea, sugere a possibilidade de se utilizar os níveis plasmáticos destas citocinas como marcadores tumorais visando monitorizar o curso da doença. Diversos estudos fazem uso de medições regulares destas citocinas no plasma para monitorar os efeitos terapêuticos da RT (KONG et al., 1996, 1999).

O TNF-a é um importante mediador inflamatório (BEUTLER, 1999; HUSSAIN; HOFSETH; HARRIS, 2003). Porém, nos estudos de Balkwill (2002), Leek et al. (1998), Relf et al. (1997), Ryuto et al. (1996), Samaniego et al. (1997), Yoshida et al. (1997), foi observado que o TNF-a endógeno é cronicamente produzido no microambiente tumoral e aumenta o crescimento e invasão tumoral através da indução de outras citocinas / quimiocinas envolvidas na progressão do câncer, tal como a IL-6.

No presente trabalho, o GRT englobava aquelas que fizeram ou não a QT; por outro lado, na literatura existem evidências de que esta não apresenta influência significativa nos mediadores inflamatórios estudados (MAZUR et al., 2004; MENDONÇA, CUNHA, 2006). Para chegar a essas conclusões Mendonça e Cunha (2006), avaliaram os níveis séricos de óxido nítrico, TNF-a, IL-6, IL-8 e IL-10 em mulheres com câncer de mama durante o período de QT (5-fluoruracil adriamicina e ciclofosfamida) e não observaram alteração significante destes nos níveis séricos. Já no estudo de Mazur et al. (2004), que avaliaram mediadores inflamatórios sistêmicos em pacientes submetidas à QT em relação ao GC, não observaram alterações significativas nos níveis séricos de IL-6 e IL-10 induzidas por quimioterápico em relação ao $\mathrm{GC}$ no período da pesquisa que foi 1, 3, 6, 9, 12 meses após QT, mas 
observaram aumento na IL-2 e uma diminuição da TNF- $\alpha$ e IL-8 em relação ao GC controle.

No presente estudo foi observado que os valores basais de $\mathrm{IL}-1 \beta$ não eram estatisticamente diferentes do GC, grupo constituído de mulheres saudáveis, sem nenhum processo infeccioso vigente e da mesma faixa etária. $O$ valor basal foi baixo, média da fase pré-RT de foi $1,64 \mathrm{pg} / \mathrm{ml}$. Na fase pós-RT não foi observada nenhuma alteração significativa em relação à fase pré-RT, portanto, a concentração inicial e a variação deste parâmetro não podem ser consideradas índices preditivos de lesão induzida pela radiação; estes resultados são sinérgicos com aqueles observados por Geinitz et al. (2001) e Rube et al. (2008).

Em relação aos níveis basais de TNF-a, também eles não foram estatisticamente diferentes do GC. É importante destacar que o GRT apresentou uma tendência a ser maior que no GC, mas a diferença não foi estatisticamente significante $(p=0,06)$, sendo o valor médio basal de $25,55 \mathrm{pg} / \mathrm{ml}$. Na fase pós-RT não foi observada nenhuma alteração significativa em relação à fase pré-RT $(p=0,16)$, ou seja, a variação destes não pode ser considerada índices preditivos de lesão induzida pela radiação; estes resultados são sinérgicos com dados observados por Geinitz et al. (2001) e Rube et al. (2008).

Bates e Mercurio (2003) sugeriram que o TNF- $\alpha$ também é um potente estimulador da transição epitelial-mesenquimal do câncer de mama. Apesar de discreta, a tendência de diminuição do TNF- $\alpha$ na fase após a RT observada no presente estudo, média pré-RT 25,55 pg/ml e da fase após a RT 12,7 pg/ml, talvez possa ser interpretada como um sinal de que as células do câncer de mama estejam fazendo menor transcrição epitelial-mesenquimal, ou seja, controle tumoral. Esse 
raciocínio vem de encontro com outra observação realizada no presente estudo, a tendência de maior nível do TNF- $\alpha$ observado na fase pré-RT no GRT $(p=0,06)$.

Também a IL-6 do GRT apresentou na fase pré-RT maior nível que o GC, sendo essa diferença estatisticamente significante $(p<0,01)$, sugerindo que níveis elevados da IL-6 pré-RT parecem ser um bom índice preditivo para repercussões pulmonares a serem induzidas pela radiação, um vez que este grupo também apresentou alterações mais frequentes após a RT na TCAR, na DLCO e no FEF50\%. Em uma análise mais detalhada observa-se que $77 \%$ do GRT (17 pacientes) apresentaram aumento da IL-6 na fase pré-RT. Como descrito nos resultados, 60,87\% (14 pacientes) do GRT apresentaram alterações tomográficas, destas pacientes 78,57\% (11 pacientes) também apresentaram IL-6 aumentada, ou seja, maior que zero na avaliação inicial. Já a DLCO diminuiu em 65,2\% das pacientes avaliáveis (15 voluntárias) e destas, 53,33\% (8 pacientes) apresentavam aumento IL-6 na avaliação pré-RT. Em relação ao FEF50\%, 56,52\% das pacientes avaliáveis (13 voluntárias) apresentaram redução entre as avaliações e destas 77\% (10 pacientes) também apresentavam aumento IL-6 na avaliação pré-RT, portanto, observa-se que as pacientes com alterações pulmonares apresentavam em sua grande maioria aumento IL-6 na fase pré-RT. Esse comportamento da IL-6 também foi observado por Chen et al. (2001), que apesar heterogeneidade da população estudada por estes autores; diversos tipos de câncer, porém todas tiveram o toráx irradiado, ainda assim, apresentaram resultados semelhantes aos do presente estudo. Em 2005 estes mesmos autores observaram que as pacientes que apresentavam maiores níveis plasmáticos de IL-1a e IL-6, antes e durante a primeira 
semana da RT, tiveram maior incidência de alterações pulmonares induzidas pela RT (CHEN et al., 2005).

Das 17 pacientes que apresentaram níveis de IL-6 maior que zero na fase pré-RT, 14 pacientes (83,35\%) apresentaram diminuição na avaliação pós-RT. Destas pacientes que apresentaram esse comportamento da IL-6, 64,28\% (9 pacientes) apresentaram diminuição da DLCO; 64,28\% (9 pacientes) apresentaram diminuição do FEF50\%; 64,28\% (9 pacientes) apresentaram alterações tomográficas após a RT. Se ocorreu queda da IL-6 após a RT, para pouco razoável considerar que a concentração da IL-6 durante as fases das avaliações provocou / influenciou a diminuição da DLCO, FEF50\% ou provocou alterações pulmonares observadas na TCAR.

Entretanto, esse comportamento observado nos níveis da IL-6 neste e em outros estudos, aparentemente deixou de ser observado por outros autores (ARPIN et al., 2005). Porém, quando o estudo destes autores é avaliado com mais detalhes, observa-se que a população da pesquisa foi muito heterogênea: diversos tipos de câncer, com diferentes áreas do corpo irradiada (tórax ou qualquer outra parte), homens e mulheres, pacientes que realizaram cirurgia prévia a RT e os que não a realizaram, pacientes fumantes e não fumantes, condições dificultam a comparação com os resultados do presente estudo.

Já Geinitz et al. (2001) avaliaram uma população mais próxima à da presente pesquisa e também consideraram que as alterações nos níveis de IL-1 $\beta$, IL-6 e TNFa durante a RT e até mesmo 2 meses após seu término, não eram bons índices preditivos de alterações pulmonares induzidas pela RT. Assim como Rube et al. (2008), também consideraram que as alterações dos níveis do TNF- $\alpha$, IL-1 $1 \beta$, IL-6 e 
TGF-ß1 durante e após a RT não eram bons índices preditivos de risco para alterações pulmonares, entretanto é necessário considerar que a população estudada por Rube et al. (2008) foi de pacientes com câncer de pulmão, condição essa ainda imponderável como influencia para divergência de resultados; após analisarem a resposta individual dos tumores estes autores aventaram a hipótese de que o tumor era a principal fonte produtora de interleucinas circulantes em pacientes que fizeram RT. Usar a medição das citocinas no plasma para monitorar o efeito terapêutico da RT é sugerida fortemente por diversos autores desde o século XX (KONG et al., 1996, 1999).

Assim sendo, é plausível presumir que as diferenças pré-RT e pós-RT nas concentrações de TNF- $\alpha$, IL-1 $1 \beta$ e IL-6 não podem ser consideradas bons índices preditivos de lesão pulmonar induzida pela radiação, resultados coincidentes com as observações de outros autores (DE JAEGER et al., 2004; RUBE et al., 2008; NOVAKOVA-JIRESOVA et al., 2004). Porém, nível elevado pré-RT da IL-6 parece ser um bom índice preditivo de alterações pulmonares induzidas pela radiação de acordo com os resultados de Chen et al. $(2001 ; 2005)$ e aos observados no presente estudo.

A grande importância de ser capaz de selecionar as pacientes com risco de lesão induzida pela RT seria a entrega com maior segurança de doses mais elevadas de radiação em pacientes com baixo risco, o que acarretaria para melhor controle local e a sobrevida. Na tentativa de elucidar o mecanismo de ação da lesão induzida pela RT, diversos autores estudaram o comportamento das citocinas circulantes, e porém ainda o assunto ainda permanece controverso, estudos 
adicionais ainda são necessários para esclarecê-los (ANSCHER et al., 1997, 1998, 2001, 2003; ARPIN et al., 2005; CHEN et al., 2001, 2005; FU et al., 2001).

Mesmo não estando claro o quanto as citocinas estão envolvidas ou não no mecanismo de ação da lesão induzida pela RT, suas funções continuam sendo exploradas por diversos autores, muitos dos quais continuam a relacioná-las mais ao câncer que às lesões induzidas pela RT (AUGUSTE et al., 2007; BALKWILL, MANTOVANI, 2001; BALKWILL, CHARLES, MANTOVANI, 2005; CALIGIURI; LOTZE, 2007; DRANOFF, 2004; KONG et al., 1996, 1999; MANTOVANI et al. 2008). E já existem diversos estudos de drogas tentando controlar as citocinas inflamatórias do câncer, na tentativa de inibir a proliferação celular cancerígena. Ensaios clínicos com antagonistas TNF- $\alpha$ têm demonstrado uma estabilização da doença (BROWN et al., 2008; HARRISON et al., 2007; MADHUSUDAN et al., 2005).

Ferreira (2008) demonstrou uma correlação positiva entre aumento das citocinas pró-inflamatórias IL-6, IL-8, IL-1 $\beta$ e TNF- $\alpha$ e o aumento da dor e com piora na QV. Os resultados deste estudo sugerem que tratamento com antagonistas / inibidores das citocinas IL-6, IL-8, IL-1 $1 \beta$ e TNF- $\alpha$ pode contribuir para o alívio da dor em pacientes com câncer.

O próprio diagnóstico de câncer já altera a QV, pois os pacientes passam a temer pela vida e pelos efeitos colaterais de seus tratamentos (BJÖRNEKLETT et al., 2012; SVENSK et al., 2009). A QV destas pacientes tem sido muito valorizada, principalmente após 1985, como reflexo da declaração do Food and Drug Admininstration (FDA) dos Estados Unidos de que este seria um dos critérios para a aprovação de novas drogas anticâncer (JOHNSON; TEMPLE, 1985). Tornando-se um aspecto ainda mais importante desde 1999, quando Velikova; Stark; Selby 
(1999), propuseram que este aspecto seja considerado nos programas de avaliação para a alocação de recursos.

O câncer de mama tem uma particularidade, ele é muito prejudicial à imagem corporal e à autoestima da mulher, além de influenciar fortemente e de forma negativa a sua vida sexual (CARPENTER et al., 2004; CULOS-REED et al., 2006; SAVARD et al., 2004). Tais estímulos proporcionaram o aparecimento de inúmeros estudos que avaliaram a QV destas mulheres e a influência dos diferentes tratamentos para câncer de mama sobre a QV das pacientes a eles submetidas (ARNDT et al., 2008; MUNSHI et al., 2010; PENTTINEN et al., 2011; REIDUNSDATTER et al., 2013).

Diversos estudos demonstraram que a QV apresenta piora durante e após os tratamentos para o câncer de mama e esta piora pode persistir por muitos anos (ARNDT et al., 2008) e está associada ao desempenho físico, nível de atividade da paciente e fadiga (PENTTINEN et al., 2011; SCHMIDT et al., 2012).

O presente trabalho avaliou influência da RT no pulmão e suas repercussões na QV, aplicando o questionário do SGRQ antes do início da RT e após três meses do término da mesma. Existem na literatura diversos estudos que relatam que a QT prejudica de forma importante a QV destas pacientes, principalmente, em aspectos relacionados à atividade física, devido à fadiga (DAGNELIE et al., 2007; NOAL et al., 2011; SCHMIDT et al., 2012; STONE et al., 2000). O presente estudo analisou separadamente o grupo de pacientes que fizeram QT temporalmente dissociada da RT e comparou com o grupo que não a fizeram; foi observado que as variáveis de ambos os grupos comportaram-se de forma semelhante (Tabela 7), portanto, a QT não representou piora na QV quando avaliado pela SGRQ, questionário voltado para 
exploração do sistema respiratório e suas consequências. Estes resultados diferem daqueles encontrados por Dagnelie et al. (2007); Noal et al. (2011); Schmidt et al. (2012); Stone et al. (2000). Esta aparente divergência de resultados pode estar vinculada à utilização de questionários de QV genéricos, pois os outros autores queriam avaliar a QV holística, já o presente estudo quis avaliar a influência pulmonar sobre a QV e por isso utilizou um instrumento específico.

A análise dos resultados de todas as pacientes avaliadas no presente estudo evidenciou que o único domínio alterado foi o Domínio Atividade; importante ressaltar que o mesmo já se encontrava alterado na fase pré-RT, pontuação média de $22,37 \%$ e manteve-se alterado na fase após a RT, com pontuação média de 20,26\%. Por definição, segundo os autores Sousa; Jardim; Jones (2000), valores acima de 10 refletem alteração na QV do domínio e alterações iguais ou superiores a 4 após uma intervenção indicam uma mudança significativa na QV das pacientes. Após a RT não houve alteração significativa, pois a diferença da média pós-RT menos pré-RT no Domínio Atividade foi de $-2,11$; ou seja, houve até melhora, pois diminuiu a porcentagem da média após a RT, mas esta melhora não foi significativa, pois a alteração foi menor que 4. Os demais domínios avaliados não apresentaram alteração, pois o Domínio Sintomas apresentou média pré-RT e pós-RT de 3,64 e 7,52, o Domínio Impactos apresentou 4,21 e 3,71 e no total de pontos do SGRQ foi 9,65 e 9,35 e não houve alteração significativa após a RT, pois a diferença após a RT menos pré-RT foi de 3,89 no Domínio Sintomas; de -0,5 no Domínio Impacto e a Total foi $-0,29$.

O Domínio Atividade do SGRQ avalia as condições para desempenho das atividades físicas destas pacientes, que ficaram muito reduzidas devido à fadiga 
apresentada após iniciarem o tratamento oncológico. Os resultados do presente estudo veem de encontro com os de Penttinen et al. (2011) e Schmidt et al. (2012), que também observaram que há uma piora da QV das pacientes submetidas a tratamentos para câncer de mama, destacando a piora no desempenho físico.

Noal et al. (2011) observaram que há uma piora importante em relação à intensidade da fadiga após a RT, resultados divergentes aos observados no presente estudo no qual nenhum dos domínios ou o total de pontos do SGRQ foram alterados pela RT. Essa diferença pode ser justificada, pois o SGRQ não é específico para avaliar a fadiga. Diversos autores destacam que as comorbidades são determinantes mais importantes para o nível de fadiga que a própria RT realizada para o tratamento do câncer (REIDUNSDATTER et al., 2013). Karakoyun-Celik et al. (2010), sugeriram que a piora na QV após a RT estava correlacionada com a incidência de linfedema em membro superior.

A ausência de piora na QV após a RT observada no presente estudo também foi observada na estudo de Munshi et al. (2010); estes autores compararam as pacientes que fizeram cirurgia conservadora e as que fizeram mastectomia e observaram através dos questionários da EORTC, os QLQ-C30 (AARONSON et al., 1993) e o QLQ-BR23 (SPRANGERS et al. 1996) que na QV global não houve diferença entre os grupos e nem piora durante as avaliações que foram realizadas pré-RT, durante e após o término da mesma, o que vem de encontro com os resultados obtidos no presente trabalho. Comparando os grupos de pacientes que foram submetidas à mastectomia, 6 pacientes, com as que foram submetidas à cirurgia conservadora, as outras 18 pacientes do presente estudo, observa-se que não houve alteração na QV após a RT, em nenhum dos domínios e em nenhum dos 
grupos. O grupo das pacientes que foram submetidas à mastectomia apresentaram diferenças das médias da pós-RT menos a média da pré-RT nos Domínios Sintomas de -2,03, no Domínio Atividade foi 2,82, no Domínio Impacto foi -0,7 e o Total do SGRQ foi 0,14 ; já no grupo de pacientes submetidas a cirurgia conservadora no Domínio Sintomas foi 2,49, Domínio Atividade foi $-3,75$ e no Domínio Impacto foi 0,44 e o Total do SGRQ foi -1,06. Portanto, não houve alteração significativa após a $R T$, pois a diferença entre as fases das avaliações não foram maiores que 4 como definido por Sousa; Jardim; Jones (2000).

A afirmação do presente estudo que a RT não piora a QV após 3 meses do término da mesma vem de encontro com os resultados observados por Arraras et al. (2008), que só observaram alteração da QV imediatamente após o término da RT e que após 6 semanas não havia mais essa alteração e também com os resultados de Versmessen et al. (2012), no qual compararam RT convencional com campos de radiação tangenciais e a tomoterapia hipofracionada e observaram a piora significativa da QV e aumento da fadiga em ambos os grupos na avaliação no dia que terminou a RT, apresentando recuperação espontânea nas demais avaliações, ou seja, na avaliação de 3 meses e 1, 2 e 3 anos pós-RT. Diversos autores também encontraram piora na QV em avaliações imediatamente após o término da RT e com melhora espontânea ao logo do tempo (GRAYDON, 1994; LEE et al., 2008; WENGSTROM et al., 2000; WHELAN et al., 2000).

A fadiga é considerada por diversos autores como um dos fatores que causam a diminuição da QV (VERSMESSEN et al., 2012). Em decorrência desta observação busca-se o desenvolvimento de exercícios fisicos para ajudar as pacientes a aumentar a tolerância à fadiga durante a RT; os resultados sugerem que 
as pacientes que se exercitaram durante a RT tiveram melhora no desempenho físico e menos fadiga, ansiedade e insônia do que as pacientes que não se exercitaram (DROUIN et al., 2005; DUIJTS et al., 2011; WALKER et al., 1996). Estes benenfícios também foram observados quando as pacientes realizaram ioga (BANERJEE et al., 2007; CHANDWANI et al., 2010, VADIRAJA et al., 2009), ou psicoterapia comportamental (DUIJTS et al., 2011; MATTHEW et al. 2013; HOFFMAN et al., 2012).

As alterações pulmonares induzidas pela radiação ainda não são claras, estímulo bastante suficiente para o desenvolvimento de diversos estudos na tentativa de melhor entendê-las, parâmetros oriundos da função pulmonar podem ser promissores índices preditivos destas alterações (MARKS et al., 2000).

No presente estudo foi realizada avaliação antes de iniciar a RT e três meses após o término da mesma, pois é neste período onde se detectam os maiores efeitos precoces da radiação sobre a função pulmonar, segundo diversos trabalhos na literatura (KRENGLI et al., 2008; LUND et al., 1991; OOl et al., 2000; 2001). No presente estudo não se observou alterações significantes na CVF, VEF1, na relação VEF1/CVF, FEF75\%, CPT, CRF, CV e VR; só ocorreram alterações significativas nas medidas do FEF50\% e da DLCO. A diminuição da DLCO também foi observada por Theuws et al. (1998), mas estes autores também encontraram uma diminuição significativa da CV, VEF1, VR; o possível motivo para essa aparente diferença seja que estes autores não tiveram o cuidado de não incluírem pacientes com fatores de risco para alteração pulmonar prévia, como as tabagistas. Vários autores demonstraram as alterações anatômicas pulmonares relacionadas ao tabagismo, destacando-se as inflamatórias (BEHR; NOWAK, 2002; KUSCHNER et al., 1996). Do 
ponto de vista funcional, reforçam estes relatos o trabalho desenvolvido por Theuws et al. (1998), que demonstrou diminuição mais evidente destes parâmetros quando as pacientes eram tabagistas. Devido aos inúmeros estudos na literatura que demonstraram as alterações pulmonares causadas pelo tabagismo, o presente estudo tomou o cuidado de não incluir fumantes uma vez que o objetivo era avaliar apenas os efeitos da RT (HANSEN; SUN; WASSERMAN, 2007).

$\mathrm{Na}$ PFP identificam-se algumas pacientes que se destacaram das demais como a paciente número 21 , que apresentou valores maiores que o GRT em diversos parâmetros, como apresentado nos resultados. Porém é importante destacar que os valores apresentados por essa paciente são reais, pois a soma de CV e VR que é a CPT na fase pré-RT foi de 4,77 litros e 1,62 litros, respectivamente, que resultou 6,39 litros, que foi a CPT desta paciente nesta fase de avaliação; e na fase após a RT apresentou CV de 4,55 litros e no VR de 1,82 litros que somados resultam em 6,37 litros, que foi o valor da CPT na fase pós-RT, valores que são muito próximos. Fatores que justificam que esta paciente tenha apresentado maiores valores de alguns parâmetros em relação ao restante do GRT é a estatura, pois esta paciente é mais alta do que as demais, a média de altura do GRT foi de 157 centímetros e a paciente número 21 tem 180 centímetros de altura, e a idade, pois a paciente tinha 43 anos de idade e a média do GRT foi 54 anos. Como relatado no artigo "Força-tarefa da ATS / ERS para padronização dos testes de função pulmonar" editado por Brusasco; Crapo, Viegi, Padronização de Espirometria publicado na revista Eur Respir J, por Miller et al. (2005), a altura e a idade influenciam fortemente os parâmetros funcionais do pulmão. 
Outra paciente a destacar foi a número 13, com 43 anos de idade, que apresentou valores do VEF1 reduzidos nas fases pré $(75 \%)$ e pós-RT $(78 \%$ do predito). Como as CVF permaneceram dentro da faixa de normalidade, aquelas reduções influenciaram os valores das relações VEF1/CVF pré $(65 \%)$ e pós (63\%) ambos os valores abaixo do predito, compatíveis com a presença de distúrbio ventilatório obstrutivo. Cabe salientar que esta alteração funcional esteve associada a alterações tomográficas dos pulmões, imagens estas compatíveis com a presença de bronquiectasia, estas já presentes na fase pré-RT, apesar de na época da avaliação a mesma não ter este diagnóstico clínico. Cogitou-se excluir esta paciente por apresentar alteração pulmonar prévia, mesmo sem repercussões clinicas que a paciente ou os médicos da mesma tivessem evidenciado / identificado, porém, optou-se pela não exclusão, escudado na observação de que comportou-se funcionalmente como o restante do GRT, ou seja, alterações pouco relevantes com a RT. Chama atenção o fato que mesmo os pulmões apresentando alterações funcionais e radiológicas prévias, a RT não provocou alterações mais acentuada nesta paciente.

Erven et al. (2012), encontraram significativa piora na PFP nos seguintes parâmetros: CV, CVF, VEF1, CPT e DLCO, na avaliação após três meses em relação à fase pré-RT. Estes autores não avaliam o FEF50\% e FEF75\%. A aparente divergência entre os resultados observados por Erven et al. (2012) e o presente trabalho justifica-se, pois estes autores só não incluíram no estudo as pacientes que tiveram câncer anterior ou doença respiratória crônica grave, porém incluíram pacientes tabagistas e ex-tabagistas e outro fator que pode ter influenciado fortemente para aparecimento de alterações em todos os parâmetros acima citados 
foi o fato que $25 \%$ da população por ele estudada realizou QT concomitante a RT, assim sendo não é possível concluir que estas alterações foram decorrentes da RT. Essa consideração vem de encontro com os achados de Theuws et al. (1999) que observaram em seu estudo que o momento de aplicação da QT influi significantemente na alteração dos valores dos parâmetros da PFP; se realizada antes RT podem reduzir os valores da linha de base, enquanto que a QT após ou durante a RT é responsável por uma redução extra na avaliação realizada três meses após o tratamento.

Nos estudos que tiveram o cuidado de não incluir pacientes com histórico de tabagismo ou de doença respiratória, como o de Miranda (2009), encontraram diminuição da DLCO, FEF50\% e FE75\%, na avaliação após três meses do término da RT e não encontraram alterações nos demais parâmetros avaliados, CVF, VEF1, VEF1 / CVF, CPT, CRF, CV e VR. O presente trabalho também não observou alteração nestes paramentos e nem no FEF75\% e observou diminuição na DLCO e no FEF50\%. Importante destacar que em Miranda (2009) as pacientes realizaram RT tradicional, que irradia uma maior área pulmonar que a RT conformacional; esta é capaz de fazer melhor delineamento dos contornos da área alvo, escolher ângulos de feixe, e determinar distribuições de dose com maior precisão do que a RT tradicional (BRADLEY et al., 2002), portanto, produzindo menos efeitos colaterais e de menor intensidade (BONAN et al., 2005), tanto que em Miranda (2009) as pacientes apresentaram uma piora significativa na QV e no presente trabalho não houve alteração na QV após a RT, portanto, pode-se concluir que houve menor repercussão pulmonar devido a RT. Tais observações permitiram inferir que 
aparentemente ocorreram menores repercussões funcionais nos pulmões com a RT conformacional, observação coincidente com a de Bonan et al. (2005).

É importante lembrar que FEF25-75\% mede o fluxo expiratório forçado médio na faixa intermediária da CVF, isto é, entre 25 e 75\% da curva de CVF (TERRAFILHO, 1998), que inclui o fluxo de vias aéreas de médio e pequeno calibre (DIRKSEN; GROTH, 1986) e é sensível para detecção de obstrução (MCFADDEN; LINDEN, 1972; VALENÇA, MORAES, 1976). A redução do FEF25-75\% correlacionase bem com o FEF50\% e em distúrbios obstrutivos a alteração destes é uma observação frequente e precoce em muitas doenças obstrutivas (TERRA-FILHO, 1998). Em 2003, Bar-Yishay; Amirav; Goldberg (2003), realizaram um estudo para investigar se o FEF50\% e o FEF25-75\% tinham correlação ou se a diferença entre ambos refletia o grau de obstrução ao fluxo aéreo. Estes autores concluíram que os dois índices, apesar de não serem idênticos, FEF50\% apresenta valor maior que FEF25-75\%, são altamente correlacionados e a razão entre eles é razoavelmente constante; dessa forma, a prática de se descrever os dois em uma espirometria é desnecessária. Recomendou-se, ainda nesse estudo, que se prefira o FEF50\%. Uma característica importante é que o FEF50\% pode ser anormal isoladamente nas fases iniciais de distúrbios obstrutivos (BECKLAKE, PERMUTT, 1979; FERRIS, 1978).

A explicação para que o FEF50\% apresente-se com valor anormal isoladamente nas fases iniciais de distúrbios obstrutivos é que a curva com obstrução das vias aéreas é côncava (WEST, 2000), ou seja, é esta a diferença para a curva normal que é maior no meio que nas extremidades; portanto, é possível inferir que a redução isolada do FEF50\% represente um sinal de obstrução precoce e leve das vias aéreas de médios e pequenos calibres. Possivelmente esse 
mecanismo foi o que ocorreu no presente trabalho. Uma vez que observou-se uma diminuição no FEF50\%, sem alteração no valor de FEF75\%, que leva a acreditar que seja uma obstrução inicial e leve das vias aéreas. Corrobora para essa conclusão, o fato desta alteração não ter prejudicado a QV destas pacientes.

Outro parâmetro alterado no presente trabalho foi a DLCO, sendo importante destacar a redução deste parâmetro era o achado mais consensual após a RT tradicional, prevalente pela extensão do envolvimento da área periférica à área irradiada (BONAN et al., 2005; BRADLEY et al., 2002), extensão está marcada pela presença de infiltrado mais intenso e grosseiro, frequentemente visualizado no exame radiológico (VERELLEN; DE RIDDER; STORME, 2008). Com a radioterapia conformacional, a extensão da área comprometida é aparentemente menor e os infiltrados mais delicados e menos intensos como observou-se em $60,87 \%$ das pacientes que participaram do estudo e que apresentaram exames de TCAR passívies de avaliação, ou seja, 23 pacientes.

A DLCO em condições normais depende diretamente de área ventilatória e simultaneamente perfundida, considerando-se normal o comportamento da hemoglobina. Neste caso, a constatação de redução no valor da DLCO comporta algumas considerações envolvendo os fatores que influenciam o transporte dos gases através da membrana alvéolo-capilar:

1. É possível que as repercussões da RT conformacional, comprometam áreas mais extensas dos pulmões do que aquelas reveladas pela TCAR do tórax. A alteração funcional observada na espirometria (FEF50\%) sugere envolvimento difuso das vias aéreas de médios e pequenos calibres (WEST, 2000), uma vez que seu 
valor foi significantemente reduzido pela RT. Apenas se ocorrer bloqueio da ventilação alveolar em áreas mais extensas dos pulmões ocorreria queda da DLCO. Podemos considerar essa hipótese fundamentada em premissas apenas teóricas uma vez que a hipoventilação pulmonar observada em portadores de bronquite crônica e asma brônquica não está frequentemente associada à queda na DLCO, a não ser quando associada a outras alterações no parênquima (TERRA-FILHO, 1998).

2. A presença simultânea de obstrução das vias aéreas com áreas dispersas de atelectasia pode levar à redução significativa da ventilação alveolar com reflexos sobre a DLCO (TERRA-FILHO, 1998). Neste estudo demonstrou-se obstrução das vias aéreas associada à descrição na TCAR de discretas áreas de atelectasias. Se a hipótese for consistente, neste caso a lesão dominante responsável pela redução da DLCO seria o decréscimo efetivo da área disponível para troca gasosa.

3. Alterações nas caraterísticas físicas da membrana alvéolo-capilar, como presença de líquido (edema), fibrina, inflamação podem alterar os coeficientes de solubilidade e de difusão dos gases, comprometendo a sua migração pela membrana. Ademais, os alvéolos também podem ser invadidos pelo exsudato, aumentando a distância para difusão (TERRA-FILHO, 1998).

4. Condições clínicas que reduzam ou afetem o volume de sangue ou o leito capilar pulmonar como as micro tromboses, distorções / retrações, ou estiramento dos vasos que comprometam o trânsito das hemácias, mesmo com a hemoglobina normal, pode ocorrer queda da DLCO (TERRA-FILHO, 1998). 
Diversos estímulos, principalmente os lesivos, podem permitir que algum fator ou fatores presentes no plasma penetrem e se acumulem no subendotélio vascular, causando alterações estruturais e funcionais deste endotélio por alterar alguns componentes da matriz extracelular; além de causar aumento dos fatores de crescimento e outras moléculas sinalizadoras na gênese do remodelamento vascular pulmonar (RABINOVITCH, 1998), causando espessamento vascular pulmonar que aumenta a distância para a DLCO, a RT pode ser este estímulo.

Pelos relatos radiológicos e histopatológicos disponíveis na literatura (ARPIN et al., 2005; KRENGLI et al., 2008) é presumível que estas alterações estejam presentes em maior ou menor extensão em pulmões de pacientes submetidas à RT, mesmo a conformacional.

A análise destas considerações permite sugerir que mesmo não sendo extensas na RT conformacional, é provável que para a redução observada na DLCO concorram devido a uma combinação destes fatores daí, ser este um achado frequente nesta condição clínica.

Este possível edema / inflamação ocorrendo em níveis periféricos das vias aéreas e na membrana-alvéolo-capilar também podem concorrer para a presença das alterações tomográficas observadas em 60,87\% das pacientes estudadas, porém alterações tomográficas observadas em 60,87\% para causar as alterações da TCAR, uma vez que não houve clara associação entre alterações tomográficas pulmonares e a DLCO. Mesmas considerações são pertinentes para a correlação entre a redução do FEF50\% e as alterações na TCAR. Esta conclusão impõe-se, quando analisadas as 22 pacientes, das quais todas as variáveis estão disponíveis: 14 pacientes $(63,63 \%)$ apresentaram alteração tomográfica na fase após a $R T$, sete 
destas pacientes (50\%) não alteraram a DLCO em valores que superassem 10\% em relação à fase pré-RT, somente uma paciente $(7,14 \%)$ apresentou aumento da DLCO e as outras seis $(42,85 \%)$ apresentaram diminuição da DLCO. Das oito pacientes que não apresentaram alterações na TCAR, seis destas pacientes (75\%) apresentaram diminuição significativa na DLCO e as outras duas pacientes (25\%) não apresentaram alterações na DLCO.

Quando o mesmo procedimento foi aplicado para comparar alterações tomográficas com as alterações no FEF50\%, também não observou-se correlação clara entre elas; das 14 pacientes que apresentaram alteração na TCAR, metade delas não apresentaram alterações importantes no valor do FEF50\% (superior a $10 \%$ da linha de base) e as outras sete pacientes apresentaram diminuição do FEF50\% maior que $10 \%$ em relação à fase pré-RT. Por outro lado, nas oito pacientes que não apresentaram alterações na TCAR, duas destas pacientes (25\%) tiveram diminuição da FEF50\%, três (37,50\%) tiveram aumento e as outras três pacientes $(37,50 \%)$ não alteraram mais que $10 \%$ em relação à fase pré-RT. Resultados semelhantes foram observados por Marks et al. (2000), em estudo envolvendo 175 pacientes, da mesma forma, também não observaram associação entre alterações na TCAR com as alterações nos parâmetros da PFP.

Para tornar a situação ainda mais complexa, outras observações discordantes ocorreram, apesar da maioria das pacientes terem apresentado alterações tomográficas, essas alterações não estão associadas a significativas alterações na QV destas pacientes. Senão, vejamos, das 23 pacientes que realizaram questionário de QV e TCAR em ambas as fases do estudo 14 pacientes apresentaram TCAR alterada na fase pós-RT, cinco destas pacientes não alteraram a QV $(21,74 \%$ das 
pacientes avaliáveis), quatro pioraram a QV (17,39\%) e as outras cinco pacientes (21,74\%) apresentaram melhora da QV na fase após a RT; já das nove pacientes que não tiveram alteração da TCAR após a RT, duas (8,69\%) apresentaram piora, uma $(4,35 \%)$ melhorou e as outras seis pacientes $(26,09 \%)$ não apresentaram alteração da QV, ou seja, os dados são dispersos e aleatórios não apresentando tendência para nenhum padrão de comportamento. Há de considerar-se que esta constatação ocorreu mesmo utilizando-se o SGRQ, que é um questionário específico que avalia as repercussões das alterações pulmonares na QV. Achados desta natureza permitem sugerir que as alterações estruturais / funcionais do pulmão provocadas pela RT embora identificáveis e ou mensuráveis devam ter sido de pequena monta frente a grande reserva funcional do pulmão, insuficientes para influenciar a QV da maioria da pacientes.

Outra evidência indireta que reforçaria as considerações acima foi fornecida pelas imagens tomográficas. As medidas dos volumes pulmonares realizados através das TCAR não apresentaram alterações após a RT $(p=0,99)$ quando analisados todos os dados da TCAR disponíveis, ou seja, não incluindas as pacientes número 6 , por técnica inadequada para leitura volumétrica, e a paciente número 7, por perda da imagem tomográfica. Essa não alteração do volume pulmonar pré-RT e pós-RT também foi observada na análise dos lados irradiados e não irradiados $(p=0,13$ e $p=0,65)$, respectivamente. 


\section{CONCLUSÕES}

Os resultados observados no presente trabalho sugerem que a RT:

- Causou obstrução inicial leve de médias e pequenas vias aéreas constatada pela redução significativa do fluxo expiratório a $50 \%$ da capacidade vital forçada.

- A difusão foi a alteração mais evidente e parece ser o índice que melhor reflete as alterações pulmonares que afetam essas pacientes. Diante das discretas alterações tomográficas e funcionais observadas após a RT, é provável que para a redução observada na difusão concorram uma combinação de fatores ocorrendo ao nível da membrana alvéolo-capilar.

- O comportamento das interleucinas, IL-1 $1 \beta$, IL-6 e TNF- $\alpha$ durante as avaliações não sugerem a presença de significativo processo inflamatório pulmonar provocado pela radioterapia.

- A tomografia computadorizada de alta resolução alterou-se na maioria das pacientes $(60,87 \%)$ após a radioterapia, entretanto, as alterações não apresentaram clara correlação com a piora na qualidade de vida, com os parâmetros alterados da prova de função pulmonar ou com os mediadores inflamatórios mensurados.

- A radioterapia não alterou a qualidade de vida, mesmo quando utilizando questionário específico para avaliar a influência do pulmão nesta. 
- No conjunto, as alterações induzidas pela radioterapia conformacional nas pacientes estudadas foram de pequena monta, insuficientes para influenciar aspectos funcionais do pulmão e a qualidade de vida. 


\section{REFERÊNCIAS BIBLIOGRÁFICAS}

AARONSON N. K. et al. The European Organization for Research and Treatment of Cancer QLQ-C30: a quality-of-life instrument for use in international clinical trials in oncology. J Natl Cancer Inst, v. 85, p. 365-376, 1993.

ABRAMS, J. S. et al. Strategies of anti-cytokine monoclonal antibody development: immunoassay of IL-10 and IL-5 in clinical samples. Immunol Rev, v. 127, p. 5-24, 1992.

AMERICAN THORACIC SOCIETY (ATS) Medical section of the American Lung Association-Standartion of Sprirometry - 1987 Update. Am Rev Resp Dis, v. 136, p. $1285,1987$.

AMERICAN THORACIC SOCIETY (ATS) Single-breath carbon monoxide diffusing capacity. Am J Respir Crit Care Med, v. 152, p. 2158-2198, 1995.

ANSCHER, M. S. et al. Plasma transforming growth factor beta1 as a predictor of radiation pneumonitis. Int J Radiat Oncol Biol Phys, n. 41, p. 1029-1035, 1998.

ANSCHER, M. S. et al. (1997) Changes in plasma transforming growth factor beta during radiotherapy and the risk of symptomatic radiation-induced pneumonitis. Int $\mathbf{J}$ Radiat Oncol Biol Phys, v. 37, p. 253-258, 1997.

ANSCHER, M. S. et al. Using plasma transforming growth factor beta-1 during radiotherapy to select patients for dose escalation. J Clin Oncol, n. 19, p. 37583765, 2001. 
ANSCHER, M. S. et al. Risk of long-term complications after TFG-beta1-guided veryhigh-dose thoracic radiotherapy. Int J Radiat Oncol Biol Phys, n. 56, p. 988-995, 2003.

ARNDT, V. et al. Quality of life over 5 years in women with breast cancer after breast-conserving therapy versus mastectomy: a population-based study. Journal of Cancer Research and Clinical Oncology, v. 134, n. 12, p. 1311-1318, Dez. 2008.

ARPIN, D. et al. Early variations of circulating interleukin-6 and interleukin-10 levels during thoracic radiotherapy are predictive for radiation pneumonitis. J Clin Oncol, v. 23, 8748-8756, 2005.

ARRARAS, J. I. et al. Impact of radiotherapy on the quality of life of elderly patients with localized breast cancer. A prospective study. Clinical and Translational Oncology, v. 10, n. 8, p. 498-504, Ago. 2008.

AUGUSTE, P., et al. The host inflammatory response promotes liver metastasis by increasing tumor cell arrest and extravasation. Am J Pathol, v. 170, n. 5, p. 17811792, 2007.

AZIGMOND, A. S.; SNAITH, R. P. The Hospital Anxiety and Depression Scale. Acta Psychiatrica Scandinavica, v. 67, n. 6, 361-370, Jun. 1983.

BALKWILL, F. Tumor necrosis factor or tumor promoting factor? Cytokine Growth Factor Rev, v. 13, p. 135-141, 2002.

BALKWILL, F.; CHARLES, K. A.; MANTOVANI, A. Smoldering and polarized inflammation in the initiation and promotion of malignant disease. Cancer Cell, v. 7 , p. 211-217, 2005. 
BALKWILL, F.; MANTOVANI, A. Inflammation and cancer: back to Virchow? Lancet, v. 357, p. 539-545, 2001.

BANERJEE, B. et al. Effects of an integrated yoga program in modulating psychological stress and radiation-induced genotoxic stress in breast cancer patients undergoing radiotherapy. Integr Cancer Ther, v. 6, n. 3, p. 242-250, Set, 2007.

BATES, D. V.; MACKLEM, P. T.; CHRISTIE, R. U. Respiratory function in disease. Philadelphia: Saundres, 1971, p. 93-94.

BATES, R. C.; MERCURIO, A. M. Tumor necrosis factor- $\alpha$ stimulates the epithelialto-mesenchymal transition of human colonic organoids. Mol. Biol. Cell, v. 14, p. 1790-1800, 2003.

BAR-YISHAY, E.; AMIRAV, I.; GOLDBERG, S. Comparison of maximal midexpiratory flow rate and forced expiratory flow at $50 \%$ of vital capacity in children. Chest, v. 123, n. 3, p. 731-735, 2003.

BECKLAKE, M. R.; PERMUTT, S. Evaluation of tests of lung functions for screening for early detection of chronic obstructive lung disease. In: MACKLEM et al. The lung in transition between health and disease. New York: Marcel Dekker, 1979. p. 345387.

BEHR, J.; NOWAK, D. Tobacco smoke and respiratory disease. Eur Respi Mon, v. 7, p. 161-79, 2002.

BERGH, J. et al. A systematic overview of chemotherapy effects in breast cancer. Acta Oncologica, v. 40, p. 253-281, 2001. 
BEUTLER, B. A. The role of tumor necrosis factor in health and disease. $\mathbf{J}$ Rheumatol, v. 26, n. 57, p. 16-21, 1999.

BJÖRNEKLETT, H. G. et al. A randomized controlled trial of a support group intervention on the quality of life and fatigue in women after primary treatment for early breast cancer. Supportive Care in Cancer, v. 20, n.12, p. 3325-3334, Dez. 2012.

BONAN, P. R. F. et al. Aspectos clínicos, biológicos, histopatológico e tratamentos propostos para a mucosite oral induzida por radioterapia: revisão da literature. Revista Brasileira de Cancerologia, v. 51, n. 3, p. 235-242, 2005.

BOTTERI, E. et al. Analysis of local and regional recurrences in breast cancer after conservative surgery. Annals of Oncology, v. 21, p. 723-728, 2010.

BRADLEY, J. D. et al. Gross tumor volume, critical prognostic factor in patients treated with three-dimensional conformal radiation therapy for non-small-cell lung carcinoma. Int J Radiat Oncol Biol Phys, v. 52, n. 1, p. 49-57, Jan. 2002.

BROWN, E. R. et al. A clinical study assessing the tolerability and biological effects of infliximab, a TNF- $\alpha$ inhibitor, in patients with advanced cancer. Ann. Oncol, v. 19, n.7, p. 1340-1346, 2008.

CALIGIURI, M. A.; LOTZE, M. T. Cytokines in the genesis and treatment of cancer. 7 ed. New Jersey: Humana Press, 2007. 502 p.

CARPENTER, J. S. et al. Sleep, fatigue, and depressive symptoms in breast cancer survivors and matched healthy women experiencing hot flashes. Oncol Nurs Forum, v. 31, p. 591-598, 2004. 
CHANDWANI, K. D. et al. Yoga improves quality of life and benefit finding in women undergoing radiotherapy for breast cancer. Journal of the Society for Integrative Oncology, v. 8, n. 2, p. 43-55, 2010.

CHEN, Y. et al. Circulating IL-6 as a predictor of radiation pneumonitis. Int $\mathbf{J}$ Radiat Oncol Biol Phys, n. 49, n.3, p. 641-648, 2001.

CHEN, Y. et al. Interleukin (IL)-1 $\alpha$ and IL-6: applications to the predictive diagnostic testing of radiation pneumonitis. Int J Radiat Oncol Biol Phys, v. 62, n. 1, p. 260266, 2005.

COHEN, S.; WILLIAMSON, G. M. Perceived stress in a probability sample of the United States. In: SPACAPAN, S.; OSKAMP, S. The Social Psychology of Health: Claremont Symposium on Applied Social Psychology. Newbury Park, CA: Sage, 1988, p.31-67.

CRAPO, R. O.; MORRIS, A. H. Standardized single breath normal values for carbon monoxide diffusing capacity. Am Rev Respir Dis, v. 123, n. 2, p. 185-189, 1981.

CRIVELLARI, D. et al. Adjuvant endocrine therapy compared with no systemic therapy for elderly women with early breast cancer: 21-year results of International Breast Cancer Study Group trial IV. J Clin Oncol, v. 21, p. 4517-4523, 2003.

CULOS-REED, S. N. et al. A pilot study of yoga for breast cancer survivors: physical and psychological benefits. Psychooncology. v. 15, p. 891-897, 2006.

DAGNELIE, P. C. et al. Impact of fatigue on overall quality of life in lung and breast cancer patients selected for high-dose radiotherapy. Ann Oncol, v.18, n. 5, p. 940944, 2007. 
DE JAEGER, K. et al. Significance of plasma transforming growth factor-beta levels in radiotherapy for non-small-cell lung cancer. Int J Radiat Oncol Biol Phys, v. 58, p. 1378-1387, 2004.

DIRKSEN, A, GROTH S. Calculation of reference values for lung function tests. Bull Eur Physiopathol Respir, v. 22, p. 231-237, 1986.

DRANOFF, G. Cytokines in cancer pathogenesis and cancer therapy. Nat Rev Cancer, v. 4, p. 11-22, 2004.

DROUIN, J. S. et al. Effects of aerobic exercise training on peak aerobic capacity, fatigue, and psychological factors during radiation for breast cancer. Rehabil Oncol, v. 23, p. 11-7, 2005.

DUIJTS, S. F. A. et al. Effectiveness of behavioral techniques and physical exercise on psychosocial functioning and health-related quality of life in breast cancer patients and survivors a meta-analysis. Psychooncology, v. 20, n. 2, p. 115-26, Fev. 2011.

DURIC, V.; STOCKLER, M. Patients preferences for adjuvant chemotherapy in early breast cancer: a review of what makes it worthwhile. Lancet Oncol, v. 2, n. 11, p. 691-697, 2001.

EARLY BREAST CANCER TRIALISTS' COLLABORATIVE GROUP (EBCTCG) Effects of radiotherapy and surgery in early breast cancer: an overview of the randomized trials. N Engl J Med, v. 333, p. 1444-1455, 1995.

EARLY BREAST CANCER TRIALISTS' COLLABORATIVE GROUP (EBCTCG) Favourable and unfavourable effects on long-term survival of radiotherapy for early breast cancer: an overview of the randomised trials. Lancet, v. 355, p. 1757-1770, 2000. 
EARLY BREAST CANCER TRIALISTS' COLLABORATIVE GROUP (EBCTCG) Effects of radiotherapy and of differences in the extent of surgery for early breast cancer on local recurrence and 15-year survival. An overview of the randomised trials. Lancet, v.366, p. 2087-2106, 2005.

EARLY BREAST CANCER TRIALISTS' COLLABORATIVE GROUP (EBCTCG). Systemic treatment of early breast cancer by hormonal, cytotoxic, or imune therapy (part 2). Lancet, v. 339, p. 71-85, 1992.

ERVEN, K. et al. Changes in Pulmonary Function Up to 10 Years After Locoregional Breast Irradiation. Int J Radiat Oncol Biol Phys, v. 82, n. 2, p. 701-707, Fev. 2012.

ESTEVA, F. J.; HORTOBAGYI, G. N. Locally advanced breast cancer. Hematol Oncol Clin North Am, v. 13, p. 457-472, 1999.

FARIA, S, L; LEITE, M, T, T. Tumor de Mama. In: SALVAJOLI, J. V.; SOUHAMI, L.; FARIA, S. L. Radioterapia em oncologia. Rio de Janeiro: Medsi, cap. 31, p. 819838, 1999.

FERREIRA, K. A. S. L. Dor e qualidade de vida relacionada à saúde de pacientes com câncer: influência das citocinas pró-inflamatórias TNF- $\alpha$, IL-6, IL-8 e IL -1 $\beta$. 2008. Tese (Doutorado em Enfermagem na Saúde do Adulto) - Escola de Enfermagem da Universidade de São Paulo, São Paulo, 2008. Disponível em <http://www.teses.usp.br/teses/disponiveis/7/7139/tde-04032008-092629/pt-br.php>. Acesso em: 20 de Jan, 2013.

FERRIS B. G. Epidemiology standardization project III. Procedures for pulmonary function testing. Am Rev Respir Dis, n. 118, v. 2, p. 55-88, 1978. 
FLECKENSTEIN, K.; ZGONJANIN, L.; CHEN, L. Temporal onset of hypoxia and oxidative stress after pulmonary irradiation. Int J Radiat Oncol Biol Phys, v. 68, p. 196-204, 2007.

FISHER, B et al. Twenty-year follow-up of a randomized trial comparing total mastectomy, lumpectomy, and lumpectomy plus irradiation for the treatment of invasive breast cancer. N Engl J Med, v. 347, p. 1233-1241, 2002.

FOWBLE, B.; GLICK, J.; GOODMAN, R. Radiotherapy for the prevention of localregional recurrence in high risk patients post mastectomy receiving adjuvant chemotherapy. Int J Radiat Oncol Biol Phys, v. 15, p. 627-631, 1988.

FU, X. L. et al. Predicting the risk of symptomatic radiation-induced lung injury using both the physical and biologic parameters $\mathrm{V}(30)$ and transforming growth factor beta. Int J Radiat Oncol Biol Phys, v. 50, p. 899-908, 2001.

GEINITZ, H. et al. Fatigue, serum cytokine levels, and blood cell counts during radiotherapy of patients with breast cancer. Int $\mathbf{J}$ Radiat Oncol Biol Phys, v. 51, $\mathrm{n}$. 3, p. 691-698, 2001.

GIANNI, L. et al. Phase III trial evaluating the addition of paclitaxel to doxorubicin followed by cyclophosphamide, methotrexate, and fluorouracil, as adjuvant or primary systemic therapy: European Cooperative Trial in Operable Breast Cancer. J Clin Oncol, v. 27, p. 2474-2481, 2009.

GLAUS, A. Fatigue in patients with cancer: Analysis and assessment. Recent Results Cancer Res, v. 145, p. 1-172, 1998. 
GRAVES, P. R. et al. Radiation Pulmonary Toxicity: From Mechanisms to Management. Semin Radiat Oncol, v. 20, n. 3, p. 201-207, Jul. 2010.

GRAYDON, J. Women with breast cancer: their quality of life following a course of radiation therapy. J Adv Nurs, v. 19, p. 617-622, 1994.

GRIVENNIKOV, S.; KARIN, M. Autocrine IL-6 signaling: a key event in tumorigenesis? Cancer Cell, n. 13, p. 7-9, 2008.

GROSS, N. J. Pathogenesis of radiation-induced lung damage. Lung, v. 159, n. 3, p. 115-125, 1981.

GUYATT, G. H.; FEENEY, D. H.; PATRICK, D .L. Measuring health-related quality of life. Ann Intern Med, v. 118, p.622-9, 1993.

HANSEN, J. E.; SUN, X. G.; WASSERMAN, K. Spirometric criteria for airway obstruction: Use percentage of FEV1/FVC ratio below the fifth percentile, not $<70 \%$. Chest, v. 131, n. 2, p. 349-355, 2007.

HARRISON, M. L. et al. Tumor necrosis factor $\alpha$ as a new target for renal cell carcinoma: two sequential phase II trials of infliximab at standard and high dose. $\mathbf{J}$ Clin Oncol, v. 25, v. 29, p. 4542-4549, 2007.

HOFFMAN, C. J. et al. Effectiveness of Mindfulness-Based Stress Reduction in Mood, Breast- and Endocrine-Related Quality of Life, and Well-Being in Stage 0 to III Breast Cancer: A Randomized, Controlled Trial. Journal of Clinical Oncology, v. 30, n. 12, p. 1335-42, Abr, 2012. 
HOPWOOD, P. et al. Comparison of patient-reported breast, arm, and shoulder symptoms and body image after radiotherapy for early breast cancer: 5-year followup in the randomised Standardisation of Breast Radiotherapy (START) trials. The Lancet Oncology, v. 11, n. 3, p. 231-240 Mar, 2010.

HUNT, S. M. et al. The Nottingham health profile: Subjective health status and medical consultations. Social Science \& Medicine. Part A: Medical Psychology \& Medical Sociology, v. 15, v. 3, p. 221-229, Mai., 1981.

HUSSAIN, S. P.; HOFSETH L. J.; HARRIS C. C.: Radical causes of cancer. Nat Rev Cancer, v. 3, p. 276-285, 2003.

ISRAEL, D. A.; PEEK, R. M. Review article: pathogenesis of Helicobacter pyloriinduced gastric inflammation. Aliment Pharmacol Ther, v.15, p. 1271-1290, 2001.

JAÉN, J. et al. Long-term Changes in Pulmonary Function After Incidental Lung Irradiation for Breast Cancer: A Prospective Study With 7-Year Follow-up. Int $\mathbf{J}$ Radiat Oncol Biol Phys, v. 84, n. 5, p. 565-570, Dez 2012.

JEMAL, A. et al. Annual report to the nation on the status of cancer, 1975-2001, with a special feature regarding survival. Cancer, n. 101, p. 3-27, 2004.

JOHNSON, J. R.; TEMPLE, R. Food and Drug Administration requirements for approval of new anticancer drugs. Cancer Treat Rep, v. 69, p. 1155-9, 1985.

JONES P. W.; QUIRK, F. H.; BAVEYSTOCK, C. M. The St George's Respiratory Questionnaire. Resp Med. v. 85, p. 25-31, 1991. Suplemento B. 
KAPLAN, R. M.; BUSH, J. W.; BERRY, C. C. Health Status Index: Category Rating versus Magnitude Estimation for Measuring Levels of Well-Being. Medical Care, v. 17, n. 5, p. 501-525, Mai., 1979.

KARAKOYUN-CELIK, O. et al. Depression and anxiety levels in woman under followup for breast cancer: relationship to coping with cancer and quality of life. Med Oncology, v. 27, p. 108-113, 2010.

KARIN, M.; GRETEN, F. R. NF-kappaB: linking inflammation and immunity to cancer development and progression. Nat Rev Immunol, v. 5, p. 749-759, 2005.

KARIN, M. Nuclear factor-kB in cancer development and progression. Nature, v. 441, p. 431-436, 2006.

KLEFSTROM, P. et al. Adjuvant postoperative radiotherapy, chemotherapy, and immunotherapy in stage III breast cancer. Cancer, v. 60, p. 936-942, 1987.

KNUDSON, R. J. et al. Influence of airway geometry on expiratory flow. Respir Physiol, v. 52, n. 1, p. 113-123, 1983.

KONG, F. M. et al. Plasma transforming growth factor-beta1 level before radiotherapy correlates with long term outcome of patients with lung carcinoma. Cancer, n. 86, p. 1712-1719, 1999.

KONG, F. M. et al. Plasma transforming growth factor-beta 1 reflects disease status in patients with lung cancer after radiotherapy: a possible tumor marker. Lung Cancer, n. 16, p. 47-59, 1996. 
KRENGLI, M. et al. Pulmonary Changes After Radiotherapy for Conservative Treatment of Breast Cancer: A Prospective Study. Int J Radiat Oncol Biol Phys, v. 70, n. 5, p. 1460-1467, Abri, 2008.

KUSCHNER, W. G. et al. Dose dependent cigarette smoking-related inflammatory responses in healthy adults. Eur Repir Journal, v. 9, n. 10, p. 1989-1994, 1996.

KUYKEN, W. et al. The world health organization quality of life assessment (WHOQOL) - position paper from the world health organization. Social Science and Medicine, v. 10; p. 1403-1409, 1995.

LANDBERG, T. The role of radiotherapy in breast conserving treatment. Acta Oncol, v. 34, p. 675-680, 1995.

LANGOWSKI, J. L. et al. IL-23 promotes tumour incidence and growth. Nature, v. 442, p. 461-465, p. 2006.

LEE, T. S. et al. Quality of life of women treated with radiotherapy for breast cancer. Support Care Center, v. 16, n. 4, p. 399-405, 2008.

LEEK, R. D. et al. Association of tumour necrosis factor alpha and its receptors with thymidine phosphorylase expression in invasive breast carcinoma. $\mathbf{B r} \mathbf{J}$ Cancer, v. 77, p. 2246-2251, 1998.

LIND, P. A. R. M. et al. Pulmonary function following adjuvant chemotherapy and radiotherapy for breast cancer and the issue of three-dimensional treatment planning. Radiother Oncol, v. 49, n. 3, p. 245-254, Dez, 1998. 
LIND, P. A. R. M. et al. Pulmonary complications following different radiotherapy techniques for breast cancer, and the association to irradiated lung volume and dose. Breast Cancer Research and Treatment, v. 68, n. 3, p. 199-210, Ago, 2001.

LUND, M. B. et al. The effect on pulmonary function of tangential field technique in radiotherapy for carcinoma of the breast. Br J Radiol, v. 64 p. 520-523, 1991.

MADHUSUDAN, S. et al. Study of etanercept, a tumor necrosis factor-ainhibitor, in recurrent ovarian cancer. J Clin Oncol, v. 23, n. 25, 5950-5959, 2005.

MANTOVANI, A. et al. Cancer-related inflammation. Nature, v. 454, p. $436-$ 444, 2008.

MARKS et al. Radiation-induced pulmonary injury: symptomatic versus subclinical endpoints. International Journal of Radiation Biology, v. 76, n. 4, p. 469-475, 2000.

MARTINS, S. J.; YAMAMOTO, C. A. Aspectos clínico-econômicos da quimioterapia adjuvante no cancer de mama HER-2 positivo. Rev Assoc Med Bras, v. 54, n. 6, p. 494-499, Nov./Dec. $2008 . \quad$ Disponível em: < http://www.scielo.br/scielo.php?pid=S010442302008000600012\&script=sci_arttext>A cesso em: 12 Dez. 2012.

MATTHEW, M. et al. Randomized controlled trial of maintaining quality of life during radiotherapy for advanced cancer. Cancer, v.119, n.4 p. 880-887, Fev. 2013.

MAZUR, B. et al. Concentration of IL-2, IL-6, IL-8, IL-10 and TNF-alpha in children with acute lymphoblastic leukemia after cessation of chemotherapy. Hematol Oncol, v. 22, n.1, p. 27-34, 2004. 
MCFADDEN E. R.; LINDEN D. A. A reduction in maximum mid-expiratory flow rate: A spirographic manifestation of small airway disease. Am J Med, v.52, p. 725-737, 1972.

MCGRATH, M. W.; THOMSON, M. L. The effect of age, body, size and lung volume change on alveolar capillary permeability and diffusing in man. J Physiol, v. 146, 572-582, 1959.

MENDONÇA, M. A. O.; CUNHA, F. Q Failure of neutrophil chemotactic function in breast cancer patients treated with chemotherapy.Cancer Chemotherapy and Pharmacology, v. 57, n. 5, p.663-670, Mai, 2006.

MENNELY, G. R.; KALTREIDER, N. L. The volume of lung by helium dilution: Description of the method and comparison with other procedures. J Clin Invert, v. 28, n.1, p. 129-140, 1949.

MILLER, M. R. et al. Series "ATS/ERS task force: Standardisation of lung function testing" Edited by V. BRUSASCO, R. CRAPO and G. VIEGI number 2 in this series: Standardisation of Spirometry. Eur Respir J, v. 26, p. 319-338, 2005.

MINISTÉRIO DA SAÚDE - INSTITUTO NACIONAL DE CÂNCER (INCA); COORDENAÇÃO DE PREVENÇÃO E VIGILÂNCIA (CONPREV). Controle do câncer de mama: documento de consenso. Rio de Janeiro: p. 1-39, Abril, 2004. Disponível em: <http://www.inca.gov.br/publicacoes/Consensointegra.pdf> Acesso em: 29 Nov. 2012.

MINISTÉRIO DA SAÚDE - INSTITUTO NACIONAL DE CÂNCER (INCA). Estimativa 2012: Incidência de câncer no Brasil. Rio de Janeiro. Disponível em: $<$ http://www.inca.gov.br/estimativa/2012/index.asp?ID=5>. Acesso em: 25 Nov. 2012a. 
MINISTÉRIO DA SAÚDE - INSTITUTO NACIONAL DE CÂNCER (INCA). Programa Nacionlal de Controle do Câncer de Mama. Rio de Janeiro <http://www2.inca.gov.br/wps/wcm/connect/acoes_programas/site/home/nobrasil/pro grama_controle_cancer_mama/tratamento>Acesso em: 12 Dez. 2012b.

MINISTÉRIO DA SAÚDE - INSTITUTO NACIONAL DE CÂNCER (INCA) Radioterapia. Rio de Janeiro. Disponível em: <http://www.inca.gov.br/conteudo_view.asp?id=100>. Acesso em: 18 Dez. 2012c.

MIRANDA, A. A. Efeitos da radioterapia torácica sobre a responsividade brônquica. Mestrado em Ciências Médicas. Área de Concentração: Clínica Médica Pneumologia - Faculdade de Medicina de Ribeirão Preto, Universidade de São Paulo, Ribeirão Preto, 2009.

MIZIARA-FILHO, M. A.; PINTO, A. C. C. Câncer de Mama: Epidemiologia etiopatogênia, Diagnostico e Estadiamento Clínico. In: MINISTÉRIO DA SAÚDE INSTITUTO NACIONAL DE CÂNCER (INCA). Programa de Qualidade em Radioterapia: $1^{\circ}$ Seminário em Radioterapia. Angra dos Reis: 2001. Capitulo 2, p. 81-90. Disponível em: <http://www.inca.gov.br/pqrt/download/tec_int/cap2_p1.pdf >. Acesso em: 07 de Fev. 2013.

MORRIS, J. F; KOSKI, A.; JOHNSON, L.C. Spirometric standards for healthy nonsmoking adults. Am Rev Resp Dis, v. 116, p. 209-213, 1971.

MUNSHI, A. et al. Comparison of early quality of life in patients treated with radiotherapy following mastectomy or breast conservation therapy: A prospective study. Radiotherapy and Oncology, v. 97, n. 2, p. 288-293, Nov. 2010. 
NISHIOKA, A. et al. Analysis of radiation pneumonitis and radiation-induced lung fibrosis in breast cancer patients after breast conservation treatment. Oncol Rep, v. 6, n. 3, p. 513-517, 1999.

NOAL, S. et al. One-Year Longitudinal Study of Fatigue, Cognitive Functions, and Quality of Life After Adjuvant Radiotherapy for Breast Cancer International. Int $\mathbf{J}$ Radiat Oncol Biol Phys, v. 81, n. 3, p. 795-803, Nov. 2011.

NOVAKOVA-JIRESOVA, A. et al. Transforming growth factor-beta plasma dynamics and post-irradiation lung injury in lung cancer patients. Radiother Oncol, v. 71, p. 183-189, 2004.

NUNES, D. F. et al. Relaxation and guided imagery program in patients with breast cancer undergoing radiotherapy is not associated with neuroimmunomodulatory effects. J Psychosom Res, v. 63, n. 6, p. 647-655, Dez, 2007.

OLSON, J, E. et al. The role of radiotherapy in the management of operable locally advanced breast cancer: Results of a randomized trial by the Eastern Cooperative Oncology Group. Cancer, v. 79, p. 1138-1149, 1997.

OOI, G. C. et al. Pulmonary sequelae of treatment for breast cancer: a prospective study. Int J Radiation Oncology Biol Phys, v. 50, n. 2, p. 411-419, 2001.

OOI, G. C. et al. Serial HRCT Lung Changes after 3-Field Radiation Treatment of Breast Cancer. Clinical Radiology, v. 55, n. 11, p. 817-824, 2000.

OSBORNE, C, K. Tamoxifen in the treatment of breast cancer. N Engl J Med, v. 339, p. 1609-1618, 1998. 
OVERGAARD, $\mathrm{M}$ et al. Postmastectomy irradiation in high-risk breast cancer patients: present status of the Danish Breast Cancer Cooperative Group trials. Acta Oncol, v. 27, p. 707-714, 1998.

OVERGAARD, $M$ et al. Postoperative radiotherapy in high-risk postmenopausal breast cancer patients given adjuvant tamoxifen: Danish Breast Cancer Cooperative Group DBCG 82c randomised trial. Lancet, v. 353, p. 1641-1648, 1999.

OZTURK, B. et al. Pentoxifylline in prevention of radiation-induced lung toxicity in patients with breast and lung cancer: a double-blind randomized trial. Int $\mathbf{J}$ Radiation Oncology Biol Phys, v. 58, n. 1, p. 213-219, Jan, 2004.

PAZ, A. V. et al. Biópsia de linfonodo sentinela; experiência clínica. Revista Brasileira de Cancerologia, v. 47, p. 309-315, 2001.

PENTTINEN, H. M. et al. Quality of life and physical performance and activity of breast cancer patients after adjuvant treatments. Psycho-Oncology, v. 20, n. 11, p. 1211-1220, Nov. 2011.

PIERCE, L. J.; LICHTER, A. S. Defining the role of post-mastectomy radiotherapy. The new evidence. Oncology, v.10, p. 991-1002, 1996.

RABINOVITCH M. Elastase and the pathobiology of unexplained pulmonary hypertension. Chest, n. 114, p. 213S-224S, 1998.

RAGAZ, J. et al. Locoregional radiation therapy in patients with high-risk breast cancer receiving adjuvant chemotherapy: 20-year results of the British Columbia randomized trial. J Natl Cancer Inst, v. 97, p. 116-126, 2005. 
REIDUNSDATTER, R. J. et al. One-year course of fatigue after post-operative radiotherapy in Norwegian breast cancer patients - comparison to general population. Acta Oncologica, v. 52, n. 2, p. 239-248, Fev. 2013.

RELF, M. et al. Expression of the angiogenic factors vascular endothelial cell growth factor, acidic and basic fibroblast growth factor, tumor growth factor beta-1, plateletderived endothelial cell growth factor, placenta growth factor, and pleiotrophin in human primary breast cancer and its relation to angiogenesis. Cancer Res, v. 57, p. 963-969, 1997.

ROBBINS, C. T.; COTRAN, R. S. Patologia: Bases patológicas das doenças. Sétima edição, Editora Guanabara Koogan, 2007, cap. 2, p. 49-90.

RUBE, C. et al. Irradiation induces a biphasic expression of pro-inflammatory cytokines in the lung. Strahlenther Onkol, v. 180, n. 7, p. 442-448, Abr, 2004.

RUBE, C. E. et al. Cytokine plasma levels: reliable predictors for radiation pneumonitis? PLoS ONE, v. 3, n 8, e2898, p. 1-9, Ago, 2008.

RUBE, C. E.; RODEMANN, H. P.; RUBE, C. The relevance of cytokines in the radiation-induced lung reaction. Experimental basis and clinical significance. Strahlenther Onkol, v. 180, n. 9, p. 541-549, 2004.

RYUTO, M. et al. Induction of vascular endothelial growth factor by tumor necrosis factor alpha in human glioma cells. Possible roles of SP-1. J Biol Chem, v. 271, p. 28220-28228, 1996. 
SAMANIEGO, F. et al. Inflammatory cytokines induce endothelial cells to produce and release basic fibroblast growth factor and to promote Kaposi's sarcoma-like lesions in nude mice. J Immunol, v. 158, p. 1887-1894, 1997.

SAMPAIO, M. M. C. Quimioterapia Neoadjuvante e reconstrução mamária. Boletim da Sociedade Brasileira de Mastologia, Regional São Paulo, Ano XV, N 93, Mai, 2011. Disponível em: <http://www.spmastologia.com.br/Boletins/2011/maio/MASTOBOL-2011-(05)-MAI\%20-\%2023.pdf >. Acesso em: 05 Dez. 2012.

SANCHES, S. M.; SILVA, J. M. A. Interação entre especialidades: miocardiopatia dilatada e neoplasia de mama HER2 positiva. Arq. Bras. Cardiol, v. 94, n. 1, 2010.

SÁNCHEZ-NIETO, B. et al. Predictive Models for Pulmonary Function Changes After Radiotherapy for Breast Cancer and Lymphoma. Int J Radiat Oncol Biol Phys, v. 82, n. 2, p.257-264, Fev, 2012.

SARTOR, C. et al. Effect of addition of adjuvant paclitaxel on radiotherapy delivery and locoregional control of node-positive breast cancer: Cancer and Leukemia Group B 9344. J Clin Oncol, v. 23, p. 30-40, 2005.

SAVARD, J. et al. The association between nocturnal hot flashes and sleep in breast cancer survivors. J Pain Symptom Manage, v. 24, p. 513-522, 2004.

SCHALL, R. Estimation in generalized linear models with random effects. Biometrika, v. 78, n. 4, p. 719-727, 1991. 
SCHMIDT, M. E. et al. Fatigue and quality of life in breast cancer survivors: temporal courses and long-term pattern. Journal of Cancer Survivorship, v. 6, n. 1 p. 11-19, Mar, 2012.

SIMES, R. J.; COATES, A. S. Patient preferences for adjuvant chemotherapy of early breast cancer: how much benefit is needed? J Natl Cancer Inst Monogr., v. 30, p.146-152, 2001.

SOUSA, T. C.; JARDIM, J. R.; JONES, P. Validação do questionário do Hospital Saint George na Doença Respiratória (SGRQ) em pacientes portadores de doença pulmonar obstrutiva crônica no Brasil. J Bras Pneumol, v. 26, n. 3, p. 119-125, Mai.Jun. 2000.

SPRANGERS, M. A. et al. The European Organization for Research and Treatment of Cancer breast cancer-specific quality-of-life questionnaire module: First results from a three-country field study. J Clin Oncol, v. 14, n. 10, p. 2756-2768, Out. 1996.

STONE, P. et al. Cancer-related fatigue: Inevitable, unimportant and untreatable? Results of a multi-centre patient survey. Cancer Fatigue Forum Ann Oncol, v. 11, n. 8, p. 971-975, 2000.

STROM, E, A.; MCNEESE, M, D. Postmastectomy irradiation rationale for treatment field selection. Semin Radiat Oncol, v. 9, p. 247-253, 1999. 
SVENSK, A. C. et al. Art therapy improves experienced quality of life among women undergoing treatment for breast cancer: a randomized controlled study. European Journal of Cancer Care. v. 18, n. 1, p. 69-77, Jan. 2009.

SZLOSAREK, P. W.; BALKWILL, F. R. Tumour necrosis factor $\alpha$ : a potential target for the therapy of solid tumours. Lancet Oncol, v. 4, p. 565-573. 2003.

TERRA-FILHO, J. Avaliação laboratorial da função pulmonar. Medicina, v. 31, p. 191-207, Ribeirão Preto, Abr/Jun, 1998.

THERIAULT, R. L. et al. Clinical Practice Guidelines in Oncology: Breast Cancer; versão 3.2013 in National Comprehensive Cancer Network (NCCN). Disponível em: $<$ http://www.nccn.org/professionals/physician_gls/f_guidelines.asp\#breast>. Acesso em: 02 de Set. 2013.

THEUWS, J. C. M. et al. Effect of Radiotherapy and Chemotherapy on Pulmonary Function After Treatment for Breast Cancer and Lymphoma: A Follow-Up Study. Jornal of Clinical Oncology, v.17, n.10, p. 3091, Out, 1999.

THEUWS, J. C. et al. Prediction of overall pulmonary function loss in relation to the 3D dose distribution for patients with breast cancer and malignant lymphoma. Radiother Oncol, v. 49, n. 3, p. 233-243,_Dez, 1998.

TOKATLI F. et al. Sequential pulmonary effects of radiotherapy detected by functional and radiological end points in women with breast cancer. Clinical Oncology, v. 17, n. 1, p. 39-48, Fev, 2005. 
TROTT K. R.; HERRMANN T.; KASPER M. Target cells in radiation pneumopathy. Int J Radiat Oncol Biol Phys, v. 58, p. 463-469, 2004.

TROTTI, A. et al. Common toxicity criteria: version 2.0. An improved reference for grading the acute effects of cancer treatment: Impact on radiotherapy. Int $\mathbf{J}$ Radiat Oncol Biol Phys, v. 47, n. 1, p. 13-47, 2000.

TSOUTSOU, P. G.; KOUKOURAKIS, M. I. Radiation pneumonitis and fibrosis: mechanisms underlying its pathogenesis and implications for future research. Int $\mathbf{J}$ Radiat Oncol Biol Phys, v. 66, p. 1281-1293, 2006.

VADIRAJA, H. S. Effects of yoga program on quality of life and affect in early breast cancer patients undergoing adjuvant radiotherapy: A randomized controlled trial. Complementary Therapies in Medicine, v. 17, n. 5, p. 274-280, 2009.

VALENÇA, L. M.; MORAES R. C. Manifestações espirográficas da doença das vias aéreas periféricas. J Pneumol, v. 2, 23-27, 1976.

VAN-KESSEL, A. L. Pulmonary diffusion capacity for carbon monoxide. In: JACK, L. $C$. Pulmonary function testing guidelines and controversies. New York, Guine and Stratton INC, p. 165-85, 1984.

VELIKOVA, G.; STARK, D.; SELBY, P. Quality of life instruments in oncology. Eur J Cancer, v. 35, p. 1571-1580, 1999. 
VERBANCK, S. et. al. Small airways function in breast cancer patients before and after radiotherapy. Breast Cancer Research and Treatment, v. 135, n. 3, p. 857865, Out, 2012.

VERELLEN, D.; DE RIDDER, M.; STORME, G. A. (short) history of image-guided radiotherapy. Radiother. Oncol, v. 86, n. 1, p. 4-13, 2008.

VERSMESSEN, H. et al. Health-related quality of life in survivors of stage I-II breast cancer: randomized trial of post-operative conventional radiotherapy and hypofractionated tomotherapy. BMC Cancer, v. 12, n. 495, p. 1-16, 2012.

VORONOV, E. et al. IL-1 is required for tumor invasiveness and angiogenesis. Proc Natl Acad Sci USA, v. 100, p. 2645-2650, 2003.

VUJASKOVIC, Z.; GROEN, H. J. TGF-beta, radiation-induced pulmonary injury and lung cancer. Int J Radiat Biol, v. 76, p. 511-516, 2000.

WALKER, B. L. et al. Concerns, affect and cognitive disruption following completion of radiation treatment for localised breast or prostate cancer. Oncol Nurs Forum, v. 23, p.1181-1187, 1996.

WARE-Jr, J. E.; SHERBOURNE, C. D. The MOS 36-Item Short-Form Health Survey (SF-36): I. Conceptual Framework and Item Selection. Medical Care, v. 30, n.6, p. 473-483, Jun., 1992. 
WATSON, D.; CLARK, L. A.; TELLEGEN, A. Development and validation of brief measures of positive and negative effect: the PANAS scales. J Pers Soc Psychol, v. 54, p. 1063-1070, 1988.

WENGSTROM, Y. et al. Perceived symptoms and quality of life in women with breast cancer receiving radiation therapy. Eur J Oncol Nurs, v. 4, p. 78-88, 2000.

WENNBERG, B. et al. Early response of lung in breast cancer irradiation: radiologic density changes measured by $\mathrm{CT}$ and symptomatic radiation pneumonitis. Int $\mathbf{J}$ Radiat Oncol Biol Phys, v. 52, n.1, p. 1196-1206, Abr., 2002.

WEST, J. B. Fisiopatologia Pulmonar: Princípios básicos. $7^{\text {ạ }}$ Edição. São Paulo: Artmed, 2000. Capitulo I: Testes de função pulmonar e o que eles significam; p.18.

WHELAN, T. J. et al. The effects of radiation therapy on quality of life of women with breast carcinoma: results of a randomised trial. Cancer, v. 88, p. 2260-2266, 2000.

WIEBE, S., et al. Comparative responsiveness of generic and specific quality-of-life instruments. J Clin Epidemiol, v. 56, p. 52-60, 2003.

WLUDARSKI, S. C. L. Comparação dos resultados de marcadores prognósticos e preditivos (HER2 e receptores de estrógeno e progesterona) para carcinoma de mama entre laboratórios locais e de referência no Brasil. Doutorado na Área de Concentração: Clínica Médica - Patologia - Faculdade de Medicina, Universidade de São Paulo, São Paulo, 2010.

WYNN, T. A. Cellular and molecular mechanisms of fibrosis. J Pathol, v. 214, p. 199-210, 2008. 
YARDEN, Y. Biology of HER2 and its importance in breast cancer. Oncology ${ }_{2}$ v. 61, n. 2, p. 1-13, 2001.

YOSHIDA, S. et al. Involvement of interleukin-8, vascular endothelial growth factor, and basic fibroblast growth factor in tumor necrosis factor alpha-dependent angiogenesis. Mol Cell Biol, v. 17, p. 4015-4023, 1997.

YU, H.; KORTYLEWSKI, M.; PARDOLL, D. Crosstalk between cancer and immune cells: role of STAT3 in the tumour microenvironment. Nature Ver Immunol, v. 7, p. 41-51, 2007.

ZHAO, W.; ROBBINS, M. E. Inflammation and chronic oxidative stress in radiationinduced late normal tissue injury: Therapeutic implications. Curr Med Chem, v. 16, p. 130-43, 2009. 


\section{ANEXOS}

ANEXO A - Termo aprovado pelo Comitê de Ética e Pesquisa da Faculdade de Medicina de Ribeirão Preto da Universidade de São Paulo

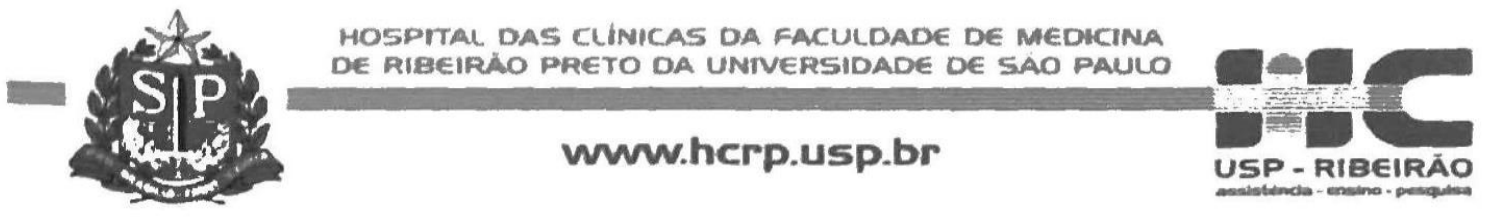

Ribeirão Preto, 12 de maio de 2010

Oficio $n^{\circ} 1449 / 2010$

CEP/MGV

Prezados Senhores,

O trabalho intitulado "TOXICIDADE PULMONAR NA RADIOTERAPIA TORÁCICA ADJUVANTE EM MULHERES COM CÂNCER DE MAMA" foi analisado pelo Comitê de Ética em Pesquisa, em sua $307^{a}$ Reunião Ordinária realizada em 10/05/2010 e enquadrado na categoria: APROVADO, bem como o Termo de Consentimento Livre e Esclarecido, de acordo com o Processo HCRP $n^{\circ} 3116 / 2010$.

Este Comitê segue integralmente a Conferência Internacional de Harmonização de Boas Práticas Clínicas (IGH-GCP), bem como a Resolução no 196/96 CNS/MS.

Lembramos que devem ser apresentados a este CEP, o Relatório Parcial e o Relatório Final da pesquisa.

Atenciosamente.

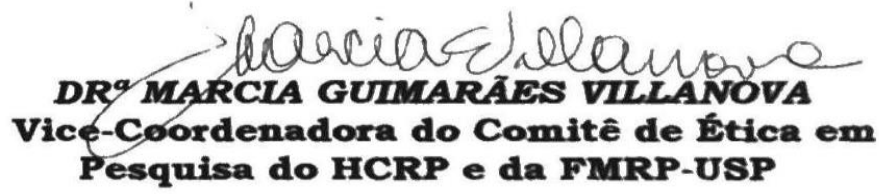

Ilustríssimos Senhores

ADRIANA ASSIS MIRANDA

PROF. DR. JOÃO TERRA FILHO (Orientador)

Depto. de Clínica Médica

Comité de Ética em Pesquisa HCRP e FMRP-USP - Campus Universitário

FWA - 00002733 ; IRB - 00002186 e Registro SISNEP/CONEP n ${ }^{\circ} 4$

Fone (16) 3602-2228 - E-mail : cep@hcrp.usp.br

Monte Alegre 14048-900 Ribeiráo Preto SP 
ANEXO B - Termo aprovado do adendo de inclusão do grupo controle pelo Comitê de Ética e Pesquisa da Faculdade de Medicina de Ribeirão Preto da Universidade de São Paulo

SiP. hospital das clinicas da faculdade de medicina DE RIBEIRAO PRETO DA UNIVERSIDADE DE SÁO PAULO

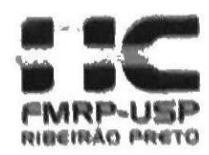

Ofício $n^{\circ} 4506 / 2011$

$\mathrm{CEP} / \mathrm{MGV}$

Ribeirão Preto, 07 de dezembro de 2011

PROCESSO HCRP n $3116 / 2010$

\section{3}

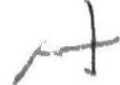

Prezados Senhores,

O Comitê de Ética em Pesquisa em sua $338^{a}$ Reunião Ordinária, realizada em $05 / 12 / 2011$, aprovou o adendo referente a inclusão de um grupo controle, bem como o Termo de Consentimento Livre e Esclarecido do Grupo Controle e tomou ciència do relatório parcial da pesquisa intitulada "TOXICIDADE PULMONAR NA RADIOTERAPIA TORÁCICA ADJUVANTE EM MULHERES COM CÂNCER DE MAMA".

Atenciosamente.

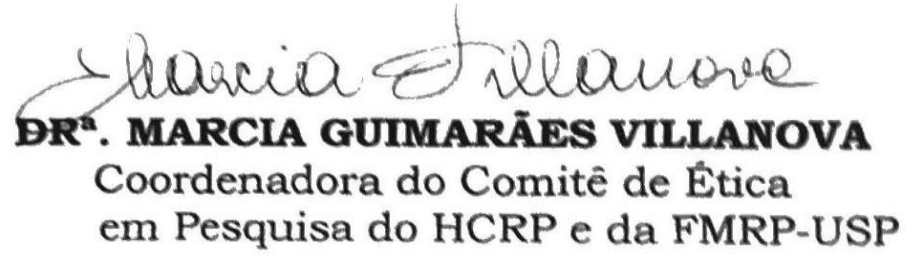

Ilustrissimos Senhores

ADRIANA ASSIS MIRANDA

PROF. DR. JOĀO TERRA FILHO(Orientador)

Depto. de Clínica Médica 


\section{ANEXO C - Termo de Consentimento Livre e Esclarecido - Grupo Radioterapia}

\section{Termo de Consentimento Livre e Esclarecido}

Este é um estudo prospectivo para avaliar o pulmão em com pacientes submetidas à radioterapia torácica

Nome do investigador: Adriana Assis Miranda

Número do telefone: (16) 8182-1022

Você está sendo convidada para participar de um estudo intitulado: "Toxicidade pulmonar na radioterapia torácica adjuvante em mulheres com câncer de mama." As informações a seguir descrevem o estudo e seu papel como possível participante. Este documento, Termo de Consentimento Livre e Esclarecido, possui este nome, pois você só deve decidir a participar depois de ler e entender este folheto e só depende de sua vontade em participar, podendo retirar seu consentimento em qualquer fase da pesquisa, sem penalização alguma e sem prejuízo ao seu tratamento. A pesquisadora irá responder a todas as perguntas que você possa ter sobre este Termo de Consentimento Livre e Esclarecido e sobre o estudo. Portanto, leia essas informações com cuidado e faça qualquer pergunta que considere necessária.

\section{Objetivos:}

Você está sendo convidada a participar desse estudo porque deverá se submeter à radioterapia no tórax. $\mathrm{O}$ objetivo deste estudo é avaliar se a radioterapia pode alterar, de alguma forma, a sua capacidade de respirar.

Procedimentos do estudo:

Se você concordar em participar do estudo e tiver assinado o Termo de Consentimento Livre e Esclarecido, você passará, antes de iniciar a radioterapia, por quarto testes:

- Teste de função pulmonar: esse teste serve para medirmos a sua capacidade respiratória. Você permanecerá sentada frente a um aparelho que possui um tubo 
por onde você irá soprar, quando the for solicitado. Somente se este teste for normal, você irá realizar os testes seguintes.

- Exame de sangue: quando for realizada a coleta do seu sangue para o hemograma de rotina de seu tratamento será coletado três $\mathrm{ml}$ para a pesquisa. Este servirá para avaliar se ocorrerá alteração de alguma enzima inflamatória estudada.

- Tomografia computadorizada: também realizada na rotina de seu tratamento. Será utilizada para ver se há alteração de imagem do pulmão.

- Teste de qualidade de vida: é um questionário. Esse serve para avaliar o quanto à função de respirar está influenciando no seu dia-a-dia.

Esses testes serão realizados antes de iniciar a radioterapia (que servirá de controle) e três meses após a mesma (para vermos o efeito da radioterapia).

Riscos e desconfortos:

Não há riscos durante esses testes. Se ocorrer desconforto é cansaço por ter que soprar cumprindo, porém esse desconforto é passageiro.

\section{Benefícios:}

Caso comprove-se uma queda na capacidade funcional pulmonar (capacidade de você respirar), outros pacientes que necessitem se submeter ao mesmo tratamento poderão, no futuro, se beneficiar de possíveis tratamentos propostos.

\section{Alternativa:}

Se você optar por não participar deste estudo, você continuará seu tratamento normalmente. 


\section{Custos e reembolsos:}

Você não receberá qualquer pagamento pela sua participação neste estudo, mas também não precisará pagar por qualquer dos testes do mesmo.

\section{Em caso de danos associados ao estudo de pesquisa:}

Assinando este documento você não perderá nenhum direito legal, incluindo o direito de procurar obter indenização por algum dano decorrente pela participação na pesquisa.

\section{Mais informações; quem contatar:}

Caso você tenha qualquer dúvida sobre o estudo, ou não queira mais participar, você poderá contatar a pesquisadora Adriana Assis Miranda pelo (16) 8281-1022.

Este Termo de Consentimento Livre e Esclarecido e este estudo foram aprovados pelo comitê de ética em pesquisa do HCRP-USP - Hospital das Clínicas da Faculdade de Medicina da Universidade de São Paulo - Campus de Ribeirão Preto, que é um grupo de pessoas - cientistas e não cientistas - que analisam e aprovam ou desaprovam estudos de pesquisa envolvendo seres humanos, de acordo com as regras estabelecidas pela Comissão Nacional de Ética em Pesquisa (CONEP). Pelas regras da CONEP, o Comitê de Ética em Pesquisa do HCRP-USP, também é obrigado a fazer revisões periódicas dos estudos em andamento. As perguntas sobre ética e seus direitos podem ser encaminhadas ao Comitê de Ética de Pesquisa do HCRP-USP. Avenida Bandeirantes, 3900 - Campus Universitário Monte Alegre - 14.048-900 - Ribeirão Preto - SP.

\section{Participação voluntária:}

Sua participação é voluntária, ou seja, só depende de sua vontade de participar ou não. Você poderá se recusar a participar ou sair do estudo a qualquer momento, sem risco de sofrer penalidade ou perda de benefício a que você teria direito. Se você sair do estudo não sofrerá qualquer preconceito em termos de cuidados médicos ou participação em estudo de pesquisa no futuro. 
Confidencialidade:

Comitê de Ética em Pesquisa do HCRP-USP e a CONEP também poderão analisar seus registros. Os resultados deste estudo poderão ser publicados, sejam eles favoráveis ou não, mas seu nome não será mencionado.

\section{Autorizando o uso de material biológico:}

É importante ressaltar que as amostra de sangue coletadas neste estudo serão usados apenas para os objetivos explicados neste Termo de Consentimento Livre e Esclarecido. Caso haja sobra deste material biológico, este será apropriadamente descartado (jogado fora).

\section{Autorização do sujeito (voluntário) ao Termo de Consentimento Livre e Esclarecido:}

Declaro que li este Termo de Consentimento Livre e Esclarecido e que minhas perguntas sobre este e sobre o estudo foram respondidas para minha satisfação. Fui informando que eu ou meu representante legal receberá uma cópia deste Termo de Consentimento Livre e Esclarecido, assinada e datada, e que o termo original ficará arquivado com a pesquisadora. Eu não estou abrindo mão de nenhum direito legal ao assinar este termo. Eu consinto voluntariamente minha participação neste estudo.

Assinatura do paciente

Data

Nome do paciente em letras de forma 
(Se o paciente é fisicamente incapaz de assinar e datar o termo de consentimento livre e esclarecido, como analfabetos, cegos, porém é capaz de consentir oralmente em participar).

Nome da testemunha imparcial em letra de forma

Assinatura da pessoa autorizada que explicou e obteve consentimento Data

Nome da pessoa autorizada que explicou e obteve consentimento 


\title{
ANEXO D - Termo de Consentimento Livre e Esclarecido - Grupo Controle
}

\author{
Termo de Consentimento Livre e Esclarecido (TCLE)
}

Nome do investigador: Adriana Assis Miranda

Número do telefone: (16) 8182-1022

Você está sendo convidada para participar de um estudo intitulado: "Toxicidade pulmonar na radioterapia torácica adjuvante em mulheres com câncer de mama." As informações a seguir descrevem o estudo e seu papel como possível participante. Este documento, Termo de Consentimento Livre e Esclarecido, possui este nome, pois você só deve decidir a participar depois de ler e entender este folheto e só depende de sua vontade em participar, podendo retirar seu consentimento em qualquer fase da pesquisa, sem penalização alguma e sem prejuízo ao seu tratamento. A pesquisadora irá responder a todas as perguntas que você possa ter sobre este Termo de Consentimento Livre e Esclarecido e sobre o estudo. Portanto, leia essas informações com cuidado e faça qualquer pergunta que considere necessária.

\section{Objetivos:}

Você está sendo convidado a participar desse estudo porque você não tem câncer ou processo inflamatório. $O$ objetivo deste estudo é avaliar se a radioterapia pode alterar, de alguma forma, a sua capacidade de respirar ou se a mesma causa alguma inflamação no sangue.

Procedimentos do estudo:

Se você concordar em participar do estudo e tiver assinado o Termo de Consentimento Livre e Esclarecido, você irá doar cerca de três $\mathrm{ml}$ de seu sangue, quando for colher algum exame de sangue para seu tratamento de rotina.

\section{Este exame será realizado somente uma única vez.}

Riscos e desconfortos:

Não há riscos ou desconforto, pois o sangue já seria colhido. 
Benefícios:

Você irá contribuir com parâmetros de normalidade para comparar com as pacientes com câncer.

Alternativa:

Se você optar por não participar deste estudo, você continuará seu tratamento normalmente.

Custos e reembolsos:

Você não receberá qualquer pagamento pela sua participação neste estudo, mas também não precisará pagar por qualquer dos testes do mesmo.

Mais informações; quem contatar:

Caso você tenha qualquer dúvida sobre o estudo, ou não queira mais participar, você poderá contatar a pesquisadora Adriana Assis Miranda pelo (16) 8281-1022.

Este Termo de Consentimento Livre e Esclarecido e este estudo foram aprovados pelo comitê de ética em pesquisa do HCRP-USP - Hospital das Clínicas da Faculdade de Medicina da Universidade de São Paulo - Campus de Ribeirão Preto, que é um grupo de pessoas - cientistas e não cientistas - que analisam e aprovam ou desaprovam estudos de pesquisa envolvendo seres humanos, de acordo com as regras estabelecidas pela Comissão Nacional de Ética em Pesquisa (CONEP). Pelas regras da CONEP, o Comitê de Ética em Pesquisa do HCRP-USP, também é obrigado a fazer revisões periódicas dos estudos em andamento. As perguntas sobre ética e seus direitos podem ser encaminhadas ao Comitê de Ética de Pesquisa do HCRP-USP. Avenida Bandeirantes, 3900 - Campus Universitário Monte Alegre - 14.048-900 - Ribeirão Preto - SP. 
Participação voluntária:

Sua participação é voluntária, ou seja, só depende de sua vontade de participar ou não. Você poderá se recusar a participar ou sair do estudo a qualquer momento, sem risco de sofrer penalidade ou perda de beneficio a que você teria direito. Se você sair do estudo não sofrerá qualquer preconceito em termos de cuidados médicos ou participação em estudo de pesquisa no futuro.

Confidencialidade:

Comitê de Ética em Pesquisa do HCRP-USP e a CONEP também poderão analisar seus registros. Os resultados deste estudo poderão ser publicados, sejam eles favoráveis ou não, mas seu nome não será mencionado.

Autorizando o uso de material biológico:

É importante ressaltar que as amostra de sangue coletadas neste estudo serão usados apenas para os objetivos explicados neste Termo de Consentimento Livre e Esclarecido. Caso haja sobra deste material biológico, este será apropriadamente descartado (jogado fora).

Autorização do sujeito (voluntário) ao Termo de Consentimento Livre e Esclarecido:

Declaro que li este Termo de Consentimento Livre e Esclarecido e que minhas perguntas sobre este e sobre o estudo foram respondidas para minha satisfação. Fui informando que eu ou meu representante legal receberá uma cópia deste Termo de Consentimento Livre e Esclarecido, assinada e datada, e que o termo original ficará arquivado com a pesquisadora. Eu não estou abrindo mão de nenhum direito legal ao assinar este termo. Eu consinto voluntariamente minha participação neste estudo.

Assinatura da voluntária

Data

Nome do paciente em letras de forma 


\section{ANEXO E - Questionário do Hospital Saint George na Doença Respiratória (SGRQ)}

Esse apresentado foi traduzido e validado no Brasil por Thais Costa se Souza, José Roberto Jardim e Paul Jones.

Este questionário ajuda a compreender até que ponto a sua dificuldade respiratória a perturba e afeta a sua vida.

Nós o utilizamos para descobrir quais os aspectos da sua doença que causam mais problemas.

Estamos interessados em saber o que você sente e não o que os médicos, enfermeiros e fisioterapeutas acham que você sente.

Leia atentamente as instruções.

Esclareça as dúvidas que tiver.

Não perca tempo nas suas respostas.

\section{PARTE 1}

- Nas perguntas abaixo, assinale que melhor identifica seus problemas respiratórios nos últimos três meses.

- Obs.: Assinale um só para as questões de 1 a 8.

$\begin{array}{ccccc}\begin{array}{c}\text { Maioria dos } \\ \text { dias da } \\ \text { semana }\end{array} & \begin{array}{c}\text { Vários dias } \\ \text { na semana }\end{array} & \begin{array}{c}\text { Alguns } \\ \text { dias no }\end{array} & \begin{array}{c}\text { Só com } \\ \text { Infecções }\end{array} & \text { Nunca } \\ \text { (5-7 dias) } & \text { (2-4 dias) } & \text { mês } & \text { respiratórias } & \end{array}$

1.) Durante os

últimos 3 meses

tossi.

2.) Durante os

últimos 3 meses tive

catarro.

3.) Durante os

últimos 3 meses tive

falta de ar.

4.) Durante os

últimos 3 meses tive

"chiado no peito". 


$\begin{array}{lllll}\begin{array}{llll}\text { Mais } \\ \text { de } 3\end{array} & 3 & 2 & 1 & \text { Nenhuma }\end{array}$

5.) Durante os últimos 3 meses, quantas vezes você teve crises graves de problemas respiratórios.

$\begin{array}{cccc}1 \text { semana ou } & 3 \text { ou } & 1 \text { ou } & \text { Menos de } 1 \\ \text { mais } & \text { mais } & 2 & \text { dia }\end{array}$

6.) Quanto tempo durou a pior dessas crises?

Passe para a 7 se não teve crises graves

$\begin{array}{lllll}\text { Mais } & 3 & 2 & 1 & \text { Nenhuma } \\ \text { de } 3 & & & & \end{array}$

7.) Durante os últimos 3 meses, em uma semana considerada habitual, quantas dias bons (com poucos problemas respiratórios) você teve.

Sim Não

8.) Se você tem "chiado no peito", ele piora pela manhã? 
- Parte 2

- Seção 1

A.) Assinale um só quadro $p$ descrever a sua doença respiratória:

É o meu maior problema
Me causa muitos problemas
Me causa alguns problemas
Não me causa nenhum problema

\begin{tabular}{lll}
\hline$\square$ & $\square$ & $\square$ \\
\hline
\end{tabular}

B.) Se você já teve um trabalho pago assinale um dos quadros:

Passe para Seção 2, se você não trabalhar.

Minha doença respiratória me obrigou a parar de trabalhar

Minha doença respiratória interferiu muito com o meu trabalho normal ou já me obrigou a mudar de trabalho

Minha doença respiratória não afeta (ou não afetou) o meu trabalho

- Seção 2

As perguntas a baixo referem-se às atividades que normalmente têm provocado falta de ar em você nos últimos dias. Assinale com " $x$ " no quadrado de cada pergunta abaixo, indicando a resposta Sim ou Não, de acordo com o seu caso:

Sim Não

Sentada ou deitada

Tomando banho ou vestido

Caminhando dentro de casa

Caminhando em terreno plano

Subindo um lance de escada

Subindo ladeiras

Praticando esportes ou jogos que impliquem esforços físicos 
- Seção 3

Mais algumas perguntas sobre sua tosse e sua falta de ar nos últimos dias. Assinale com um " $x$ " no quadrado de cada pergunta abaixo indicando a resposta Sim ou Não, de acordo com o seu caso:

Sim Não

Minha tosse me causa dor

Minha tosse me cansa

Tenho falta de ar quando falo

Tenho falta de ar quando dobro o corpo para frente

Minha tosse ou falta de ar perturba meu sono

Fico exausta com facilidade

- Seção 4

Perguntas sobre os efeitos causados pela sua doença respiratória nos últimos dias. Assinale com um " $x$ " no quadrado de cada pergunta abaixo indicando a resposta Sim ou Não, de acordo com o seu caso:

Sim Não

Minha tosse ou falta de ar me deixam envergonhada em público

Minha doença respiratória é inconveniente para minha família, amigos e vizinhos.

Tenho medo ou pânico quando não consigo respirar

Sinto que minha doença respiratória escapa ao meu controle

Eu não espero nenhuma melhora da minha doença respiratória

Minha doença me debilitou fisicamente, o que faz com que eu precise da ajuda de alguém. 
Fazer exercício é arriscado para mim

Tudo o que faço parece ser um esforço muito grande para mim

- Seção 5

A.) Perguntas sobre sua medicação. Assinale com um " $x$ " no quadrado de cada pergunta abaixo indicando a resposta Sim ou Não, de acordo com o seu caso:

Passe para seção 6 se não toma medicação.

$\operatorname{Sim} \quad$ Não

Minha medicação está me ajudando muito

Fico envergonhada ao tomar medicamentos em publico

Minha medicação provoca efeitos colaterais desagradáveis

Minha medicação interfere muito em meu dia-a-dia

- Seção 6

As perguntas seguintes se referem às atividades que podem ser afetadas pela sua doença respiratória. Assinale com um " $x$ " no quadrado de cada pergunta abaixo indicando a resposta Sim se pelo menos uma parte da frase corresponde ao seu caso; se não, assinale Não.

Sim Não

Levo muito tempo para me lavar ou me vestir

Demoro muito tempo ou não consigo tomar banho de chuveiro ou de banheira 
Ando mais devagar que outras pessoas, ou tenho que parar para descansar.

Demoro muito tempo para realizar as tarefas como trabalho de casa, ou tenho que parar para descansar.

Quando subo um lance de escada, vou muito devagar, ou tenho que parar para descansar.

Se estiver apressada ou caminho mais depressa, tenho que parar para descansar ou ir mais devagar.

Por causa da minha doença respiratória, tenho dificuldade para fazer atividades como: subir ladeiras, carregar objetos subindo escadas, dançar.

Por causa da minha doença respiratória, tenho dificuldade para fazer atividades como: carregar grandes pesos, fazer "cooper", andar muito rápido ou nadar.

Por causa da minha doença respiratória, tenho dificuldade para fazer atividades como: trabalho manual pesado, correr, nadar rápido ou praticar esportes muito cansativos.

\section{- Seção 7}

Assinale com um " $x$ " no quadrado de cada pergunta abaixo indicando a resposta Sim ou Não, para indicar outras atividades que geralmente podem ser afetadas pela sua doença respiratória no seu dia-a-dia:

(Não se esqueça de que o SIM só se aplica ao seu caso quando não puder fazer essa atividade devido à sua doença respiratória).

$\operatorname{Sim} \quad$ Não

Praticar esportes ou jogos que impliquem em esforço físico

Sair de casa para me divertir

Sair de casa para fazer compras

Fazer o trabalho de casa 
B.) A lista seguinte descreve uma série de outras atividades que seu problema respiratório pode impedir você de realizar (você não tem que assinalar nenhuma das atividades, pretendemos apenas lembrá-la das atividades que podem ser afetadas pela sua falta de ar).

Passear a pé ou passear com seu cachorro

Fazer trabalho doméstico ou jardinagem

Ter relações sexuais

Ir à igreja, bar ou locais de diversão.

Sair com mau tempo ou permanecer em locais com fumaça

Visitar parentes e os amigos ou brincar com as crianças

Por favor, escreva qualquer atividade importante que sua doença respiratória pode impedir você de fazer:

C.) Assinale com um " $x$ " somente a resposta que melhor define a forma como você é afetada pela sua doença respiratória:

Não me impede de fazer nenhuma das coisas que eu gostaria de fazer

Me impede de fazer um ou duas das coisas que eu gostaria de fazer

Me impede de fazer a maioria das coisas que eu gostaria de fazer

Me impede de fazer tudo que eu gostaria de fazer

Obrigada por ter respondido o questionário. Antes de terminar, verifique se você respondeu todas as questões. 
ANEXO F - Características da neoplasia mamária, tratamento cirúrgico, quimioterápico e complementares de cada paciente

\begin{tabular}{|c|c|c|c|c|c|c|c|c|}
\hline & Idade & Estádio & Tipo Histológico & Cirurgia & $\begin{array}{l}\text { Quimioterapia } \\
\text { Neoadjuvante }\end{array}$ & $\begin{array}{c}\text { Quimioterapia } \\
\text { Adjuvante }\end{array}$ & Tamoxifeno & Herceptin \\
\hline 1 & 65 & T2N0M0 & $\begin{array}{l}\text { Carcinoma Ductal } \\
\text { Invasivo grau II }\end{array}$ & $\begin{array}{c}\text { Tumorectomia a } \\
D+E A^{*}\end{array}$ & $4 \times$ Epi+Ciclo*** & $4 \times$ Docetaxel & Sim & Não \\
\hline 2 & 52 & T1N0M0 & $\begin{array}{l}\text { Carcinoma Ductal } \\
\text { Invasivo grau II }\end{array}$ & $\begin{array}{c}\text { Tumorectomia a } \\
\mathrm{D}+\mathrm{BLS} \mathrm{S}^{\star *}\end{array}$ & Não realizou & $6 \times$ Epi+Ciclo*** & Não & Não \\
\hline 3 & 65 & T1N0M0 & $\begin{array}{l}\text { Carcinoma Ductal } \\
\text { Invasivo grau II }\end{array}$ & $\begin{array}{c}\text { Tumorectomia a } \\
E+B L S^{* *}\end{array}$ & Não realizou & Não realizou & Sim & Não \\
\hline 4 & 65 & T2NOMO & $\begin{array}{l}\text { Carcinoma Ductal } \\
\text { Invasivo grau II }\end{array}$ & $\begin{array}{c}\text { Tumorectomia a } \\
D+B L S^{\star *}\end{array}$ & Não realizou & Não realizou & Sim & Não \\
\hline 5 & 60 & T2 NOMO & $\begin{array}{l}\text { Carcinoma Ductal } \\
\text { Invasivo grau III }\end{array}$ & $\begin{array}{c}\text { Tumorectomia a } \\
E+B L S^{\star *}\end{array}$ & Não realizou & Não realizou & Sim & Não \\
\hline 6 & 56 & T1N0M0 & $\begin{array}{l}\text { Carcinoma Lobular } \\
\text { Invasivo grau I }\end{array}$ & $\begin{array}{c}\text { Tumorectomia a } \\
D+E A^{*}\end{array}$ & Não realizou & Não realizou & Sim & Não \\
\hline 7 & 55 & T3N1M0 & $\begin{array}{l}\text { Carcinoma Ductal } \\
\text { Invasivo grau II }\end{array}$ & $\begin{array}{c}\text { Tumorectomia a } \\
E+E A^{*}\end{array}$ & $4 \times$ Epi+Ciclo*** & $4 \times$ Docetaxel & Sim & Não \\
\hline 8 & 46 & T4N2M0 & $\begin{array}{l}\text { Carcinoma Ductal } \\
\text { Invasivo grau II }\end{array}$ & $\begin{array}{c}\text { Mastectomia a } \\
E+E A^{*}\end{array}$ & $4 \times$ Epi+Ciclo*** & $4 \times$ Docetaxel & Sim & Sim \\
\hline 9 & 54 & T2N1M0 & $\begin{array}{l}\text { Carcinoma Ductal } \\
\text { Invasivo grau III }\end{array}$ & $\begin{array}{c}\text { Tumorectomia a } \\
E+E A^{*}\end{array}$ & Não realizou & $\begin{array}{l}4 \times \text { Epi+Ciclo*** } \\
\text { e } 4 \text { x Docetaxel }\end{array}$ & Sim & Sim \\
\hline 10 & 50 & T2N2M0 & $\begin{array}{l}\text { Carcinoma Ductal } \\
\text { Invasivo grau II }\end{array}$ & $\begin{array}{c}\text { Tumorectomia a } \\
D+E A^{*}\end{array}$ & Não realizou & $\begin{array}{l}4 \times \text { Epi+Ciclo*** } \\
\text { e } 4 \text { x Docetaxel }\end{array}$ & Sim & Sim \\
\hline 11 & 55 & T1 N0M0 & $\begin{array}{l}\text { Carcinoma Ductal } \\
\text { Invasivo grau II }\end{array}$ & $\begin{array}{c}\text { Tumorectomia a } \\
E+B L S^{\star *}\end{array}$ & Não realizou & Não realizou & Sim & Não \\
\hline 12 & 63 & T1 NoM0 & $\begin{array}{l}\text { Carcinoma Ductal } \\
\text { Invasivo arau I }\end{array}$ & $\begin{array}{c}\text { Tumorectomia a } \\
D+B L S^{* *}\end{array}$ & Não realizou & Não realizou & Sim & Não \\
\hline
\end{tabular}

*EA: esvasiamente axilar; **BLS: biópsia de linfonodo sentinela; ${ }^{\star * \star}$ Epi+Ciclo: epirrubicina + ciclofosfamida 
ANEXO F - Continuação - Características da neoplasia mamária, tratamento cirúrgico, quimioterápico e complementares de cada paciente

\begin{tabular}{|c|c|c|c|c|c|c|c|c|}
\hline & Idade & Estádio & Tipo Histológico & Cirurgia & $\begin{array}{l}\text { Quimioterapia } \\
\text { Neoadjuvante }\end{array}$ & $\begin{array}{l}\text { Quimioterapia } \\
\text { Adjuvante }\end{array}$ & Tamoxifeno & Herceptin \\
\hline 13 & 42 & T1N1M0 & $\begin{array}{l}\text { Carcinoma Ductal } \\
\text { invasivo grau II }\end{array}$ & $\begin{array}{c}\text { Mastectomia a } \\
D+E A^{*}\end{array}$ & Não realizou & $6 \times$ Epi+Ciclo*** & Sim & Não \\
\hline 14 & 60 & T2N1M0 & $\begin{array}{l}\text { Carcinoma Ductal } \\
\text { Invasivo grau II }\end{array}$ & $\begin{array}{c}\text { Tumorectomia a } \\
\qquad E+E A^{*}\end{array}$ & $4 \times$ Epi+Ciclo*** & $4 \times$ Docetaxel & Sim & Não \\
\hline 15 & 25 & T2NOMO & $\begin{array}{l}\text { Carcinoma Ductal } \\
\text { Invasivo grau III }\end{array}$ & $\begin{array}{c}\text { Tumorectomia a } \\
E+E A^{*}\end{array}$ & $4 \times$ Epi+Ciclo*** & $4 \times$ Docetaxel & Sim & Sim \\
\hline 16 & 58 & T1N2M0 & $\begin{array}{l}\text { Carcinoma Ductal } \\
\text { Invasivo grau III }\end{array}$ & $\begin{array}{c}\text { Tumorectomia a } \\
D+E A^{*}\end{array}$ & $4 \times$ Epi+Ciclo*** & $4 \times$ Docetaxel & Não & Sim \\
\hline 17 & 63 & T2N2M0 & $\begin{array}{l}\text { Carcinoma Ductal } \\
\text { Invasivo grau III }\end{array}$ & $\begin{array}{c}\text { Tumorectomia a } \\
\qquad E+E A^{*}\end{array}$ & Não realizou & $\begin{array}{l}4 \times \text { Epi+Ciclo*** } \\
\text { e } 4 \text { x Docetaxel }\end{array}$ & Sim & Não \\
\hline 18 & 37 & T4N0M0 & $\begin{array}{l}\text { Carcinoma Ductal } \\
\text { Invasivo grau II }\end{array}$ & $\begin{array}{c}\text { Mastectomia a } \\
E+E A^{*}\end{array}$ & $4 \times$ Epi+Ciclo*** & $4 \times$ Docetaxel & Sim & Não \\
\hline 19 & 48 & T1N0M0 & $\begin{array}{l}\text { Carcinoma Ductal } \\
\text { in situs }\end{array}$ & $\begin{array}{c}\text { Tumorectomia a } \\
\text { E }\end{array}$ & Não realizou & Não realizou & Sim & Não \\
\hline 20 & 54 & T2NOMO & $\begin{array}{l}\text { Carcinoma Ductal } \\
\text { Invasivo grau III }\end{array}$ & $\begin{array}{c}\text { Tumorectomia a } \\
\qquad+E A^{*}\end{array}$ & Não realizou & $6 \times$ Epi+Ciclo*** & Não & Não \\
\hline 21 & 43 & T4N2M0 & $\begin{array}{l}\text { Carcinoma Ductal } \\
\text { Invasivo grau III }\end{array}$ & $\begin{array}{c}\text { Mastectomia a } \\
D+E A^{*}\end{array}$ & $4 \times$ Epi+Ciclo*** & $4 \times$ Docetaxel & Sim & Sim \\
\hline 22 & 63 & T1N0M0 & $\begin{array}{l}\text { Carcinona Ductal } \\
\text { in situs }\end{array}$ & $\begin{array}{c}\text { Tumorectomia a } \\
\text { D }\end{array}$ & Não realizou & Não realizou & Sim & Não \\
\hline 23 & 36 & T4N2M0 & $\begin{array}{c}\text { Carcinoma Ductal } \\
\text { invasivo grau II }\end{array}$ & $\begin{array}{c}\text { Mastectomia D } \\
+E A^{*}\end{array}$ & 4 x Epi+Ciclo*** & $4 \times$ Docetaxel & Sim & Não \\
\hline 24 & 50 & T4N0M0 & $\begin{array}{l}\text { Carcinoma Ductal } \\
\text { Invacivn araw }\end{array}$ & $\begin{array}{c}\text { Mastectomia a } \\
F \perp F \Delta^{*}\end{array}$ & 4 x Epi+Ciclo*** & $4 \times$ Docetaxel & Sim & Não \\
\hline
\end{tabular}

${ }^{*}$ EA: esvasiamente axilar; **BLS: biópsia de linfonodo sentinela; ${ }^{* * *}$ Epi+Ciclo: epirrubicina + ciclofosfamida 
ANEXO G - Características do tratamento radioterápico realizado em cada paciente

\begin{tabular}{|c|c|c|c|c|c|}
\hline $\begin{array}{l}\text { Número } \\
\text { da } \\
\text { paciente }\end{array}$ & Área irradiada & $\begin{array}{l}\text { Número } \\
\text { de } \\
\text { sessões }\end{array}$ & $\begin{array}{c}\text { Dose diaria/ } \\
\text { total (cGy) }\end{array}$ & $\begin{array}{l}\text { Boost } \\
\text { número de } \\
\text { sessões }\end{array}$ & $\begin{array}{c}\text { Dose diaria/ } \\
\text { total } \\
\text { (cGy) }\end{array}$ \\
\hline 1 & Mama D & 28 & $180 / 5040$ & 5 & $200 / 1000$ \\
\hline 2 & Mama D & 28 & $180 / 5040$ & 5 & $200 / 1000$ \\
\hline 3 & Mama E & 28 & $180 / 5040$ & 5 & $200 / 1000$ \\
\hline 4 & Mama D & 28 & $180 / 5040$ & 5 & $200 / 1000$ \\
\hline 5 & Mama E & 28 & $180 / 5040$ & 5 & $200 / 1000$ \\
\hline 6 & Mama D & 25 & $200 / 5000$ & 5 & $200 / 1000$ \\
\hline 7 & Mama E + FSC & 25 & $200 / 5000$ & 5 & $200 / 1000$ \\
\hline 8 & Mama E + FSC* & 28 & $180 / 5040$ & 5 & $200 / 1000$ \\
\hline 9 & Mama E + FSC & 28 & $180 / 5040$ & 5 & $200 / 1000$ \\
\hline 10 & Mama D +FSC* & 28 & $180 / 5040$ & 5 & $200 / 1000$ \\
\hline 11 & Mama E & 28 & $180 / 5040$ & 5 & $200 / 1000$ \\
\hline 12 & Mama D & 25 & $200 / 5000$ & 5 & $200 / 1000$ \\
\hline 13 & Mama D + FSC* & 25 & $200 / 5000$ & 5 & $200 / 1000$ \\
\hline 14 & Mama E + FSC* & 28 & $180 / 5040$ & 5 & $200 / 1000$ \\
\hline 15 & Mama E & 25 & $200 / 5000$ & 5 & $200 / 1000$ \\
\hline 16 & Mama D + FSC & 28 & $180 / 5040$ & 0 & 0 \\
\hline 17 & Mama E + FSC ${ }^{*}$ & 28 & $180 / 5040$ & 5 & $200 / 1000$ \\
\hline 18 & Mama E + FSC* & 28 & $180 / 5040$ & 5 & $200 / 1000$ \\
\hline 19 & Mama E & 25 & $200 / 5000$ & 5 & $200 / 1000$ \\
\hline 20 & Mama D & 25 & $200 / 5040$ & 5 & $200 / 1000$ \\
\hline 21 & Mama D +FSC* & 25 & $200 / 5000$ & 0 & 0 \\
\hline 22 & Mama D & 25 & $200 / 5000$ & 5 & $200 / 1000$ \\
\hline 23 & Mama D + FSC & 25 & $200 / 5000$ & 5 & $200 / 1000$ \\
\hline 24 & Mama $\mathrm{E}+\mathrm{FSC}^{*}$ & 25 & $200 / 5000$ & 5 & $200 / 1000$ \\
\hline
\end{tabular}

${ }^{\star}$ FSC: Fossa Supraclavicular 


\section{Anexo H - Descrição dos achados qualitativos e quantitativos nas tomografias pré-RT e após a RT}

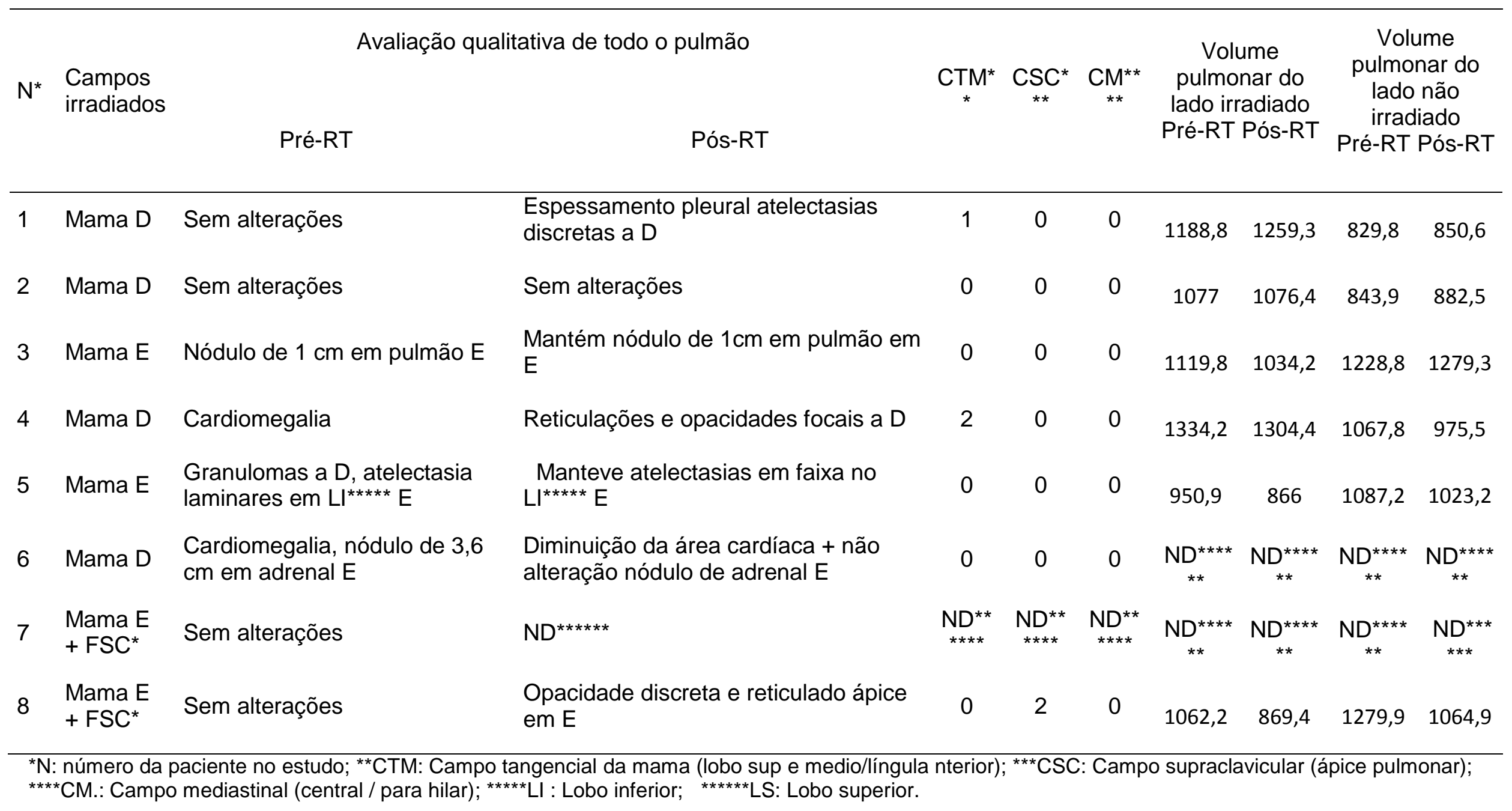


Anexo H - Continuação - Descrição dos achados qualitativos e quantitativos nas tomografias pré-RT e após a RT

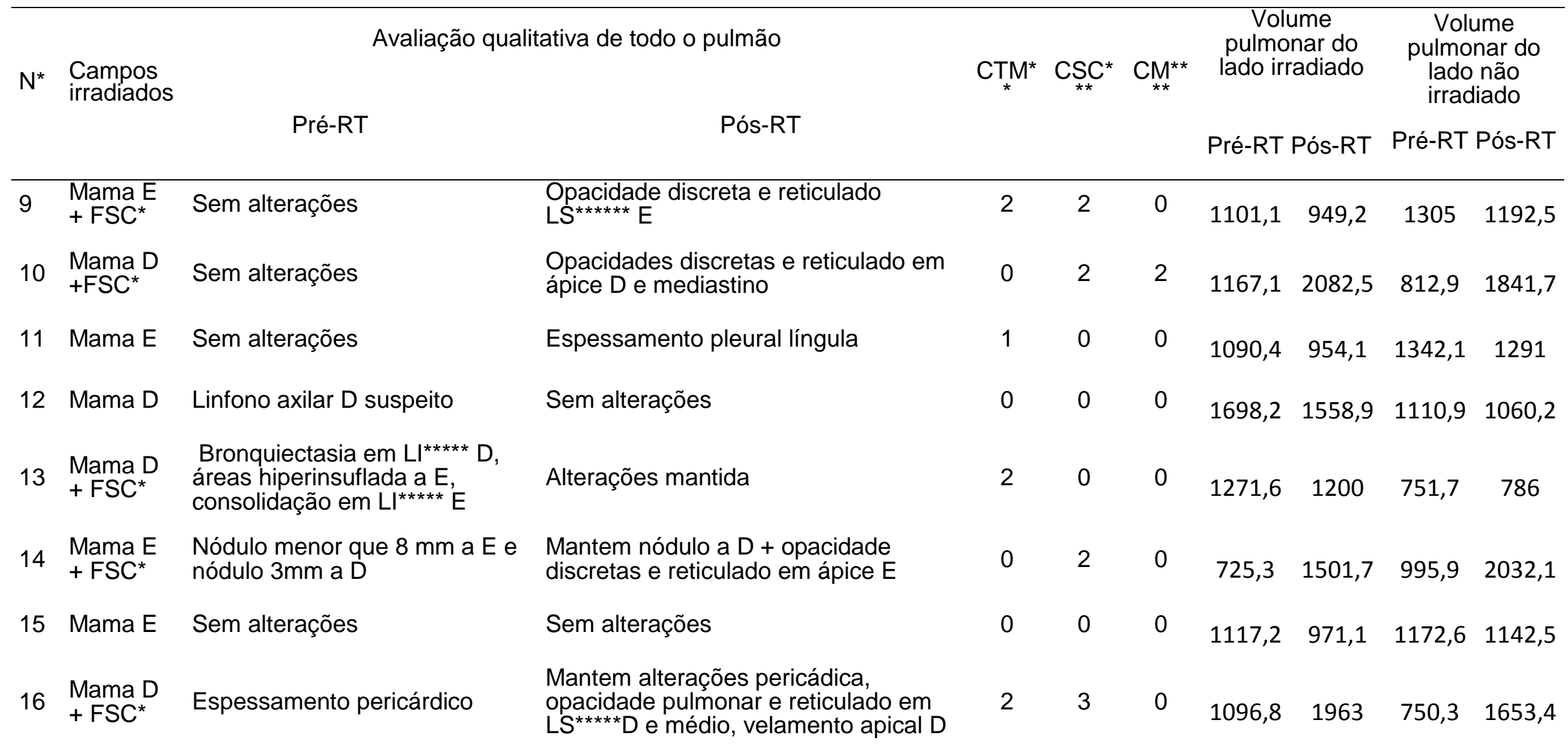

${ }^{\star} \mathrm{N}$ : número da paciente no estudo; ${ }^{* *}$ CTM: Campo tangencial da mama (lobo sup e medio/língula nterior); ${ }^{* *}$ CSC: Campo supraclavicular (ápice pulmonar);

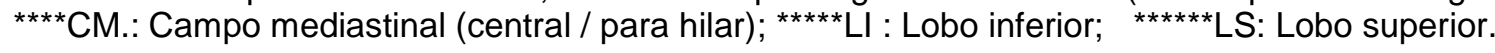


Anexo H - Continuação - Descrição dos achados qualitativos e quantitativos nas tomografias pré-RT e após a RT

\begin{tabular}{|c|c|c|c|c|c|c|c|c|c|c|}
\hline \multirow{2}{*}{$\mathrm{N}^{*}$} & \multirow{2}{*}{$\begin{array}{l}\text { Campos } \\
\text { irradiados }\end{array}$} & \multicolumn{2}{|c|}{ Avaliação qualitativa de todo o pulmão } & \multirow{2}{*}{$\mathrm{CTM}_{*}^{*}$} & \multirow{2}{*}{$\mathrm{CSC}_{* *}^{*}$} & \multirow{2}{*}{$\mathrm{CM}_{* \star}^{* *}$} & \multicolumn{2}{|c|}{$\begin{array}{c}\text { Volume } \\
\text { pulmonar do } \\
\text { lado irradiado }\end{array}$} & \multicolumn{2}{|c|}{$\begin{array}{l}\text { Volume } \\
\text { pulmonar do } \\
\text { lado não } \\
\text { irradiado }\end{array}$} \\
\hline & & Pré-RT & Pós-RT & & & & Pré-RT & Pós-RT & Pré-RT & Pós-RT \\
\hline 17 & $\begin{array}{l}\text { Mama E } \\
+ \text { FSC }^{*}\end{array}$ & $\begin{array}{l}\text { Granuloma calcificado em } \\
\mathrm{LI}^{\star \star \star \star \star} \mathrm{E}\end{array}$ & Manteve alterações & 0 & 0 & 0 & 2237,1 & 1011,2 & 2689,5 & 1229,6 \\
\hline 18 & $\begin{array}{l}\text { Mama E } \\
+\mathrm{FSC}^{*}\end{array}$ & Sem alterações & $\begin{array}{l}\text { Opacidade pulmonar e reticulado em } \\
\text { ápice E e calcificações mediastinal }\end{array}$ & 0 & 2 & 0 & 792,30 & 978,5 & 935,7 & 1238,1 \\
\hline 19 & Mama E & 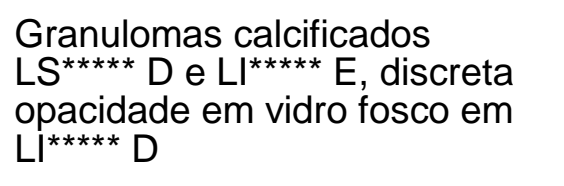 & $\begin{array}{l}\text { Acentuação das alterações e } \\
\text { espessamento pleural língular }\end{array}$ & 1 & 0 & 0 & 1067,5 & 909,6 & 1329,8 & 1168,8 \\
\hline 20 & Mama D & Sem alterações & $\begin{array}{l}\text { Opacidades pulmonares e reticulado } \\
\text { em } L S^{\star * \star * \star} \text { D e médio }\end{array}$ & 2 & 0 & 0 & 1195,5 & 1220,5 & 826,3 & 839,3 \\
\hline 23 & $\begin{array}{l}\text { Mama D } \\
+ \text { FSC }^{*}\end{array}$ & Sem alterações & Sem alterações & 0 & 0 & 0 & 1403 & 1352,4 & 1052,6 & 1018,8 \\
\hline 24 & $\begin{array}{l}\operatorname{Mama}_{+\mathrm{FSC}^{*}}\end{array}$ & Sem alterações & Sem alterações & 0 & 0 & 0 & 963,3 & 1018,8 & 1279,5 & 1365,8 \\
\hline
\end{tabular}

*N: número da paciente no estudo; ${ }^{* *}$ CTM: Campo tangencial da mama (lobo sup e medio/língula nterior); ${ }^{* * *}$ CSC: Campo supraclavicular (ápice pulmonar);

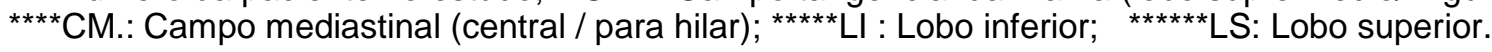




\section{ANEXO I - Valores observados na prova de função pulmonar}

\begin{tabular}{|c|c|c|c|c|c|c|c|c|c|c|}
\hline \multirow{3}{*}{$\mathrm{Pc}^{*}$} & \multicolumn{4}{|c|}{ CVF } & \multicolumn{2}{|c|}{ VR } & \multicolumn{4}{|c|}{ CPT } \\
\hline & \multicolumn{2}{|c|}{ Pré-RT } & \multicolumn{2}{|c|}{ Pós-RT } & Pré-RT & Pós-RT & \multicolumn{2}{|c|}{ Pré-RT } & \multicolumn{2}{|c|}{ Pós-RT } \\
\hline & $\mathrm{L}$ & $\%^{* *}$ & $\mathrm{~L}$ & $\%^{* *}$ & $\%^{* *}$ & $\%^{* *}$ & $L$ & $\%$ \%* & $L$ & $\%^{* *}$ \\
\hline 1 & 2,37 & (88) & 2,12 & (79) & $3,42(172)$ & 2,55 (127) & 5,79 & (124) & 4,67 & (100) \\
\hline 2 & 3,03 & $(112)$ & 2,99 & $(112)$ & 2,19 (139) & $1,87(117)$ & 5,22 & (124) & 4,86 & (116) \\
\hline 3 & 2,69 & $(97)$ & 2,63 & (95) & $2,52(125)$ & $1,87(92)$ & 5,21 & (109) & 4,5 & (101) \\
\hline 4 & 2,48 & (108) & 2,31 & $(101)$ & 1,79 (99) & 2,84 (158) & 4,27 & (104) & 5,15 & (106) \\
\hline 5 & 1,54 & (69) & 1,61 & (72) & $2,66(164)$ & 1,68 (104) & 4,2 & (110) & 3,29 & (86) \\
\hline 6 & 3,56 & (108) & 3,37 & (103) & $3,64(188)$ & 2,56 (132) & 6,9 & (135) & 5,93 & (116) \\
\hline 7 & 1,99 & (71) & 2,03 & $(72)$ & 2,9 (168) & $1,92(101)$ & 4,89 & (110) & 3,95 & (90) \\
\hline 8 & 3,38 & $(101)$ & 3,68 & $(109)$ & 2,19 (127) & 2,47 (145) & 5,57 & (113) & 6,15 & (126) \\
\hline 9 & 3,39 & (109) & 2,89 & (93) & $2,18(120)$ & 2,46 (147) & 5,57 & (115) & 5,53 & (115) \\
\hline 10 & 2,78 & (85) & 3,1 & (94) & 1,41 (79) & $1,73(97)$ & 4,19 & (85) & 4,83 & (98) \\
\hline 11 & 2,84 & (98) & 3,1 & (107) & $2,06(117)$ & $1,46(82)$ & 4,9 & (107) & 4,56 & (100) \\
\hline 12 & 3,35 & (112) & 3,38 & (114) & 2,47 (134) & 1,9 (103) & 5,86 & (117) & 5,32 & (110) \\
\hline 13 & 2,39 & (93) & 2,39 & (93) & $1,67(147)$ & 1,19 (105) & 4,06 & (109) & 3,64 & (98) \\
\hline 14 & 2,32 & (83) & 2,66 & $(91)$ & $1,69(104)$ & $1,88(110)$ & 3,91 & (89) & 4,59 & (99) \\
\hline 15 & 3,63 & (93) & 3,55 & (93) & 1,04 (87) & $1,48(102)$ & 4,44 & (82) & 4,95 & (94) \\
\hline 16 & 2,48 & $(101)$ & 2,5 & (102) & $1,3(96)$ & 1,77 (130) & 3,76 & (99) & 4,33 & (113) \\
\hline 17 & 2,75 & $(94)$ & 2,82 & (98) & $1,89(106)$ & $1,92(108)$ & 4,57 & $(97)$ & 4,93 & (105) \\
\hline 18 & 3,16 & $(92)$ & 3,22 & (94) & $1,57(106)$ & $1,2(81)$ & 4,67 & (95) & 4,48 & (91) \\
\hline 19 & 3,71 & $(111)$ & 3,57 & $(108)$ & 1,58 (92) & $1,46(84)$ & 5,26 & (104) & 5,02 & $(100)$ \\
\hline 20 & 2,98 & (99) & 3,08 & $(102)$ & $1,32(80)$ & $1,67(102)$ & 4,24 & (91) & 4,46 & (96) \\
\hline 21 & 4,8 & $(112)$ & 4,57 & $(108)$ & $1,62(72)$ & $1,82(81)$ & 6,39 & (98) & 6,37 & (98) \\
\hline 22 & 2,91 & $(141)$ & 2,52 & $(122)$ & $1,62(130)$ & 1,1 (88) & 4,57 & (138) & 3,65 & (110) \\
\hline 23 & 3,49 & $(101)$ & $\mathrm{Nd}^{* * *}$ & $\mathrm{Nd}^{* * *}$ & 2,49 (152) & $\mathrm{Nd}^{* * *} \mathrm{Nd}^{* * *}$ & 6,19 & (121) & $\mathrm{Nd}^{* * *}$ & $\mathrm{Nd}^{* * *}$ \\
\hline 24 & 3,36 & (93) & 3,02 & (85) & $1,78(91)$ & $1,78(91)$ & 5,11 & (92) & 5 & (91) \\
\hline
\end{tabular}

${ }^{*}$ Pc: paciente; ${ }^{* *}(\%)$ : valores obtidos em relação ao valor mediano previsto; ${ }^{* * *} \mathrm{Nd}$ : dados não disponíveis 
ANEXO I - Continuação - Valores observados na prova de função pulmonar

\begin{tabular}{|c|c|c|c|c|c|c|}
\hline \multirow{3}{*}{$\mathrm{Pc}^{*}$} & \multicolumn{2}{|c|}{ VEF1 } & \multicolumn{2}{|c|}{ FEF50\% } & \multicolumn{2}{|c|}{ FEF75\% } \\
\hline & Pré-RT & Pós-RT & Pré-RT & Pós-RT & Pré-RT & Pós-RT \\
\hline & L \%** & L \%** & L/seg \%** & L/seg \%** & L/seg \%** & L/seg \%** \\
\hline 1 & $1,9(98)$ & $1,66(87)$ & $2,48(66)$ & $2,36(63)$ & $0,65(46)$ & $0,32(23)$ \\
\hline 2 & $2,23(110)$ & $2,27(114)$ & $2,92(75)$ & $3,56(92)$ & $0,32(18)$ & 0,39 (22) \\
\hline 3 & $2,27(113)$ & $2,17(110)$ & $3,66(96)$ & 3,31 (88) & $1,85(129)$ & $1,14(82)$ \\
\hline 4 & $1,82(112)$ & $1,7(104)$ & $2,04(58)$ & $2,12(60)$ & $0,31 \quad(24)$ & $0,29(21)$ \\
\hline 5 & $1,24(77)$ & $1,28(79)$ & $1,93(54)$ & $2,31(65)$ & 0,37 (25) & $0,34(23)$ \\
\hline 6 & $2,83(114)$ & $2,75(112)$ & $5(120)$ & $5,29(127)$ & $0,75(41)$ & $1(55)$ \\
\hline 7 & $1,62(78)$ & $1,63(78)$ & $2,34(60)$ & 2,28 (58) & 0,48 (27) & $0,45(26)$ \\
\hline 8 & 3,27 (114) & 3,27 (126) & 6,25 (146) & $6,48(150)$ & 1,79 (86) & $2,99(141)$ \\
\hline 9 & $2,76(119)$ & $2,43(104)$ & 4,91 (120) & 3,88 (95) & $0,89(49)$ & $1,2(65)$ \\
\hline 10 & 2,33 (94) & $2,58(104)$ & $6,33(150)$ & $5,16(122)$ & $0,86(43)$ & 1,05 (53) \\
\hline 11 & 2,35 (109) & 2,41 (112) & $5,19(131)$ & $2,96(75)$ & 0,69 (39) & 0,69 (39) \\
\hline 12 & 2,67 (122) & $2,6(120)$ & 3,79 (96) & $3,16(81)$ & $0,86(55)$ & 0,23 (35) \\
\hline 13 & $1,5(75)$ & $1,56(78)$ & 0,95 (23) & $1,1 \quad(26)$ & $0,22(10)$ & 0,28 (13) \\
\hline 14 & 1,97 (97) & $2,23(103)$ & $5,2(135)$ & 4,78 (121) & $0,93(59)$ & $0,97(59)$ \\
\hline 15 & $3,16(102)$ & 3,07 (101) & $5,12(106)$ & 4,67 (98) & $1,73(61)$ & $1,53(54)$ \\
\hline 16 & 1,92 (107) & $1,95(108)$ & 2,93 (79) & $2,59(70)$ & 0,55 (35) & 0,37 (24) \\
\hline 17 & 2,19 (103) & $2,35(112)$ & $2,94(76)$ & $4,02(104)$ & 0,67 (44) & $1,01 \quad(67)$ \\
\hline 18 & 2,64 (98) & $2,63(98)$ & $3,34(75)$ & $3,05(69)$ & $1,08(44)$ & $1,04(43)$ \\
\hline 19 & $3,05(120)$ & $2,94(117)$ & $4(94)$ & 4,07 (96) & $1,35(66)$ & 1,18 (59) \\
\hline 20 & $2,47(110)$ & 2,42 (107) & 3,34 (83) & $2,2(54,6)$ & 1,48 (82) & $1,22(68)$ \\
\hline 21 & $3,72(113)$ & $3,51(108)$ & 4,28 (89) & $3,32(69)$ & $1,23(52)$ & $1,46(62)$ \\
\hline 22 & $2,31(156)$ & $2(135)$ & 3,23 (89) & $2,67(74)$ & $0,74(52)$ & $0,73(51)$ \\
\hline 23 & $3,48(129)$ & $\mathrm{Nd}^{* \star *} \mathrm{Nd}^{* \star *}$ & $5,85(122)$ & $\mathrm{Nd}^{* * *} \mathrm{Nd}^{* * *}$ & 4,07 (159) & $\mathrm{Nd}^{* * *} \mathrm{Nd}^{* * *}$ \\
\hline 24 & $2,76(98)$ & $2,46(91)$ & $3,32(76)$ & $2,8(64)$ & $0,76(37)$ & $0,89(44)$ \\
\hline
\end{tabular}

*Pc: paciente; ${ }^{* \star}(\%)$ : valores obtidos em relação ao valor mediano previsto; ${ }^{* \star *} \mathrm{Nd}$ : dados não disponíveis 
ANEXO I - Continuação - Valores observados na prova de função pulmonar

\begin{tabular}{|c|c|c|c|c|c|c|c|c|}
\hline \multirow{3}{*}{$\mathrm{Pc}^{*}$} & \multicolumn{2}{|c|}{ CV } & \multicolumn{4}{|c|}{ CRF } & \multicolumn{2}{|c|}{ DLCO } \\
\hline & \multirow{2}{*}{$\begin{array}{l}\text { Pré-RT } \\
\text { L \%** }\end{array}$} & \multirow{2}{*}{$\begin{array}{l}\text { Pós-RT } \\
\text { L \%** }\end{array}$} & \multicolumn{2}{|c|}{ Pré-RT } & \multicolumn{2}{|c|}{ Pós-RT } & \multirow{2}{*}{$\begin{array}{c}\text { Pré-RT } \\
\mathrm{L} / \mathrm{min} / \mathrm{m} \\
\mathrm{mHg}\end{array} \%$} & \multirow{2}{*}{$\begin{array}{l}\text { Pós-RT } \\
\mathrm{L} / \mathrm{min} / \mathrm{m} \\
\mathrm{mHg}\end{array}$} \\
\hline & & & $\mathrm{L}$ & $\%$ ** & $L$ & $\%$ ** & & \\
\hline 1 & $2,26(85)$ & $2,19(82)$ & 3,99 & $(149)$ & 2,9 & $(109)$ & $15,31(87)$ & $16,24(93)$ \\
\hline 2 & $2,96(114)$ & 2,88 (112) & 2,83 & (119) & 2,38 & $(100)$ & $16,41 \quad(89)$ & $17,25(94)$ \\
\hline 3 & $2,53(92)$ & 2,6 (95) & 3,05 & $(111)$ & 2,99 & $(109)$ & 19,5 (109) & 14,57 (99) \\
\hline 4 & 2,25 (98) & $2,02(88)$ & 2,52 & (107) & 3,71 & (158) & $17,26(101)$ & 14,71 (88) \\
\hline 5 & $1,63(74)$ & $1,51 \quad(67)$ & 2,82 & (129) & 2,12 & $(97)$ & $12,57(75)$ & $11,31 \quad(67)$ \\
\hline 6 & $3,26(102)$ & 3,24 (102) & 4,23 & $(144)$ & 3,23 & $(110)$ & 26,03 (132) & $25,89(132)$ \\
\hline 7 & $1,83(67)$ & 2,73 (109) & 3,03 & $(120)$ & 2,01 & (79) & $15,42(83)$ & $14,32(77)$ \\
\hline 8 & $3,21(100)$ & $3,21(100)$ & 2,77 & (99) & 3,18 & $(114)$ & 24,32 (120) & 22,62 (111) \\
\hline 9 & $3,05(102)$ & 2,98 (99) & 2,82 & $(102)$ & 2,87 & $(104)$ & $19,72(120)$ & $16,73(86)$ \\
\hline 10 & $2,66(84)$ & 3,19 (101) & 2,01 & (71) & 3,02 & $(107)$ & 19,57 (98) & $16,72(84)$ \\
\hline 11 & $3,02(108)$ & 2,87 (103) & 2,54 & (98) & 2,09 & $(80)$ & $18,56(99)$ & $19,62(105)$ \\
\hline 12 & 3,21 (107) & $3,42(115)$ & 3,43 & (125) & 3,16 & $(115)$ & $18,65(100)$ & 16,07 (87) \\
\hline 13 & 2,39 (93) & 2,45 (95) & 2,11 & (109) & 2,06 & $(106)$ & $20,36(103)$ & 20,01 (101) \\
\hline 14 & $2,22(80)$ & 2,71 (92) & 1,71 & (69) & 1,9 & (73) & $18,48(102)$ & $18,05(97)$ \\
\hline 15 & $3,39(87)$ & 3,47 (91) & 2,42 & (88) & 2,5 & (94) & 22,37 (98) & 21,28 (94) \\
\hline 16 & $2,46(100)$ & 2,57 (104) & 1,87 & $(90)$ & 2,35 & $(112)$ & 11,71 (67) & $13,23(76)$ \\
\hline 17 & 2,68 (92) & 3 (104) & 1,93 & (73) & 1,95 & (74) & $17,12(92)$ & $17,48(96)$ \\
\hline 18 & 3,1 (90) & $3,28(96)$ & 1,91 & (75) & 1,69 & $(66)$ & $23,84(113)$ & $21,02(100)$ \\
\hline 19 & $3,68(110)$ & 3,57 (108) & 2,74 & $(100)$ & 2,4 & $(87)$ & 22,1 (109) & 18,75 (93) \\
\hline 20 & $2,92(97)$ & $2,79(93)$ & 1,97 & (77) & 2,02 & $(79)$ & $17,15(90)$ & $22,96(120)$ \\
\hline 21 & 4,77 (112) & 4,55 (107) & 3,49 & (97) & 3,54 & $(99)$ & $27,82(122)$ & $26,72(118)$ \\
\hline 22 & $2,95(143)$ & 2,52 (119) & 2,21 & (119) & 1,62 & $(85)$ & 21,05 (123) & $10,72(63)$ \\
\hline 23 & 3,7 (107) & $\mathrm{Nd}^{* \star *} \mathrm{Nd}^{* \star \star}$ & 2,84 & $(104)$ & $\mathrm{Nd}^{* * *}$ & $\mathrm{Nd}^{\star \star *}$ & $26,22(115)$ & $\mathrm{Nd}^{* * *} \mathrm{Nd}^{* * *}$ \\
\hline 24 & 3,33 (92) & $3,23(91)$ & 2,1 & (68) & 2,1 & (69) & 22,45 (108) & $21,45(104)$ \\
\hline
\end{tabular}

${ }^{*}$ Pc: paciente; ${ }^{* \star}(\%)$ : valores obtidos em relação ao valor mediano previsto; ${ }^{* \star} \mathrm{Nd}$ : dados não disponíveis 
$\mathrm{Pc}^{\star} \quad$ Domínio Sintomas Domínio Atividades Domínio Impactos Total $^{\star \star *}(\%)^{\star *}$
$(\%)^{* *}$
$(\%)^{\star *}$
$(\%)^{* *}$

Pré-RT Pós-RT Pré-RT Pós-RT Pré-RT Pós-RT Pré-RT Pós-RT

\begin{tabular}{|c|c|c|c|c|c|c|c|c|}
\hline 1 & 0 & 4,24 & 17 & 7,49 & 0 & 0 & 5,24 & 2,97 \\
\hline 2 & 0 & 33,96 & 85,85 & 72,41 & 24,34 & 24,13 & 38,94 & 40,40 \\
\hline 3 & 0 & 0 & 0 & 0 & 0 & 0 & 0 & 0 \\
\hline 4 & 0 & 14,29 & 47,70 & 50,32 & 3,96 & 7,96 & 16,55 & 21,85 \\
\hline 5 & 0 & 14,19 & 35,47 & 47,64 & 3,06 & 8,11 & 12,37 & 21,10 \\
\hline 6 & 0 & 76,10 & 0 & 0 & 0 & 0 & 0 & 12,64 \\
\hline 7 & 0 & 0 & 0 & 0 & 0 & 0 & 0 & 0 \\
\hline 8 & 0 & 0 & 12,71 & 11,16 & 0 & 0 & 3,87 & 3,38 \\
\hline 9 & 45,52 & 2,32 & 53,54 & 63,88 & 27,94 & 0 & 39,29 & 19,75 \\
\hline 10 & 0 & 0 & 53,53 & 35,24 & 11,02 & 3,06 & 22,07 & 12,31 \\
\hline 11 & 0 & 8,80 & 0 & 0 & 0 & 0 & 0 & 1,46 \\
\hline 12 & 4,42 & 0 & 0 & 0 & 7,88 & 0 & 4,92 & 0 \\
\hline 13 & 0 & 0 & 0 & 0 & 0 & 0 & 0 & 0 \\
\hline 14 & 0 & 0 & 0 & 0 & 0 & 0 & 0 & 0 \\
\hline 15 & 8,8 & 15,97 & 0 & 0 & 0 & 0 & 1,46 & 2,56 \\
\hline 16 & 0 & 10,78 & 47,85 & 55,18 & 0 & 24,60 & 14,50 & 31,57 \\
\hline 17 & 0 & 4,56 & 59,46 & 59,46 & 7,96 & 18,22 & 22,24 & 28,45 \\
\hline 18 & 12,17 & 0 & 23,30 & 0 & 4,15 & 0 & 11,28 & 0 \\
\hline 19 & 12,16 & 4,24 & 23,28 & 0 & 7,80 & 0 & 13,22 & 0,70 \\
\hline 20 & 4,42 & 0 & 35,79 & 0 & 0 & 0 & 11,58 & 0 \\
\hline 21 & 0 & 0 & 0 & 41,76 & 0 & 0 & 0 & 12,66 \\
\hline 22 & 0 & 0 & 41,39 & 41,76 & 3,06 & 3,06 & 14,17 & 14,28 \\
\hline 23 & 0 & 0 & 0 & 0 & 0 & 0 & 0 & 0 \\
\hline 24 & 0 & 0 & 0 & 0 & 0 & 0 & 0 & 0 \\
\hline
\end{tabular}

${ }^{*}$ Pc: paciente; ${ }^{* *}(\%)$ : porcentagem de pontos atingidos do máximo possível em cada domínio; ***Total: somatória dos pontos atingidos nos três domínios em relação ao total de pontos possíveis do questionário. 


\begin{tabular}{|c|c|c|c|c|c|c|}
\hline \multirow{2}{*}{$\mathrm{Pc}^{*}$} & \multicolumn{2}{|c|}{$\mathrm{IL}-1 \beta(\mathrm{pg} / \mathrm{ml})^{\star *}$} & \multicolumn{2}{|c|}{$\mathrm{IL}-6(\mathrm{pg} / \mathrm{ml})^{\star \star}$} & \multicolumn{2}{|c|}{ TNF- $\alpha(p g / m l)^{\star \star}$} \\
\hline & Pré-RT & Pós-RT & Pré-RT & Pós-RT & Pré-RT & Pós-RT \\
\hline 1 & 0,0 & 0 & 39,74 & 72,99 & 0,0 & 0 \\
\hline 2 & 0,0 & 0 & 251,31 & 11,03 & 44,88 & 0 \\
\hline 3 & 0,0 & 0 & 9,52 & 0 & 0,68 & 0 \\
\hline 4 & 0,0 & 44,85 & 62,41 & 29,16 & 73,90 & 0,02 \\
\hline 5 & 0,0 & - & 4,99 & - & 20,47 & - \\
\hline 6 & 0,0 & 0 & 0,0 & 0 & 100,29 & 0 \\
\hline 7 & 0,0 & 178,64 & 117,57 & 128,90 & 0,0 & 14,53 \\
\hline 8 & 36,00 & 0 & 0,0 & 0 & 18,49 & 0 \\
\hline 9 & 0,0 & 125,72 & 86,59 & 2,73 & 46,20 & 0 \\
\hline 10 & 0,0 & 0 & 131,93 & 58,63 & 54,16 & 0 \\
\hline 11 & 0,0 & 0 & 65,96 & 0 & 85,12 & 1,32 \\
\hline 12 & 0,0 & 0 & 32,94 & 0 & 0,0 & 0 \\
\hline 13 & 0,0 & 0 & 45,03 & 0 & 0,0 & 0 \\
\hline 14 & 0,0 & 0 & 0,0 & 13,30 & 0,0 & 51,47 \\
\hline 15 & 0,0 & 0 & 0,0 & 0 & 0,0 & 0 \\
\hline 16 & 0,0 & 0 & 29,92 & 25,39 & 40,92 & 0,0 \\
\hline 17 & 0,0 & 0 & 57,88 & 32,94 & 0,0 & 40,96 \\
\hline 18 & 0,0 & 190,62 & 45,03 & 27,65 & 47,52 & 0 \\
\hline 19 & 0,0 & 0 & 40,50 & 0 & 4,64 & 15,19 \\
\hline 20 & 0,0 & 0 & 169,71 & 20,85 & 15,19 & 29,04 \\
\hline 21 & 0,0 & - & 0,0 & - & 5,96 & - \\
\hline 22 & 0,0 & 0 & 32,19 & 0 & 36,30 & 62,69 \\
\hline 23 & 0,0 & 0 & 0,0 & 30,68 & 18,49 & 32,69 \\
\hline 24 & 0,0 & 0 & 25,39 & 48,05 & 0,0 & 31,68 \\
\hline
\end{tabular}


ANEXO M - Resultado da dosagem de alguns mediadores infamatórios sistêmicos

(Grupo Controle)

\begin{tabular}{|c|c|c|c|}
\hline $\mathrm{Pc}^{*}$ & $\mathrm{IL}-1 \beta(\mathrm{pg} / \mathrm{ml})^{\star *}$ & IL-6 $(\mathrm{pg} / \mathrm{ml})^{\star *}$ & TNF- $\alpha(p g / m l)^{\star \star}$ \\
\hline 1 & 0 & 0 & 0 \\
\hline 2 & 0 & 0 & 15,19 \\
\hline 3 & 0 & 0 & 13,87 \\
\hline 4 & 0 & 12,54 & 3,91 \\
\hline 5 & 0 & 0 & 27,72 \\
\hline 6 & 0 & 0 & 0,68 \\
\hline 7 & 0 & 0 & 11,89 \\
\hline 8 & 0 & 0 & 0 \\
\hline 9 & 0 & 60,90 & 0 \\
\hline 10 & 0 & 0 & 0 \\
\hline 11 & 0 & 0 & 11,23 \\
\hline 12 & 0 & 29,16 & 3,98 \\
\hline 13 & 0 & 0 & 0 \\
\hline 14 & 0 & 0 & 6,62 \\
\hline 15 & 0 & 0 & 0 \\
\hline 16 & 0 & 11,03 & 8,59 \\
\hline 17 & 0 & 0 & 30,36 \\
\hline 18 & 0 & 0 & 17,83 \\
\hline 19 & 0 & 5,74 & 16,51 \\
\hline 20 & 0 & 0 & 0 \\
\hline 21 & 0 & 0 & 2 \\
\hline 22 & 0 & 0 & 14,53 \\
\hline 23 & 0 & 0 & 0 \\
\hline 24 & 0 & 0 & 0 \\
\hline 25 & 0 & 0 & 0 \\
\hline
\end{tabular}


ANEXO N - Resultado das Correlações de Sperman entre as diferenças pósRT menos pré-RT do DLCO com as diferenças pós-RT menos pré-RT de todas as variáveis mensuradas no estudo.

\begin{tabular}{|c|c|c|}
\hline Variáveis avaliadas & Correlação rho & p-valor \\
\hline DLCO $x$ VEF1 (L) & 0,39 & 0,07 \\
\hline DLCO $\times$ CVF $(L)$ & 0,24 & 0,28 \\
\hline DLCO x VEF1/CVF & 0,07 & 0,73 \\
\hline DLCO x CV(L) & 0,01 & 0,96 \\
\hline $\operatorname{DLCO} \times \operatorname{CRF}(\mathrm{L})$ & $-0,06$ & 0,78 \\
\hline DLCO x CPT(L) & 0,03 & 0,88 \\
\hline DLCO x VR (L) & 0,04 & 0,84 \\
\hline DLCO x FEF 50\% (L/seg) & 0,11 & 0,62 \\
\hline DLCO x FEF75\% (L/seg) & 0,06 & 0,78 \\
\hline DLCO $\times$ Sintomas & 0,46 & 0,03 \\
\hline DLCO $\times$ Atividade & $-0,12$ & 0,59 \\
\hline DLCO x Impacto & 0,45 & 0,03 \\
\hline DLCO x Total & 0,34 & 0,11 \\
\hline DLCO x TCAR Pulmão Direito & 0,26 & 0,25 \\
\hline DLCO x TCAR Pulmão Esquerdo & 0,24 & 0,29 \\
\hline DLCO $\times$ IL-1 $\beta$ & $-0,25$ & 0,28 \\
\hline DLCO x IL-6 & 0,06 & 0,8 \\
\hline DLCO x TNF- $\alpha$ & 0,01 & 0,98 \\
\hline
\end{tabular}


ANEXO O - Continuação - Resultado das Correlações de Sperman entre as diferenças pós-RT menos pré-RT do FEF50\% com as diferenças pós-RT menos pré-RT de todas as variáveis mensuradas no estudo.

\begin{tabular}{|c|c|c|}
\hline Variáveis avaliadas & Correlação rho & p-valor \\
\hline FEF $50 \% \times$ VEF1 (L) & 0,23 & 0,3 \\
\hline FEF $50 \% \times$ CVF(L) & 0,02 & 0,93 \\
\hline FEF50\% x FEF1/CVF & 0,41 & 0,06 \\
\hline FEF $50 \% \times$ CV(L) & 0,11 & 0,62 \\
\hline FEF $50 \% \times$ CRF $(L)$ & $-0,25$ & 0,25 \\
\hline FEF $50 \% \times$ CPT(L) & $-0,19$ & 0,39 \\
\hline FEF $50 \% \times$ VR(L) &,- 015 & 0,24 \\
\hline FEF $50 \%$ x FEF75\% (L/seg) & 0,15 & 0,49 \\
\hline FEF50\% x DLCO $(\mathrm{ml} / \mathrm{min} / \mathrm{mmHg})$ & 0,11 & 0,62 \\
\hline FEF $50 \% \times$ Sintomas & 0,38 & 0,07 \\
\hline FEF $50 \% \times$ Atividade & $-0,04$ & 0,86 \\
\hline FEF $50 \%$ x Impacto & 0,39 & 0,07 \\
\hline FEF $50 \% \times$ Total & 0,28 & 0,2 \\
\hline FEF 50\% x TCAR Pulmão Direito & $-0,27$ & 0,23 \\
\hline FEF 50\% x TCAR Pulmão Esquerdo & $-0,27$ & 0,23 \\
\hline FEF $50 \% \times$ IL- $1 \beta$ & $-0,07$ & 0,76 \\
\hline FEF $50 \%$ x IL-6 & 0,21 & 0,35 \\
\hline FEF $50 \% \times$ TNF- $\alpha$ & 0,01 & 0,96 \\
\hline
\end{tabular}


ANEXO P - Continuação - Resultado das Correlações de Sperman entre as diferenças pós-RT menos pré-RT da IL- 6 com as diferenças pós-RT menos pré-RT de todas as variáveis mensuradas no estudo.

\begin{tabular}{lcc}
\hline Variáveis avaliadas & Correlação rho & p-valor \\
\hline IL-6 x VEF1 (L) & $-0,14$ & 0,55 \\
IL-6 x CVF (L) & $-0,1$ & 0,67 \\
IL-6 x VEF1/CVF & 0,32 & 0,16 \\
IL-6 x CV (L) & 0,32 & 0,16 \\
IL-6 x CRF (L) & $-0,13$ & 0,57 \\
IL-6 x CPT (L) & $-0,13$ & 0,57 \\
IL-6 x VR(L) & $-0,23$ & 0,32 \\
IL-6 x FEF50\% (L/seg) & 0,21 & 0,35 \\
IL-6 x FEF75\% (L/seg) & $-0,11$ & 0,64 \\
IL-6 x DLCO (ml/min/mmHg) & 0,06 & 0,8 \\
IL-6 x Sintomas & 0,10 & 0,67 \\
IL-6 x Atividade & 0,14 & 0,54 \\
IL-6 x Impacto & 0,4 & 0,07 \\
IL-6 x Total & 0,13 & 0,56 \\
IL-6 x TCAR Pulmão Direito & 0,19 & 0,42 \\
IL-6 x TCAR Pulmão Esquerdo & 0,04 & 0,86 \\
IL-6 x IL-1 $\beta$ & $-0,12$ & 0,59 \\
IL-6 x TNF- $\alpha$ & 0,39 & 0,07 \\
\hline
\end{tabular}

